\title{
School Climate: Assessing a Universal Intervention Design to Reduce Academic Risks and Educate the Whole Child.
}

\author{
Shay Michael Daily
}

Follow this and additional works at: https://researchrepository.wvu.edu/etd

\section{Recommended Citation}

Daily, Shay Michael, "School Climate: Assessing a Universal Intervention Design to Reduce Academic Risks and Educate the Whole Child." (2018). Graduate Theses, Dissertations, and Problem Reports. 8189. https://researchrepository.wvu.edu/etd/8189

This Dissertation is protected by copyright and/or related rights. It has been brought to you by the The Research Repository @ WVU with permission from the rights-holder(s). You are free to use this Dissertation in any way that is permitted by the copyright and related rights legislation that applies to your use. For other uses you must obtain permission from the rights-holder(s) directly, unless additional rights are indicated by a Creative Commons license in the record and/ or on the work itself. This Dissertation has been accepted for inclusion in WVU Graduate Theses, Dissertations, and Problem Reports collection by an authorized administrator of The Research Repository @ WVU.

For more information, please contact researchrepository@mail.wvu.edu. 


\title{
School Climate: Assessing a Universal Intervention Design to Reduce Academic Risks and Educate the Whole Child
}

\author{
Shay Michael Daily \\ Dissertation submitted \\ to the School of Public Health \\ at West Virginia University \\ in partial fulfillment of the requirements for the degree of \\ Doctor of Philosophy in \\ Social and Behavioral Sciences \\ Michael J. Mann, Ph.D., Chair \\ Thomas K. Bias, Ph.D. \\ Danielle M. Davidov, Ph.D. \\ Christa L. Lilly, Ph.D. \\ Alfgeir L. Kristjansson, Ph.D. \\ Department of Social and Behavioral Sciences \\ Morgantown, West Virginia \\ 2018
}

Keywords: achievement, substance use initiation, school absenteeism, longitudinal analysis

Copyright 2018 Shay Michael Daily 


\title{
Abstract \\ School Climate: Assessing a Universal Intervention Design to Reduce Academic Risks and Educate the Whole Child
}

\author{
Shay Michael Daily
}

BACKGROUND: Health and education are inherently connected. Minimizing risky behaviors is essential for students' academic success and health outcomes. A positive school climate may reduce student risks and promote greater satisfaction and success with school. The purpose of this dissertation was to determine the associations between school climate, academic grades, substance initiation, and types of school absences in a group of middle school students who transition into high school.

METHODS: Longitudinal and cross-sectional analyses were used to examine study variables from middle and high school students across 26 regional schools located in West Virginia.

RESULTS: Students with positive perceptions of school climate demonstrated improved academic achievement $(\beta=-0.45$ to $0.30, \mathrm{p}<.05)$, delayed substance use initiation $(\beta=-0.07$ to $0.25, \mathrm{p}<.01)$, and reduced types of absences $(\widehat{\beta}=-0.46$ to $-0.23, \mathrm{p}<.01)$.

CONCLUSIONS: Findings support the value of a positive school climate to promote academic and life success. Improving school climate may be useful as an intervention to support schoolbased health promotion of students' wellbeing in and outside of school. Students' who transitioned into high school may require additional services to support and maintain high perceptions of school climate. A focus on school climate may be a useful avenue for public health and public education to collaboratively fulfill national academic and health goals. 


\section{ACKNOWLEDGEMENTS}

My endless thanks and blessings to my committee chair Dr. Michael J. Mann for his patience, leadership, and authentic generosity from start to finish.

Many thanks to the dedicated members of the dissertation committee, Dr. Thomas K. Bias, Dr.

Danielle M. Davidov, Dr. Christa L. Lilly, and Dr. Alfgeir L. Kristjansson for their kindness, guidance, and lessons on being a better researcher throughout this process.

A special thanks to Dr. Angela M. Dyer for her review and commentary.

A special thanks to my sideline cheerleader, Janet B. Hunt.

To my father and mother, I love you both.

To Dr. Maurice "Bud” Martin, from the beginning.

To my dearest Katharine "Kat" McDonald for all your loving support and keeping me grounded for four years. 


\section{TABLE OF CONTENTS}

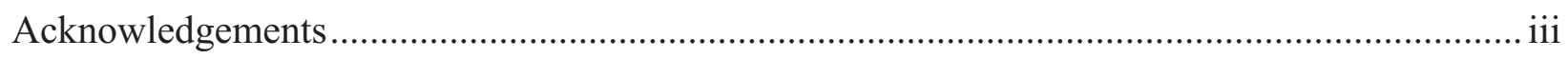

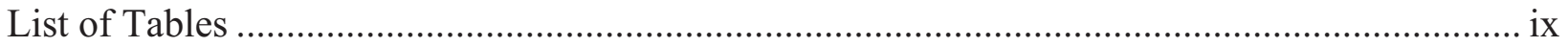

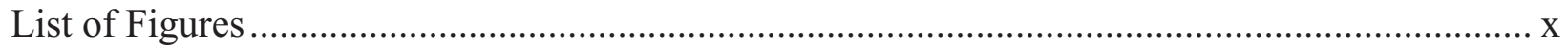

Delimitations, Limitations, and Assumptions................................................................ xi

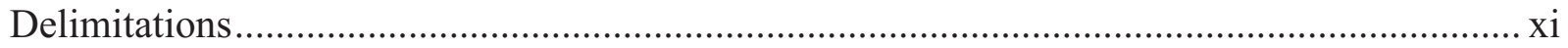

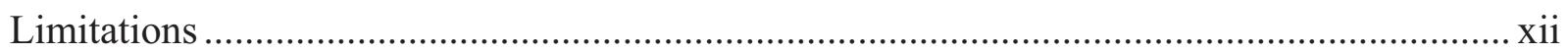

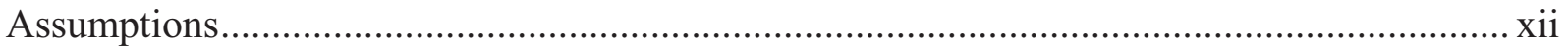

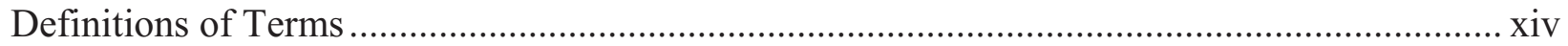

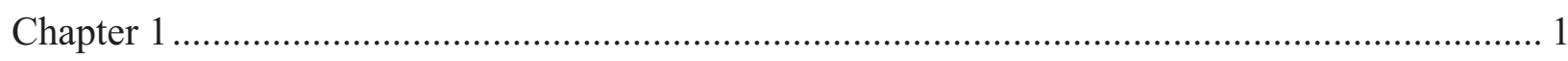

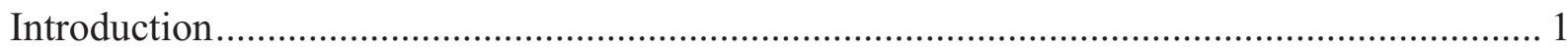

Health and Education: Two Sides of the Same Coin ...................................................... 1

The Basic Premise of Student Risks ......................................................................... 2

The Benefits of School Climate and School Satisfaction ................................................ 2

School Climate: An Intervention on a Grand Stage..................................................... 3

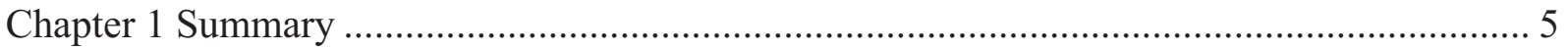

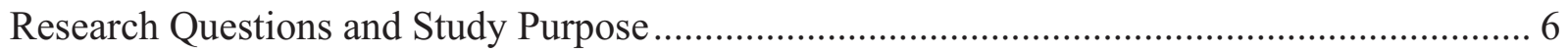

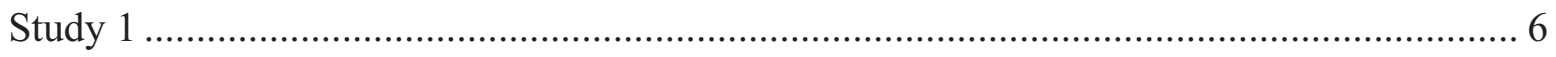

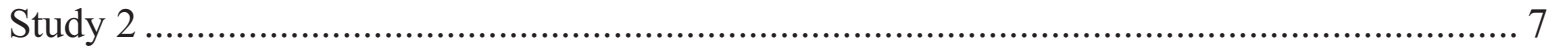




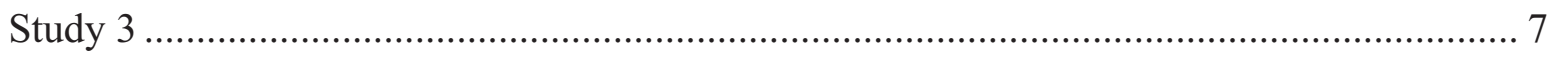

Anticipated Study Implications......................................................................................... 8

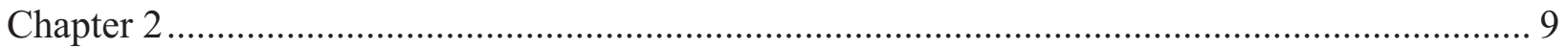

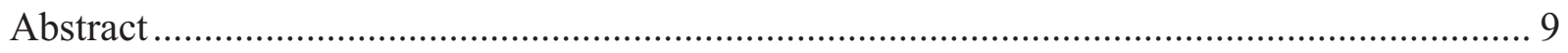

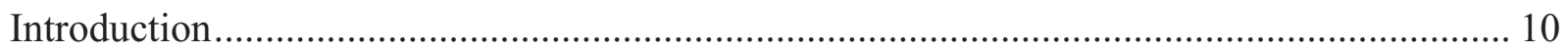

A Brief Review of Academic Success and Health........................................................... 10

An Overview of School Climate and Academic Achievement ............................................. 11

An Opportunity for School Climate to Promote Academic Success .................................... 12

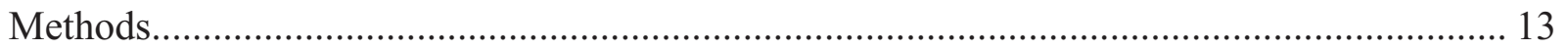

Participants, Procedures and Handling of Missing Data ...................................................... 13

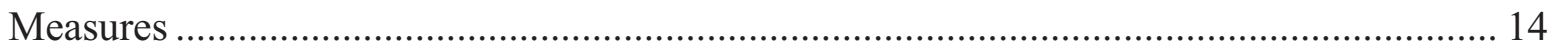

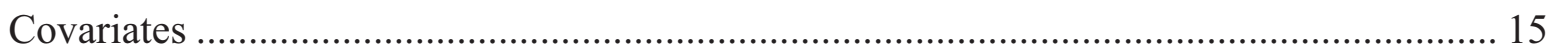

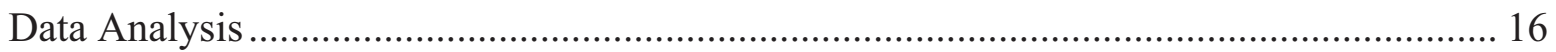

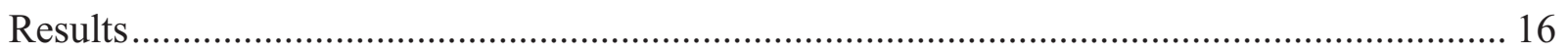

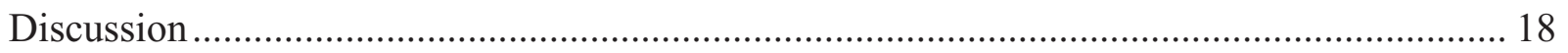

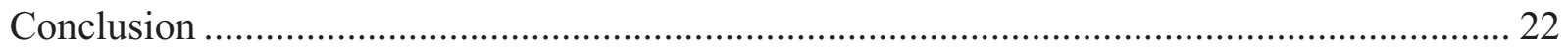

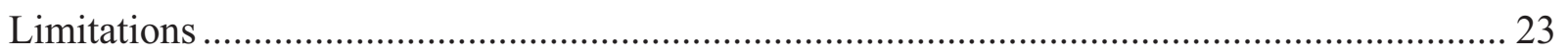

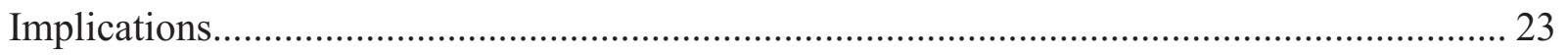

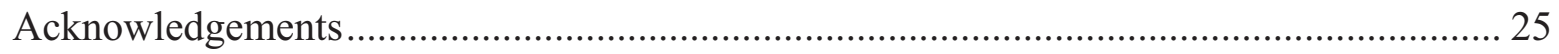




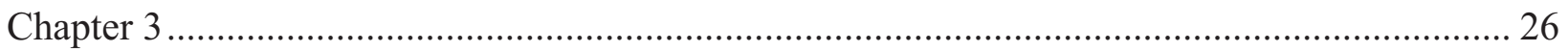

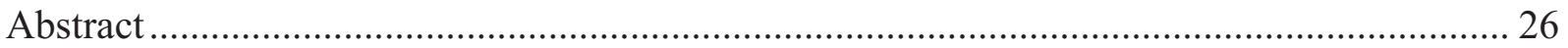

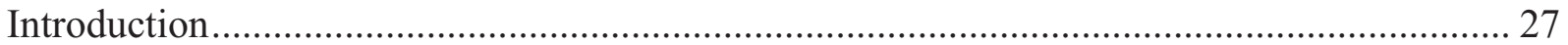

An Overview of Substance Use Initiation in the United States ..................................... 27

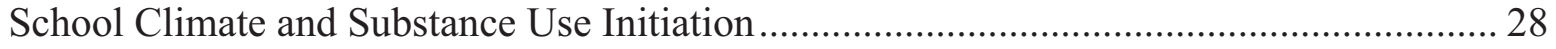

School Climate and Multi-Tiered Systems of Support (MTSS) .................................. 29

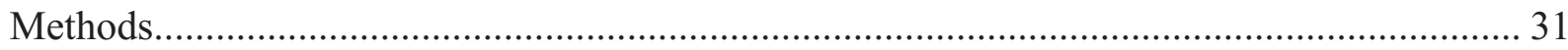

Participants, Procedures and Handling of Missing Data ............................................ 31

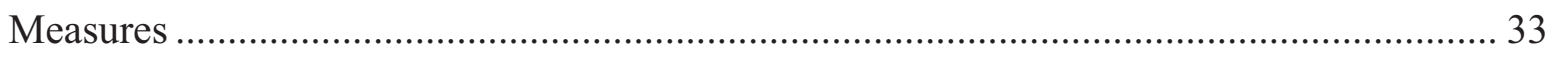

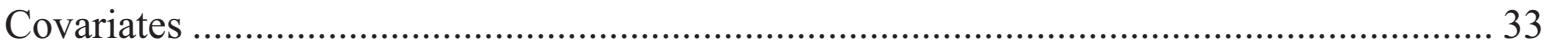

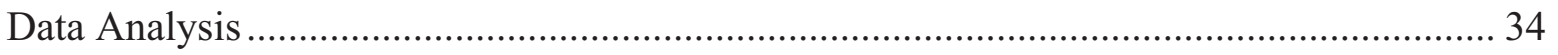

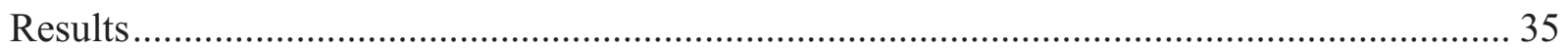

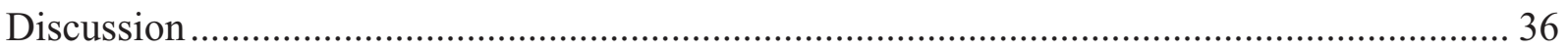

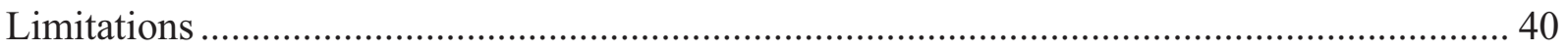

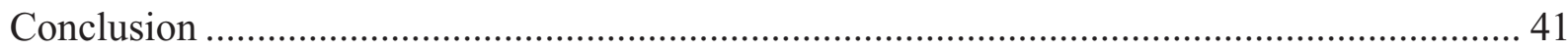

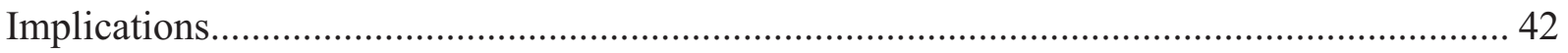

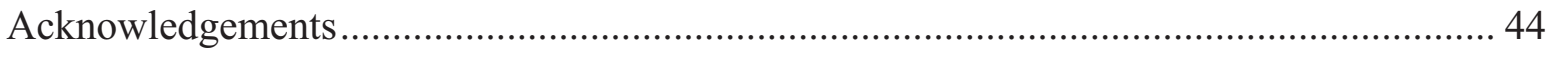

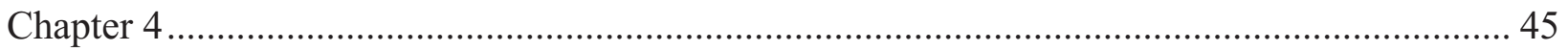

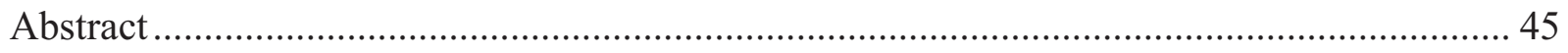




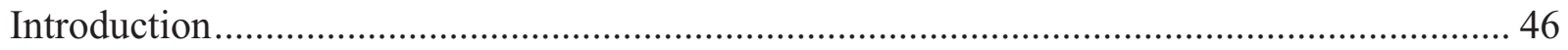

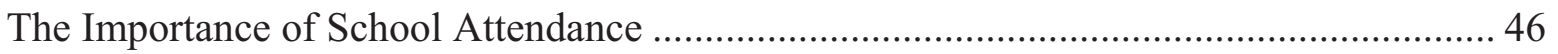

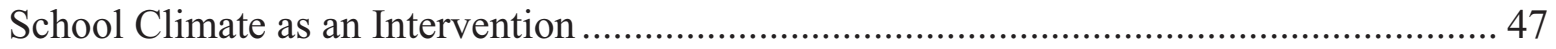

Understanding the Role of School Satisfaction and School Climate.................................... 48

An Opportunity for School Climate and School Satisfaction to Reduce Absenteeism ........ 48

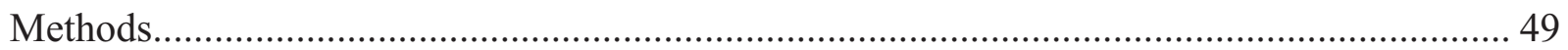

Participants, Procedures, and Data Management.................................................................. 49

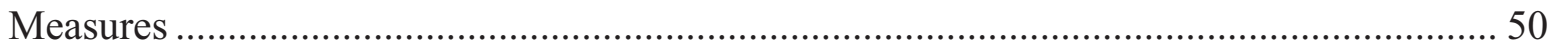

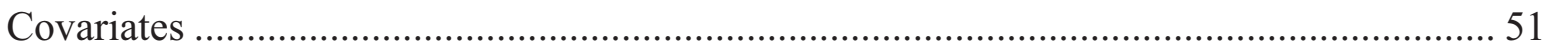

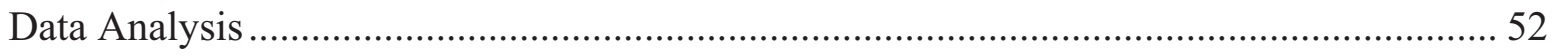

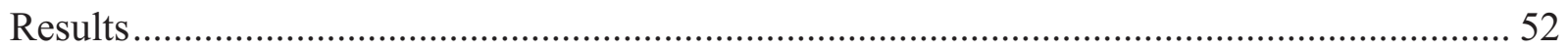

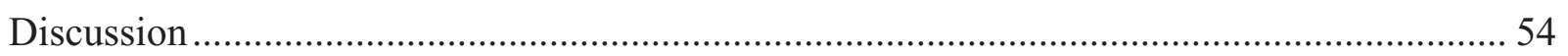

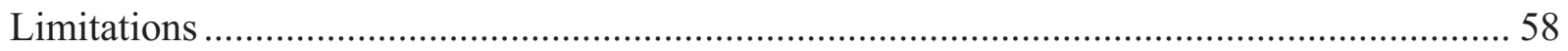

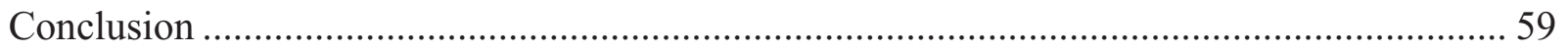

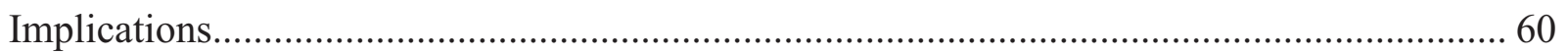

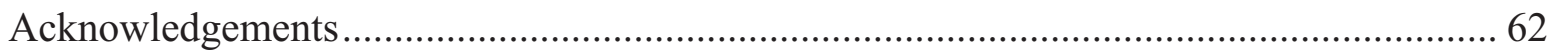

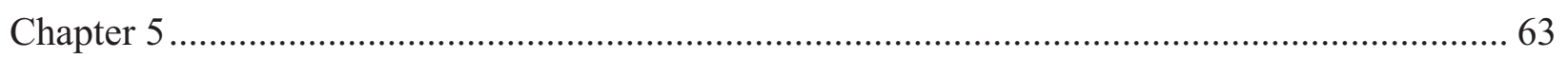

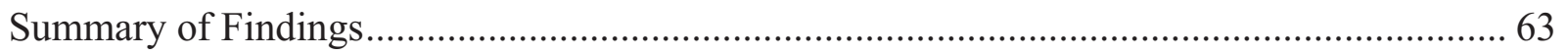

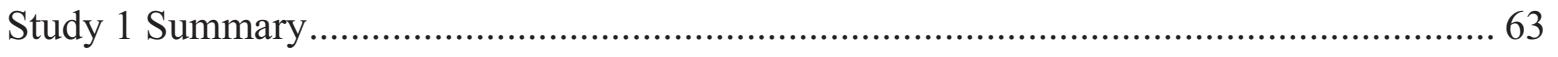




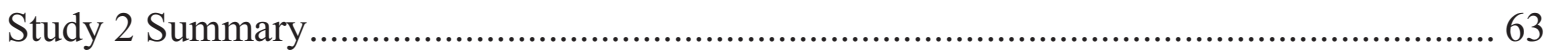

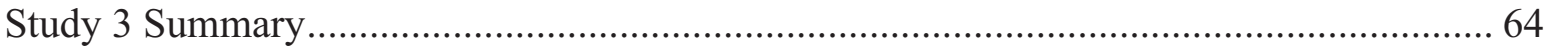

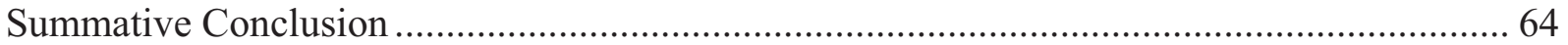

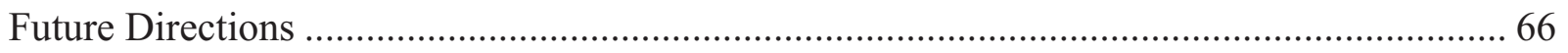

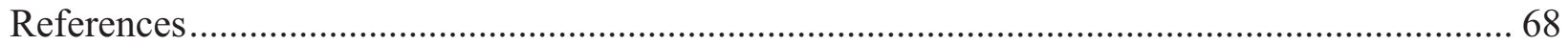

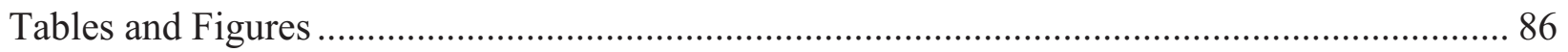

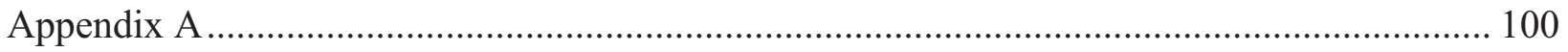

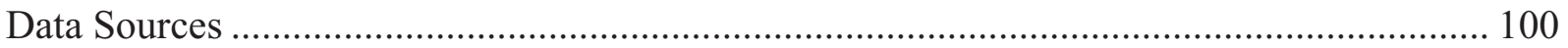

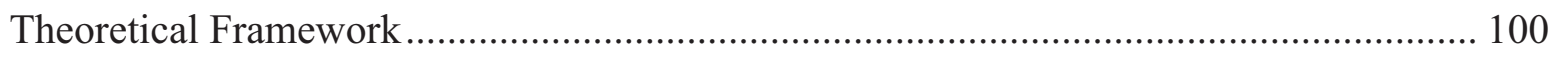

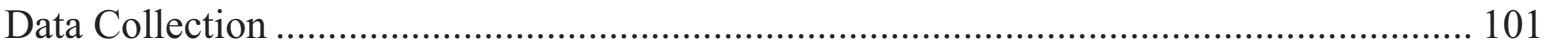

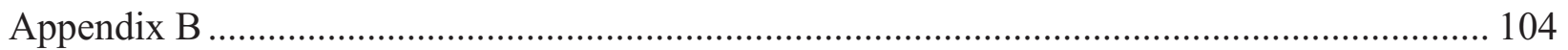

School Climate Measure Items at a Glance ......................................................................... 104

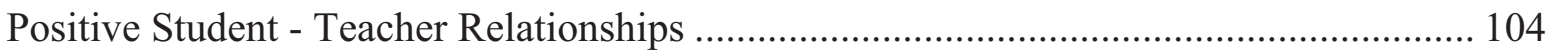

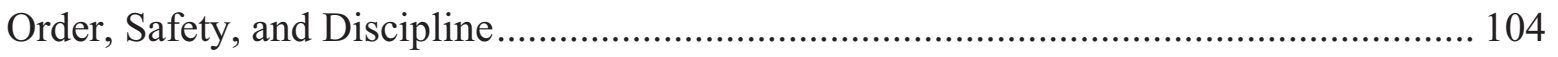

Opportunities for Student Engagement......................................................................... 104 


\section{LIST OF TABLES}

Table 1. Descriptive Results for School Climate and Academic Grades 86

Table 2. Model Results for Teacher Relationships and Academic Grades...... 87

Table 3. Model Results for Order and Safety and Academic Grades 88

Table 4. Model Results for Student Engagement and Academic Grades 89

Table 5. Descriptive Results for School Climate and Substance Initiation . 90

Table 6. Model Results for Teacher Relationships and Substance Initiation 91

Table 7. Model Results for Order and Safety and Substance Initiation 92

Table 8. Model Results for Student Engagement and Substance Initiation. 93

Table 9. Descriptive Results for School Climate and Absences..... 94

Table 10. Model Results for School Climate and Types of Absences - Middle School. 95

Table 11. Model Results for School Climate and Types of Absences - High School 96 


\section{LIST OF FIGURES}

Figure 1. Parallel Latent Growth Model for School Climate and Academic Grades ................. 97

Figure 2. Parallel Latent Growth Model for School Climate and Substance Use Initiation......... 98

Figure 3. Mediated Path Analysis Model for School Climate and Types of Absences............... 99 


\section{DELIMITATIONS, LIMITATIONS, AND ASSUMPTIONS}

\section{DELIMITATIONS}

1. A retrospective study (secondary data) design will be used from a purposefully collected sample of 16 middle and 10 high schools (26 total) located in West Virginia as part of a larger metal health prevention program.

2. Participants included all eligible students aged 13 to 18 years who attended school the day of and volunteered to partake in the survey.

3. Data were collected annually during the 2015 to 2017 academic years with slight modifications of the included and excluded instrument variables between survey years.

4. Study variables were measured based on the School Climate Measure, school absences represented by truancy and illness, lifetime use of licit substances and marijuana, and academic achievement in Mathematics and English. Demographic variables were selected based on common student characteristics and proxies found in educational and school health literature.

5. All data were based on self-reported participant information.

6. Three School Climate Measure domains: Positive Student-Teacher Relationships, Order and Safety, and Student Engagement, were chosen exclusively from the instrument's ten sub-scales. This choice was based on previous psychometric validation and the variance explained among communality estimates.

7. Quantitative analytic techniques were used to analyze cross-sectional and longitudinal study variables. 


\section{LIMITATIONS}

1. The 26 purposefully selected schools may not represent or generalized to other schools in West Virginia, Appalachia, and elsewhere in the United States.

2. Students who volunteered for the survey may not represent generalized characteristics of students attending other schools in West Virginia or elsewhere.

3. Data collected during the 2015-2017 academic years may differ due to instrumentation changes and cause under or overestimation of analytic results.

4. Scale instruments selected for the study may not accurately or fully describe their associated constructs within the sample of participants.

5. Participant responses may be based on dishonesty, inaccurate perceptions, test fatigue, classroom related distractions, and acquiescence bias.

6. Using only three domains of school climate may not capture all aspects of school climate or represent the most important constructs for the participants in these studies.

7. Use of cross-sectional and longitudinal designs may yield complex and/or inconclusive results and limit appropriate theoretical options available for data analysis.

\section{ASSUMPTIONS}

1. The choice to use secondary data from 26 purposefully chosen schools will: (1) provide a sufficient geographical representation of students in West Virginia and Central Appalachia, and (2) lead to new discoveries or hypotheses beyond the scope and intent of the primary data collection.

2. Participants who volunteered for the survey fit the primary data collection sampling frame, represent schools and students in the geographic region, and are therefore adequate for the use of this dissertation. 
3. Data collection procedures for the 2015 to 2017 academic years are considered appropriate and met the needs of the secondary data analyses for this dissertation.

4. Instruments selected for this dissertation adequately described their associated constructs and met appropriate psychometric criteria for generalizable use.

5. Participant responses were honest and contained limited bias for this dissertation.

6. The three chosen School Climate Measure domains adequately represented the strongest indicators of school climate based on established research. Adding more constructs may not improve study design and may complicate analytic approaches.

7. Use of cross-sectional and longitudinal designs provided an appropriate approach to data analysis and interpretation of results for this dissertation. 


\section{DEFINITIONS OF TERMS}

1. Academic Achievement: the ability for a student to attain good grades in their studies.

2. Alcohol: A chemical substance such as beer, wine, and liquor made from the process of fermentation that uses sugars and yeast. ${ }^{1}$

3. Combustible Cigarettes: tube-shaped tobacco product(s) that can be lit and used to inhale tobacco smoke into the lungs. ${ }^{2}$

4. Human Development: the process by which children and adolescents grow and mature into competent adults. ${ }^{3}$

5. Electronic Cigarettes: battery operated device(s) used to vaporize nicotine-based solution(s) that can be inhaled into the lungs. ${ }^{4}$

6. Lifetime Substance Use: the initiation, introduction, or ever use of a licit (i.e., alcohol) or illicit drug (i.e., marijuana). ${ }^{5}$

7. Marijuana: dried leaves of the flowering cannabis plants that contain cannabinoids that may be smoked or ingested to produce a hallucinogenic effect throughout the body. ${ }^{6}$

8. Opportunities for Student Engagement: equitable opportunity for students to participate in diverse school activities and school life. ${ }^{7,8}$

9. Order and Safety: refers to a student's sense of physical and emotional security within the presence of a school's disciplinary procedures. ${ }^{9,10}$

10. Risk: exposure or engagement in psychosocial, behavioral, and/or physical factors that have acute or chronic deleterious effects on health and wellbeing. ${ }^{11,12}$

11. School Climate: represents the physical and social-emotional environment of a school that includes the norms, values, practices, and relationships within a school setting. ${ }^{13}$ 
12. School Satisfaction: personal and independent judgment of the quality of one's overall school life and of curricular studies. ${ }^{14-16}$

13. Student-Teacher Relationships: quality and consistency of bonding relationships and interactions between students, teachers, and school personnel. ${ }^{9,17}$ 


\section{CHAPTER 1}

\section{INTRODUCTION}

\section{Health and Education: Two Sides of the Same Coin}

Humans are naturally driven to be creative and learn. ${ }^{18-21}$ Children are born curious and use a myriad of sensory experiences to explore their world. ${ }^{22}$ Decades of research has been dedicated to better understand peoples motivation to perform healthy behaviors. ${ }^{19}$ Ecological theories suggest the formation of health behaviors stems from the interplay between peoples shared experiences and interactions with their environment. ${ }^{18,23-25}$ Regardless of how the theory is defined, reasons are complex for why some people are healthier than others. Fortunately, social ecological scientists have already painted a broad picture of the intricate pathways that are linked to health. ${ }^{26-29}$

For many people, patterns of health related behaviors are often shaped during their formative educational years. ${ }^{30,31}$ In particular, people who leave school early are more likely to have lower occupational opportunities, abuse substances, and serve time in the criminal justice system. ${ }^{32-35}$ Additionally, studies suggest higher rates of chronic disease and early death disproportionately befalls the least educated. ${ }^{36-38}$ Because of its association to health outcomes, graduating from high school is often used as a baseline indicator of individual and population-

level health. ${ }^{39,40}$ Educational attainment, therefore, is often a requirement to access basic social needs, open avenues for social mobility, and reap lifelong prosperity. ${ }^{41,42}$ What we know definitively, is that schools are indispensable, not only to ensure the health and wellness of our children, but our society as a whole..$^{43-45}$ 


\section{The Basic Premise of Student Risks}

High school graduation rates in the United States (US) have steadily risen since the 1970 's. ${ }^{46}$ Nonetheless, reducing the achievement gap for all students continues to be a national priority as many students deal with daily adversity that expose them to academic and health risks. ${ }^{47,48}$ Issues like chronic academic failure, ${ }^{49}$ high absenteeism, ${ }^{50}$ and substance use ${ }^{51}$ continue to be strong determinants of negative student outcomes. Academic achievement, for example, is often viewed as an individual issue, but often may predict broader social problems. ${ }^{52}$ Additionally, students with a large number of missed school days tend to struggle in school and academically. ${ }^{53-56}$ Behaviors like substance use initiation often begin in high school with tobacco and alcohol opening potential avenues to the use of marijuana and other illicit drugs. ${ }^{57-59}$ Although the list of student risks and outcomes could be expanded, as long as they are present, schools will struggle to reduce the achievement gap and ameliorate population disparities. ${ }^{44,60}$

\section{The Benefits of School Climate and School Satisfaction}

Due to the diversity of scientific perspectives, definitions of school climate tend to diverge. ${ }^{9}$ Tangible definitions are based on patterns of behaviors influenced by the school setting such as norms, values, practices, and relationships. ${ }^{13}$ Theoretical definitions describe school climate as the spirit or "heart beat" of a school. ${ }^{61}$ Improving a school's climate may reduce academic risks while promoting healthy behaviors and wellness. ${ }^{62}$ School climate may also buffer the deleterious effects of poverty, family dysfunction, and distress in school. ${ }^{63}$ Ecological approaches suggest school climate may shape the interactions between students, teachers, families, and the broader community. ${ }^{64}$ In the context of school climate, shaping happens through the quality of classroom experiences, school policies, and places where education 
occurs. Nevertheless, the literature remains unclear how school climate may disrupt less desirable student behaviors.

When school climate is positive, social support and interactions with teachers and peers may uphold academic functioning and improve students' satisfaction with school. ${ }^{65}$ School satisfaction studies have demonstrated strong associations to academic, behavioral, and psychosocial student outcomes. ${ }^{66}$ School satisfaction is also interwoven into aspects of children's lives such as family, friends, and overall life. ${ }^{67,68}$ Based on available evidence, students who exhibit higher risk may have diminished perception of school climate and satisfaction with school. Fortunately, schools where students are immersed in a positive school climate appear more likely to foster a positive sense of school satisfaction. ${ }^{64,69}$ For example, a study by Suldo, et al. ${ }^{67}$ showed positive perceptions of school climate were associated to higher satisfaction with school and overall life. The primary stance from the literature suggests "happier" students are more satisfied with school, which may be reinforced by a positive school climate. ${ }^{67,70}$ Because school climate and satisfaction are associated with the broader psychosocial environment, they may collectively support healthy student behaviors. Additionally, when school practices are holistic and well-structured, they may support students transition through developmental periods of cognitive, emotional, and behavioral growth. ${ }^{71,72}$ Although school climate and school satisfaction have been shown to support and strengthen one another, our understanding of how they may reduce student risks is still far from complete.

\section{School Climate: An Intervention on a Grand Stage}

The US public school system serves the majority ( $85 \%$ ) of the student population. ${ }^{73-75}$ Therefore, educational systems are well-suited and have a widespread capacity to provide health services and education to children and adolescents. ${ }^{76,77}$ Although educators emphasize that 
curriculum and instruction are required for academic success, learning requires a healthy balance often found within a positive school climate like students bonding with teachers and peers, a sense of physical and emotional safety, and connectedness to school life. ${ }^{77}$ By fostering a positive school climate, schools and communities may strongly impact the health, wellbeing, and growth of their children. ${ }^{47}$ Interventions that encourage a positive school climate and professional behavior in schools have been shown to support improvements in a school's social environment and organizational health. ${ }^{78}$ High-quality and large-scale implementation of school climate may therefore support a broader capacity to promote student health and reduce risks. ${ }^{79}$ By working together, collaborative partnerships between public health practitioners and public education professionals may have practical implications toward the ways schools function, which may facilitate a shared impact to meet national academic and health goals.

Schools across the US are implementing health promotion strategies designed to reduce risky behaviors, improve health, and academic success. ${ }^{80}$ Unfortunately, many schools do so without demonstrably producing impactful and desired student outcomes. ${ }^{26,81}$ Reasons for translational gaps are, in part, due to a limited comprehensive description of how schools "do business" might shape a positive school climate and subsequently a school's output. ${ }^{82}$ Success in any organization requires strongly undergirded social and cultural priorities that align collectively to goals, missions, and visions. For schools, organizational success may require ensuring adolescent and child health is a part of the organizational structure. ${ }^{26}$ When strengthening a positive school climate becomes a central focus of schools, relationships with teachers, respectful admiration for school rules, and engaged student participation may impact what happens in and outside of the classroom. Proactive changes in school climate will likely require motivation from school stakeholders, ethical management of school information, and 
thoughtful sensitivity toward culture and place. ${ }^{76,83}$ However, scholars are divided on which approaches work best to manifest and sustain a positive school climate toward quality schoolbased health promotion. Translational and longitudinal research is therefore needed to clarify school climate's potential impact as an intervention and its relationship to students' health and academic success.

\section{CHAPTER 1 SUMMARY}

Students are affected by an assortment of context-specific internal and external school factors within a complex social environment. Preventing risky behaviors that may hinder children and adolescents from meeting their full potential continues to be a challenge. Schoolbased research continues to identify new ways to engage students as they prepare for their placement in society, but there is always room to create a fuller picture. One area with increased focus is the presence and promotion of a positive school climate. Strategies that increase school climate have shown to suppress many known student risks and increase emotional wellbeing. For example, bonding relationships with teachers and peers tends to be essential for supporting student growth and academic success. ${ }^{84}$ However, the diversity of definitions and perspectives in the school climate literature leaves much to be explored. Specifically, a better understanding of how aspects of school climate buffer student risks and promote positive pathways toward success needs further investigation. The proposed studies in this dissertation sought to clarify some of those literary gaps and provide evidence related to school climate that may inform school-based policy and practice. 


\section{RESEARCH QUESTIONS AND STUDY PURPOSE}

The purpose of this dissertation was to clarify the relationships between school climate, academic achievement, substance use initiation, and absenteeism. This dissertation answered the following research questions and filled the following empirical literary gaps outlined in Study 1, Study 2, and Study 3.

\section{Study 1}

Purpose 1: The purpose of Study 1 was to determine the longitudinal associations between school climate and academic grades across three waves from a group of middle school students who transition into high school.

Research Question 1: What is the relationship between students' perceptions of school climate and academic achievement over time using a sample of middle school student who transition into high school?

Hypothesis 1.1: School climate and self-reported academic grades would independently decline over time.

Hypothesis 1.2: Measures of school climate would significantly improve students' selfreported academic grades over time.

Hypothesis 1.3: Perceptions of a positive school climate would improve all students earning better grades over time. 


\section{Study 2}

Purpose 2: The purpose of Study 2 was to determine the longitudinal associations between school climate and substance use initiation across three waves from a group of middle school students who transition into high school.

Research Question 2: What is the relationship between students' perceptions of school climate and substance use initiation over time using a sample of middle school students who transition into high school?

Hypothesis 2.1: Perceptions of school climate would decline over time.

Hypothesis 2.2: Self-reported substance use initiation would increase over time.

Hypothesis 2.3: Measures of school climate would be significantly decrease students' self-reported substance use initiation over time.

\section{Study 3}

Purpose 3: The purpose of Study 3 was to determine the mediated relationships between school climate and school satisfaction on types of student absences and academic grades between middle and high school students.

Research Question 3: What is the mediated relationship between school climate and school satisfaction on types of absences and academic grades using a cross-sectional sample of middle and high school students?

Hypothesis 3.1: Students' absences would overall demonstrate negative associations on academic grades. 
Hypothesis 3.2: School climate and school satisfaction would be significantly support academic grades.

Hypothesis 3.3: School climate would significantly improve school satisfaction.

Hypothesis 3.4: School climate and school satisfaction would demonstrate an inverse relationship on school absences due to skipping class and illness.

Hypothesis 3.5: School climate would demonstrate stronger diminishing effects on student absences in middle school.

\section{ANTICIPATED STUDY IMPLICATIONS}

A positive school experience may prevent student risks and support academic and lifelong success. Interventions that promote a positive school climate may elevate the connection between how students learn and develop. This dissertation investigates several notable areas in the field by: (1) exploring the longitudinal relationship between school climate and academic achievement, (2) exploring the longitudinal relationships between school climate and initiation of licit substances and marijuana, and (3) exploring the relationships between school climate and school satisfaction to prevent different types of absences. Results from this dissertation may be useful to assist schools and community stakeholders interested in approaches that promote a positive educational experience, foster student wellbeing, and reduce risky student behaviors. 


\title{
CHAPTER 2
}

\section{School Climate as an Intervention to Reduce Academic Failure and Educate the Whole Child: A Longitudinal Study}

\begin{abstract}
BACKGROUND: Preventing student academic failure is crucial to student health and life success. Previous studies suggest a positive school climate may buffer student risk for academic failure and contribute to academic success. The purpose of this study was to determine the longitudinal associations between school climate and academic grades in a group of middle school students who transition into high school.
\end{abstract}

METHODS: Parallel latent growth curve modeling was used to examine changes among study variables longitudinally using a sample of $2,6046^{\text {th }}, 7^{\text {th }}$, and $8^{\text {th }}$ grade students across 16 regional schools located in three counties in West Virginia.

RESULTS: Students with higher perceptions of a positive school climate exhibited sustained or improved academic achievement over time $(\beta=0.22$ to $0.30, \mathrm{p}<.01)$. Positive perceptions of school climate appear to positively sustain students with As/Bs $(\beta=0.20$ to $0.27, p<.01)$ and strengthen students with $\mathrm{Cs} / \mathrm{Ds} / \mathrm{Fs}(\beta=-0.16$ to $-0.46, \mathrm{p}<.05)$.

CONCLUSIONS: Findings support the value of promoting a positive school climate over time. Positive student perceptions of school climate may sustain high academic performance, while strengthening students who earn $\mathrm{Cs} / \mathrm{Ds} / \mathrm{Fs}$. School climate may be useful as an intervention to support school-based health promotion to reduce the achievement gap in the United States.

Keywords: Middle school, early adolescents, achievement, parallel latent growth analysis 


\section{INTRODUCTION}

\section{A Brief Review of Academic Success and Health}

Academic success and earning a high school diploma is strongly associated to health throughout the lifespan. ${ }^{85}$ Research suggests that higher rates of chronic disease and early death disproportionately befalls the least educated. ${ }^{36-38}$ Additionally, people who leave school early are more likely to have occupational issues, social dysfunction, and participate in criminal behavior. ${ }^{32-35}$ Economic and social demands for an educated labor force underscore the value of earning at least a high school education, which is often the minimum requirement for gainful employment and college admission. ${ }^{40,48}$ Beyond the potential economic cost, educational attainment is also often required to access basic social needs and open avenues for social mobility. ${ }^{41,42}$ Preventing student academic failure is therefore crucial to student health and lifelong success. ${ }^{34,35,49}$

Preventing risky youth behaviors that may lead to less than desirable student outcomes continues to be a challenge. ${ }^{86,87}$ The United States (US) public (non-charter) school system serves an estimated $85 \%$ (47.3 million) of the child and adolescent population. ${ }^{73-75}$ The public school system is a promising location to implement large-scale interventions because of its broad capacity to provide health promotion and education to children and youth. ${ }^{76,77}$ In addition, students will spend nearly seven hours each day and much of their early life in school. ${ }^{88}$ During their time in school, students must manage a variety of contextual aspects (e.g., family, friends, and poverty), which may help or hinder their potential success. Social ecological theories support these type of interactions and suggest learning and modeling stems from interactions within an environment while sharing experiences with others. ${ }^{18,23-25}$ As a result, schools are places where most children and adolescents develop behavioral patterns that may transition into 
adulthood. ${ }^{30,31,72,89}$ Therefore, a natural partnership exists among educators and health promotion researchers making public schools potentially ideal locations to implement public health interventions and population level research ${ }^{76,77}$ By working together, collaborative partnerships between public health and public education may have practical implications toward a shared and collective impact to meet national academic and health goals.

\section{An Overview of School Climate and Academic Achievement}

A positive school climate provides an excellent example of how a positive social environment may shape student behaviors. ${ }^{77,90}$ Definitions of school climate tend to diverge. ${ }^{9}$ Tangible definitions are based on behavioral patterns of school life that are observed through norms, values, practices, and relationships. ${ }^{13}$ Theoretical definitions describe school climate as the spirit or "heart beat" of a school. ${ }^{61}$ Definition aside, most research has shown social relationships such as bonding with teachers and peers; order and safety such as respect for school rules; academic opportunities such as a sense of accomplishment and satisfaction with school; and school connectedness such as attachment and building social bonds to school tend to be essential constructs found in conceptual models of school climate. .,9,17 $^{8}$

Current school climate research that focus on ecological approaches suggests school climate can shape the interactions between students, teachers, families, and the broader community ${ }^{62,64}$ From a school climate point-of-view, shaping occurs through high quality classroom management and an emphasis on valued social norms where learning materializes. ${ }^{13,17,91}$ A collective goal of most school climate research has been to empirically highlight the importance of non-academic factors in lieu of an overemphasis on curriculum and instruction to support student success. ${ }^{92}$ Although we know many factors associated with school climate occur while students are in school, our understanding about how school climate shapes 
students' academic success over time is far from complete. ${ }^{9}$ An assortment of studies focused on the power of a positive social atmosphere in schools suggests strategies that foster a positive school climate may buffer many student risks and increase academic grades. ${ }^{47}$ Although the compendium of cross-sectional research provides a strong evidence base between school climate and academic achievement, there has been calls for more longitudinal and complex study designs. ${ }^{9,93}$

\section{An Opportunity for School Climate to Promote Academic Success}

Clarifying relationships between school climate and student outcomes is especially relevant now as two large-scale policy initiatives have included a positive school climate as a way to reduce educational and health disparities. First, the Centers for Disease Control and Prevention (CDC) has developed the Whole School, Whole Child, Whole Community (WSCC) model to intersect health and education. ${ }^{94}$ WSCC encourages schools to engage students using a platform that best meets their health and developmental needs to achieve successful academic and health outcomes. ${ }^{95}$ Second, the US legislature put forth the Every Student Succeeds Act (ESSA). ${ }^{96}$ This legislation is meant to empower schools and encourages the integration of WSCC. ${ }^{97}$ The changes brought on by ESSA emphasizes the use of school climate as an added measure of school safety and quality to corroborate standardized metrics of school performace. ${ }^{98}$ This recommendation is important because school climate information may provide useful guidance for school management and pedagogical strategies that may impact educational and health outcomes. ${ }^{47}$ With federally supportive legislation, school administrators and community members should find promise in their systematic efforts to improve educational quality, student wellbeing, and academic achievement. Hence, studies that illustrate longitudinal associations of 
school climate on academic achievement to ultimately educate the whole child, reduce academic risk, and prevent negative outcomes are both timely and relevant.

The purpose of this study was to determine the longitudinal associations between school climate and academic grades across three waves from a group of middle school students who transition into high school. We hypothesized that (1) perceptions of school climate and selfreported academic grades would decline over time, (2) measures of school climate would be significantly improve students' self-reported academic grades over time, and (3) perceptions of a positive school climate would improve all students earning better grades over time.

\section{METHODS}

\section{Participants, Procedures and Handling of Missing Data}

Annual data collections (three waves) occurred between 2015, 2016, 2017 from evenly distributed groups of students in $6^{\text {th }}(37.8 \%), 7^{\text {th }}(32.5 \%)$, and $8^{\text {th }}(29.7 \%)$ grades across 16 regional schools from three counties in West Virginia (WV). The three WV counties represent a triangulated profile of students from southern, western, and eastern regions of the state. Students from each county represent a spectrum of diverse characteristics from families living in severe isolation/poverty to modest privilege/affluence. ${ }^{99-101}$ All aspects of each annual collection were approved by West Virginia University's Institutional Review Board (IRB). A letter was sent to parents to provide an opportunity to exclude their children (parental opt out rate $<1 \%$ ). ${ }^{102,103}$ Surveys were administered by classroom teachers with oversight from a school contact agent to ensure response confidentiality. Participation was voluntary and made available to all students. Students were free to answer all or part of the survey and elect to stop participation at any time. 
For further details on data source and collection procedures, see Appendix A, Kristjansson, et al. $^{51,104,105}$, and Mann, et al. ${ }^{106}$

In 2015 (T1), students at baseline provided 6,364 eligible observations (response rate = 82.6\%). In 2016 (T2), students provided 6,336 observations (response rate $=82.0 \%$ ). In 2017 (T3), students provided 6,278 observations (response rate $=81.3 \%$ ). Student data were then matched over time using a unique self-reported identification number yielding a final sample of 2,604 retained cases (three data points per participant). With participant fallout rates common for longitudinal studies this level of attrition was anticipated. ${ }^{107,108}$ To ensure data quality and accuracy, omnibus tests under the Unrestricted Latent Class Indicator models for data missing completely at random (MCAR) were shown to be non-significant (all p > .05). ${ }^{109,110}$ Preliminary tests additionally demonstrated less than $5 \%$ missingness on dependent variables under pairwise techniques after retained cases, which has been shown to produce stable estimates. ${ }^{111}$ However, the inclusion of covariates influenced us to select a more conservative position and assume missing patterns as a function of missing at random (MAR). ${ }^{109}$ Missing data were then handled using full information maximum likelihood estimation (FIML). ${ }^{112,113}$ This strategy was chosen because FIML yields unbiased estimates under MAR hypotheses and is often equivalent to imputation techniques. ${ }^{14-118}$ Additionally, imputation methods may produce spurious estimates when missing patterns are relatively low, as was in our sample. ${ }^{118-120}$

\section{Measures}

Academic Grades. Self-reported grades were captured using a single question, "What were your FINAL grades in the following subjects LAST year?” for Mathematics and English. Responses were combined to represent students' overall grades at each time point. ${ }^{121-123}$ 
Academic grades were then pooled into ordered categories, Mostly As/Bs (coded 2), Mostly Cs (coded1), and Mostly Ds/Fs (coded 0). Mostly As/Bs signified higher academic performance.

School Climate. Three sub-scales (positive student-teacher relationships, order and safety, and opportunities for student engagement) and 20-items were selected from the School Climate Measure developed by Zullig et al. ${ }^{8,124,125}$ School climate questions use a 5-point Likert type scale with response options "strongly disagree" (coded 1) to "strongly agree" (coded 5). Higher scores indicate a positive perception of school climate. For further details on SCM items, see Zullig, et al. ${ }^{124}$ and Appendix B.

\section{Covariates}

Biological Sex. Biological sex ${ }^{51,126,127}$ was assessed by asking respondents "Are you a boy or girl?" Male (coded 0) and female (coded 1) were represented as a dichotomous timeinvariant covariate.

Family Structure. Respondents were asked to indicate their family structure ${ }^{51,126}$ using a 19-item multi-response question, "Which of the following persons live in your home?" For analysis, the question was dichotomized into "lives with both biological parents" (coded 1) and “other arrangements" (coded 0) and represented as a dichotomous time-invariant covariate.

Maternal Education. Maternal education ${ }^{126,128}$ was captured by asking students to select one of nine response options from a singular question "What is the highest level of schooling your mother has completed?" Responses were pooled into categories to simplify analyses, “college graduate" (coded 3), "high school graduate" (coded 2), "less than high school" (coded 1), and "I don't know" (coded 0) and represented as a nominal categorical time-invariant covariate. 


\section{Data Analysis}

Descriptive frequencies, means (standard deviations), scale internal consistency, and confirmatory factor analysis (CFA) estimates were analyzed using SAS 9.4®. ${ }^{129}$ Parallel latent growth curve modeling (PLGM) was selected to examine changes in school climate sub-scales and academic grades while controlling for sex, family structure, and maternal education over time. ${ }^{130}$ All PLGM analyses were performed in Mplus $8.0{ }^{131}$ using a two-tailed distribution with p-values equal to or less than .05. Model specifications used the complex option to accommodate non-normality and non-independence of participants clustered in schools, robust standard errors, and probit transormation. ${ }^{131-133}$ Numerical integration was also used to account for latent categorical and continuous dependent variable interactions between initial start-points (intercepts) and growth trajectory (slopes), with residuals unconstrained. ${ }^{131}$ Intercept (óoo) and slope ( $\left.\alpha_{10}\right)$ means represent between-person initial starting points and growth. Latent regression path estimates (B) and standard errors (SE) signify predictive relationships between school climate and substance use initiation over time. Model fits were determined using the deviance statistic (-2LL, FP), ${ }^{134,135}$ Akaike Information Criteria (AIC), and Bayesian Information Criteria (BIC). Standardized covariance ( $\rho$ ) and regression ( $\beta$ ) estimates demonstrate practical importance of predictive probabilities. Lastly, we ran sensitivity analyses for group comparisons on a middle school sample of students who did not transition into high school $(\mathrm{n}=966)$ and a sample of high school students $(\mathrm{n}=531)$ who started in $9^{\text {th }}$ and $10^{\text {th }}$ grade.

\section{RESULTS}

School climate sub-scale mean scores ranged $3.3(\mathrm{SD}=0.9)$ to $3.7(\mathrm{SD}=0.8)$ across $\mathrm{T} 1$ to T3 with all scales reporting acceptable internal consistency ( $\alpha=0.85$ to 0.94$)$. Additionally, CFAs across T1 to T3 demonstrated excellent measurement fits and ranged: $\chi^{2}=929.17-950.61$ 
$($ all $\mathrm{df}=157, \mathrm{p}=<.01), \mathrm{CFI}=0.97-0.98, \mathrm{TLI}=0.96-0.97, \mathrm{SRMR}=0.02-0.03, \mathrm{RMSEA}=$ all $0.044( \pm \mathrm{CI} 90 \% 0.041,0.047)$. Most students reported As/Bs with $80.5 \%$ at $\mathrm{T} 1$ to $74.9 \%$ at $\mathrm{T} 3$. Additional descriptive statistics are reported in Table 1.

All results for PLGMs are described in Tables 2 through 4 with a conceptual model depicted in Figure 1. For reporting parsimony and clarity please refer to Tables 2 through 4 for between-person intercept ( $\left.\alpha_{00}\right)$ and slope ( $\left.\alpha_{10}\right)$ means. Table 2 reports the results of associations between student-teacher relationships and academic grades. Student-teacher relationship growth estimates between intercepts and slopes across all academic grade groups ranged $\beta=-0.26$ to 0.24 ( $\mathrm{SE}=.09$ to .10 , all $\mathrm{p}<.01)$. Cross-lagged $\beta \mathrm{s}$ between student-teacher relationships on academic grade models ranged -0.45 to $0.30(\mathrm{SE}=.08$ to .11 , all $\mathrm{p}<.05)$. Academic grade $\beta \mathrm{s}$ on teacher relationships demonstrated no significant relationships. Standardized covariance between slopes ranged -0.29 to $0.30(\mathrm{SE}=.10$ to .15 , all $\mathrm{p}<.05)$.

Table 3 describes the standardized associations between order and safety and academic grade models. Growth estimates for order and safety across all grade models reported relatively consistent growth estimates $\beta=-0.25$ (all $\mathrm{SE}=.09, \mathrm{p}<.01$ ). For grades, only significant $\beta$ s were found for the primary model $(-0.31, \mathrm{SE}=.16, \mathrm{p}<.05)$ and mostly Ds/Fs $(-0.55, \mathrm{SE}=.26, \mathrm{p}<.05)$. Cross-lagged $\beta \mathrm{s}$ for order and safety on academic grade models ranged -0.46 to $0.29(\mathrm{SE}=.01$ to .11 , all $\mathrm{p}<.05$ ). Academic grade model $\beta$ s on order and safety indicated significant effects with mostly As/Bs $(-0.11, \mathrm{SE}=.05, \mathrm{p}<.05)$ and mostly $\mathrm{Cs}(-0.15, \mathrm{SE}=.07, \mathrm{p}<.05)$. The primary model and As/Bs showed identical significant correlational slopes $0.25(\mathrm{SE}=.11, \mathrm{p}<.05)$.

Table 4 summarizes $\beta$ s between student engagement and academic grade models. Student engagement $\beta$ s growth trajectories were all found to be significant and ranged -0.25 to -0.29 , SE $=.04$ to .06 . Similar to order and safety, only significant $\beta$ s were found for the primary model (- 
$0.32, \mathrm{SE}=.16, \mathrm{p}<.05)$ and mostly $\mathrm{Ds} / \mathrm{Fs}(-0.54, \mathrm{SE}=.27, \mathrm{p}<.05)$. All cross-lagged $\beta$ s were significant for student engagement on academic grades and ranged -0.46 to 0.29 ( $\mathrm{SE}=.09$ to $.11)$. Mostly Cs $(-0.15, \mathrm{SE}=.07, \mathrm{p}<.05)$ revealed the only significant cross-lagged relationship on student engagement. Lastly, the primary model $(0.26, \mathrm{SE}=.10, \mathrm{p}<.01)$ and mostly As/Bs $(0.24, \mathrm{SE}=.10, \mathrm{p}<.05)$ exhibited correlational relationships between student engagement slopes.

\section{DISCUSSION}

Previous empirical evidence suggests schools that foster a positive school climate are more likely to deliver academically prepared and well-rounded students. ${ }^{61,136}$ As a result, schools become places where students want to spend their time because it enriches their life, which ultimately supports success in school and preparation for adulthood. ${ }^{137-139}$ Focusing on school climate as an intervention presents opportunities for schools to expand on the dimensions related to student wellness and academic performance. ${ }^{61}$ This is likely because the social-ecological tenets of school climate are rooted in many aspects deemed essential to produce whole-human beings. ${ }^{140-142}$ Furthermore, understanding how school climate is related to academic achievement longitudinally may provide schools with the information needed to implement innovative/alternative pedagogical strategies to reduce the achievement gap and promote lifelong health. ${ }^{62}$

We sought to determine the associated growth trajectories between school climate and academic grades in a sample of students who started in middle and transitioned into high school. Our study presents five main findings: (1) academic grades changed over time, (2) school climate changed over time, (3) students with more positive perceptions of school climate sustained As/Bs and improved Cs/Ds/Fs over time, (4) teacher relationships demonstrated the most robust effects on academic grades, while academic grades diminished order and safety, and 
(5) group comparisons from sensitivity analysis revealed a few notable differences between a middle and high school students. Although our findings are by no means definitively causal, our study design and analytical techniques suggest a possible causal relationship and further support the importance of a positive school climate throughout the context of schooling and academic performance.

First, our findings demonstrated grades worsened over time. Across all school climate sub-scales, students in the mostly Ds/Fs group demonstrated significant declines in their grades. However, non-significant growth trajectories in the As/Bs/Cs groups suggest they maintained their academic standing and were less likely to change. Research focused on changes in grades as students transition tends to be mixed. ${ }^{143}$ A study by West and Schwerdt ${ }^{144}$ using longitudinal achievement data found standardized test scores declined as students transitioned into middle school. Another study by Bellmore ${ }^{145}$ tested the effects of interpersonal social position in schools on academic indicators. Her findings additionally demonstrated declines in early adolescent achievement over time. Alternatively, a meta-analytic review by Lee ${ }^{146}$ implies that transitionary effects are more likely plateaus (i.e., do not change) middle schooler's academic achievement instead of causes a decline. Furthermore, a study by Akos, et al. ${ }^{147}$ suggests the "transition effect" is more of an interruption in student achievement growth that can be mended as students reacclimate to a new school environment. Our findings support the general premise of this literature and provide a mild extension by being able to model changes between $\mathrm{As} / \mathrm{Bs}$, Cs, and Ds/Fs. However, a deeper understanding of specific student characteristics that may impact academic grades in this area is warranted.

Second, students' perceptions of school climate reduced across three selected sub-scales and academic groups over time. Previous research suggests students' perceptions of school 
climate may be fluid and subject to change. ${ }^{148}$ Our findings support this position and advocates the value of longitudinal school climate studies, as cross-sectional relationships are less likely to describe such patterns. ${ }^{9}$ By reviewing growth model slopes we additionally were able to better understand if changes in school climate occur individually and at different time points. Our findings suggest that students' perceptions of school climate appear to diminish as a group instead of individually. However, this result was not found for the student engagement sub-scale. Practical implications of these findings may suggest that perceptions of school climate may shift due to underlying transitional modifiers. ${ }^{149}$ Our findings may also suggest conceptually different sub-scales of school climate may have added significance to students' maturity and growth. A longitudinal study by Wang and Eccles ${ }^{150}$ outlined a multi-dimensional model that demonstrated when the school environment supports prosocial norms, students were more likely to engage in school life. Our findings support this position and further allude to school climate as a multidimensional and socially generated phenomenon. ${ }^{31,151}$

Third, findings suggest students averaging As/Bs and a high positive school climate maintained or improved their academic achievement over time. Additionally, students averaging Cs/Ds/Fs whose school climate improved also demonstrated better academic grades. These findings may suggest that when school climate is strengthened, students averaging Cs/Ds/Fs may increase their academic standing. These results are important because school climate appears to support the academic success of all students and not only the majority who tend to be less at risk. ${ }^{49}$ If this is the case, improved school climate may be a useful primary prevention strategy for large-scale school health promotion. ${ }^{26}$ For example, there is a need to focus on improving a school's cultural values that centralizes student health and academic success as a collective process rather than separate. Additionally, supporting school personnel's professional behavior 
using internal school policy may safeguard students averaging $\mathrm{Cs} / \mathrm{Ds} / \mathrm{Fs}$ from falling behind their As/Bs counterparts.

Fourth, although all school climate sub-scales demonstrated positive effects on academic grades, student-teacher relationships illustrated the strongest effects overall. Cross-sectional research has consistently shown nurturing relationships are a salient factor that contributes to academic outcomes. ${ }^{8,124,125}$ Our results support the cross-sectional literature but also suggests, that as students grow older, a positive school climate may be important for them to prospectively do well academically. ${ }^{152}$ On the other hand, academic grades did not appear to influence school climate sub-scales except for order and safety. Among the As/Bs/Cs, academic grades demonstrated a diminishing effect on order and safety. This finding was unanticipated and further supports the dynamic interplay between school climate sub-scales and academic achievement. Our results may indicate unintended consequences with school disciplinary procedures.$^{63}$ Studies have shown when school rules are too strict, defiance can be an unintentional result. ${ }^{149}$ Higher achieving students in our sample may possess unobserved characteristics that supports their unenthusiastic perception of school rules and authority. However, this is mildly speculative and requires further investigation.

Lastly, group comparisons from sensitivity analysis revealed a few notable differences between a middle and high school students. In the middle school only group, school climate and academic grades were found to be stable and did not significantly decline over time. This may suggest students' perceptions of school climate and academic grades stay relatively similar throughout middle school. Comparatively, high school students' perceptions of school climate are just as important to all levels of academic achievement as middle schoolers. However, high schoolers presented much steeper declines in school climate over time, which may suggest 
school climate's importance to academic achievement shifts in high school. From a primary prevention point of view, these preliminary results may allude to school climate having variation to its importance between middle and high school students. More research in this area is needed to better understand the differences between school climate and academic achievement, with an emphasis on the transition from middle to high school.

\section{CONCLUSION}

Study results demonstrated longitudinal associations between school climate and academic achievement. Findings support the value and promotion of a positive school climate, especially across sub-scales. In addition, positive perceptions of school climate may sustain high academic performance, while strengthening the grades of average and low academic performers. Given the modest variation between $\mathrm{As} / \mathrm{Bs}, \mathrm{Cs}$, and Ds/Fs future studies should examine the mechanisms that exist between more robust models of school climate and contextual characteristics of these groups. Preliminary comparisons between middle and high school students suggests there may be differences between these groups, but further investigation is required. Future studies that support longitudinal and more generalizable findings are needed to provide recommendations for the delivery of instruction and professional practice that promotes the whole child. With ESSA mandates and WSCC implementation, it will be important for schools to fully understand the usefulness of school climate to foster desired academic outcomes. As mentioned in the introduction, interventions that focus on school climate may help contribute to the success of ESSA and WSCC while offering data-driven improvements to practice. 


\section{LIMITATIONS}

First, our sample was drawn from a predominantly homogenous group of White middle school students from 16 schools in West Virginia. Findings may not be representative or generalizable to other regions of the US. Nevertheless, our sample represents three distinct counties with chronic rural poverty and rates of adolescent substance use that exceed national estimates. ${ }^{153}$ More research on prevention programs is needed to better understand the health needs of this population. Second, the potential issue of non-matched students may exacerbate the limited representativeness. However, the mechanism that may cause non-matching may be difficult to distinguish. Fortunately, even when participant attrition is high, parameter estimates are still likely to be accurate. ${ }^{107}$ Third, student self-reported information is subject to acquiescence and recall bias. Fourth, our study only modeled three aspects of school climate. The literature around school climate is diverse and considers many aspects of the socioorganizational structures of schools. However, the three sub-scales chosen in this study are consistently found in other school climate instruments and make-up half of the SCM. Additional research is needed to better understand the full spectrum of school climates impact on academic achievement. Lastly, we are unable to rule out unaccounted variance from other confounding variables that may substantially impact school climate sub-scales and academic grades over time.

\section{IMPLICATIONS}

How schools support students to achieve academic and life success will continue to be a topic for researchers and educators alike. ${ }^{154}$ Policy frameworks like WSCC and ESSA still require further research to better understand how non-academic factors like school climate may influence desired student outcomes. ${ }^{155}$ Helping students achieve good grades will likely be shaped by dedicated educators, but as our findings suggest, academic grades are related to factors 
beyond what happens in the classroom. Based on our findings, a positive school climate demonstrated associations to academic grades over time. In this way, school climate may fit well as a universal intervention within a multi-tiered framework. ${ }^{156}$ Research on a positive school climate have shown to help schools maximize their effectiveness toward academic success and student health. ${ }^{64,78,157}$ Gaining a better understanding of how school climate can influence the within-school mechanisms by which these policies are meant to impact, we may not only contribute to their success, but offer informed and improved practice. At the very least, our findings affirm the idea that schools focused on enhancing aspects of school climate may increase the potential to enrich students' lives and prepare them for academic success.

Utilizing aspects of school climate may ameliorate less desirable student outcomes and meet the needs for large-scale health promotion implementation. For example, administrators who support and encourage teachers to form bonding relationships may help students in ways which may be evident in their academic behavior. Our findings support this idea as we found students who perceived relationships with teacher as positive were as likely to sustain high academic performance. In addition, school climate may support upward academic mobility for average and lower student performers. A seminal work by Allensworth, et al. ${ }^{49}$ highlights this importance from what they deem as "personalism"(p. 32), which accounts for students initial trust of teachers and feelings of personal support. This idea is not to infer that each student requires scheduled amounts of time to meet their needs. Rather, Allensworth, et al. ${ }^{49}$ state,

"Teachers working together in a coordinated way-taking responsibility for the whole school; providing relevant, coherent instruction; and developing strong relationships with students - most strongly distinguishes schools with above-expected student performance in their courses." (p. 33-34). 
Although our study does not account for teacher performance or classroom management, our findings suggest students who earn Cs may require as much attention as student with Ds/Fs. Considering average academic performers less important than lower performers may undermine the likelihood of a student being able to cross the achievement gap toward success. In our sample, perceptions of school climate and academic grades decreased as students grew older. Because of this finding, it may be prudent to consider strengthening factors that promote a positive school climate early with sustained application throughout the schooling years. While our results provide longitudinal evidence between three dimensions of school climate and academic achievement, there is still much to be learned.

\section{Human Subjects' Approval Statement}

All aspects of each data collection year in this study, including participant involvement based on passive parental consent, were accomplished in accordance with West Virginia University's Institutional Review Board guidelines for the protection of research participants. The following are the IRB protocols for each corresponding data collection year, 2015 (\# 1406345394), 2016 (\# 1406345394R002), and 2017 (\# 1406345394R004).

\section{Acknowledgements}

This work was supported by the West Virginia Department of Education (WVDOE) in Charleston, WV and the Substance Abuse and Mental Health Service Administration (SAMHA) in Washington, DC; Project AWARE 2015-2020. The authors would like to extend our gratitude to the funders for their generous support. The authors would like to thank Dr. Megan L. Smith and the dedicated personnel who made Project AWARE 2015-2020 data collection possible. 


\title{
CHAPTER 3
}

\section{School Climate as a Universal Intervention to Prevent Substance Initiation in Early Adolescence: A Longitudinal Study}

\begin{abstract}
BACKGROUND: Initiation of substance use often starts during adolescence, with tobacco and alcohol frequently preceding the use of marijuana and other illicit drugs. Studies suggest a positive school climate reduces substance use, while promoting healthy behaviors and wellbeing. The purpose of this study was to determine the longitudinal associations between school climate and substance use initiation in a group of middle school students who transition into high school.
\end{abstract}

METHODS: Parallel latent growth curve modeling was used to examine changes among study variables longitudinally using a sample of $2,0976^{\text {th }}, 7^{\text {th }}$, and $8^{\text {th }}$ grade students across 16 regional schools located in three counties in West Virginia.

RESULTS: A positive school climate may forestall substance use initiation $(\beta=-0.07$ to -0.25 , $\mathrm{p}<.01)$, but perceptions of school climate decreased on their own over time $(\beta=-0.28$ to $-0.66, \mathrm{p}$ $<.01)$. Substance use initiation increased as students transitioned into high school $(\beta=0.96$ to $0.99, \mathrm{p}<.01)$ and reduced the effects of school climate longitudinally $(\beta=-0.07$ to $-0.24, \mathrm{p}<.01)$.

CONCLUSIONS: Findings support a positive school climate may delay substance use initiation and promote school success. Students early substance use initiation may be a warning sign to other underlying issues and require additional school support to foster success. School climate may be useful as an intervention to support school-based health promotion interventions.

Keywords: Middle school, drug initiation, substance use prevention, parallel latent growth curve 


\section{INTRODUCTION}

\section{An Overview of Substance Use Initiation in the United States}

Initiation of substance use often starts during adolescence with tobacco and alcohol frequently preceding the use of marijuana and other illicit drugs. ${ }^{57-59}$ Nationally, alcohol continues to be the most commonly used legal substance by adolescents. ${ }^{158}$ While combustible cigarette use is at an all-time low (9\% among $8^{\text {th }}$ graders and $27 \%$ among $12^{\text {th }}$ graders $),{ }^{158}$ electronic cigarette (vaping) use appears to be increasing with $13.5 \%$ of early adolescents and $37.7 \%$ of young adults reporting lifetime initiation. ${ }^{51,159,160}$ Additionally, marijuana use demonstrated significant prevalence increases in 2017, while other illicit drugs continued to decline. ${ }^{158}$ Despite these national milestones, the likelihood of youth ever using any substance is still ever present and likely to increase with age. ${ }^{161-163}$

Determinants like rurality also contribute to early substance use initiation among youth. ${ }^{164}$ Regions like rural Appalachia have seen an unprecedented surge in adolescent opioid use. ${ }^{165}$ Reasons for the opioid epidemic are linked to many determinants of health such as living in extreme poverty and poor access to quality care. ${ }^{166}$ Empirical studies have also demonstrated substance use initiation of any drug at a young age is associated to adult polysubstance use and abuse. ${ }^{167-169}$ Preventing adolescent substance use is therefore essential to reduce the probability of drug related disorders and other health problems in adulthood. ${ }^{170-172}$ Schools may be able to help support preventing substance use initiation. ${ }^{173-175}$ Studies suggest when students are exposed to a safe and supportive school climate, this may influence deviant behaviors like substance use initiation. However, most of the research on this topic is based on cross-sectional findings. ${ }^{9,17}$ Although these studies are valuable, constructs like school climate and behaviors like substance 
use initiation are subject to change longitudinally. ${ }^{148}$ Hence, more research is needed to better understand how school climate and substance use initiation may be related over time.

\section{School Climate and Substance Use Initiation}

A school's climate provides an excellent example of how a school's social environment can positively shape child and adolescent behavior. ${ }^{77,86,90}$ School climate is often defined or based on a school's social patterns that represent values, practices, and relationships within a socio-organizational structure. ${ }^{8,13,17}$ Most research suggests teacher relationships such as bonding with teachers and peers; order and safety such as respect for school rules; academic engagement such as a sense of accomplishment and emotional investment with school; and school connectedness such as attachment and building social bonds to school are often the basis of constructs found in conceptual models of school climate. ${ }^{8,9,17}$

Studies suggest that schools that foster a positive school climate are more likely to produce healthy student behaviors. ${ }^{64}$ This is likely due to the conceptual nature of school climate which is undergirded to many social aspects deemed essential to produce well-rounded human beings. ${ }^{91}$ In their review of health and education, Michael, et al. ${ }^{47}$ advocated the importance of school climate as a protective factor to prevent risky student behavior like substance use. However, their review outlines the scarcity of comprehensive evidence of school climate's importance, especially over time. Therefore, understanding longitudinal associations of school climate presents potential implications for prevention strategies that may impact student health behaviors such as substance use initiation.

School Climate constructs are linked to social ecological theories where learning and modeling is derived from contextually shared experiences with others. ${ }^{18,23-25}$ Through high 
quality classroom management and encouragement of prosocial behaviors, school climate may shape the learning environment. ${ }^{13,17,91}$ A positive school climate is also important because formal education occurs during critical stages of growth and maturity when students become vulnerable to a myriad of risky behaviors. ${ }^{30,31}$ Negative experiences during these stages may foster into cycles of deviant behavior that may not only affect school performance, but transition into adulthood. ${ }^{176-178}$ A positive school climate has also illustrated positive impacts on students' substance use and mental-emotional health. ${ }^{179}$ Studies have found associations where a positive school climate reduces substance use, while promoting healthy psychosocial development and wellbeing. ${ }^{67,180}$ However, empirical attempts to explain the relationship between school settings and substance use have been drawn primarily from cross-sectional studies, which has limited the ability to describe dynamic patterns of school climate over time. ${ }^{9,148}$ This fact leaves the literature mixed on school climate's association and potential impact on substance use, with researchers calling for more longitudinal and multilevel studies. ${ }^{9}$

\section{School Climate and Multi-Tiered Systems of Support (MTSS)}

School-based substance prevention strategies have demonstrated success at reducing initiation within a multi-tiered system of support (MTSS). ${ }^{157,181,182}$ Delivery of MTSS in schools often follows recommendations outlined by the Institute of Medicine's prevention and treatment of mental disorders guidelines. ${ }^{183,184}$ Tiered models by design use progressive levels of treatment to improve the likelihood of positive outcomes. ${ }^{64}$ In addition, tiers are integrated in order to supplement and support one another as a collective whole. ${ }^{156}$ Universal strategies (Tier 1) are often implemented in school settings and focus on students' social-emotional learning to prevent issues like substance use. ${ }^{185}$ For context, selective (Tier 2) and indicated (Tier 3) use targeted 
approaches and focus on individuals or groups that would be deemed at higher risk (i.e., treatment focused). ${ }^{157}$

Universal strategies in tiered models are designed so every child receives the benefit of an intervention simply by being in school. ${ }^{186}$ An example of a universal strategy may include changes in school policies that integrate social skill building into a curriculum or proactive classroom management. ${ }^{185}$ Studies have shown that promoting a positive school environment using MTSS reinforces prosocial skills and reduces negative behaviors. ${ }^{187}$ Improving aspects of school climate, therefore, seem practical as a universal strategy because of its inherent potential to improve outcomes by improving positive characteristics of the learning environment to impact all students. ${ }^{78}$ Nevertheless, aside from a few notable exceptions, ${ }^{78,188}$ interventions meant to promote and sensibly explain school climate as a universal service students' are fundamentally non-existent.

Holistic models that thread together health and education are gaining ground among school districts. ${ }^{188,189}$ A collective goal of school climate research has been to empirically highlight the complementary impact of non-academic factors to support desired student outcomes. $^{92}$ Although the components of MTSS are likely to improve student outcomes, integrating school climate into the MTSS model presents some challenges. ${ }^{26}$ For example, MTSS often requires substantial training to establish a coordinated system of leadership and monitoring of framework activities. ${ }^{187}$ Furthermore, MTSS also needs enthusiastic stakeholder "buy-in" at several school-levels, which may be difficult to acquire if school personnel's readiness is lacking. ${ }^{187}$ This may unintentionally and negatively impact the fidelity of MTSS if a school's climate and culture is resilient to large-scale system change. ${ }^{190}$ Additionally, measurement of school climate within MTSS frameworks often varies across studies which restricts replication 
and comparability. ${ }^{191}$ This fact further limits our understanding of how school climate may meet the goals of MTSS outcomes. Therefore, using science to create a fuller picture of how school climate may impact student factors like substance use initiation, especially over time, is warranted and may support MTSS frameworks. ${ }^{9}{ }^{192}$ By better understanding the links between school climate, schools may strengthen prevention approaches to broaden the systemic and relative impact of the academic experience.

The purpose of this study was to determine the longitudinal associations between school climate and initiation of licit substances and marijuana across three waves in a sample of middle school students who transition into high school. We hypothesized that (1) perceptions of school climate would decline overtime, (2) self-reported substance use initiation would increase over time, and (3) measures of school climate would be significantly decrease students' self-reported substance use initiation over time.

\section{METHODS}

\section{Participants, Procedures and Handling of Missing Data}

Annual data collections occurred between 2015 to 2017 using prospective clustered sampling techniques from evenly distributed groups of students in $6^{\text {th }}(37.8 \%), 7^{\text {th }}(32.5 \%)$, and $8^{\text {th }}(29.7 \%)$ grades across 16 regional schools from three counties in West Virginia (WV). The three WV counties represented a triangulation of students from the southern, western, and eastern regions of the state. Students from each county represent diverse population characteristics from families living in severe isolation/poverty to modest privilege/affluence. ${ }^{99-101}$ All aspects of each annual collection were approved by West Virginia University's Institutional Review Board (IRB). A letter was sent to parents to provide an opportunity to exclude their 
children (parental opt out rate $<1 \%$ ). ${ }^{102,103}$ Surveys were administered by classroom teachers with oversight from a school contact agent to ensure response confidentiality. Participation was voluntary and made available to all students. Students were free to answer all or part of the survey and elect to stop participation at any time. For further details on data collection procedures, see Appendix A, Kristjansson, et al. ${ }^{51,104,105}$ and Mann, et al. ${ }^{106}$

In 2015 (T1), students at baseline provided 6,364 eligible observations (response rate = 82.6\%). In 2016 (T2), students provided 6,336 observations (response rate $=82.0 \%$ ). In 2017 (T3), students provided 6,278 observations (response rate $=81.3 \%$ ). Data management and cleaning removed 507 observations due to unreliable responses across Time 1 to Time 3. Student data was then matched over time using a unique self-reported ID number yielding a final sample of 2,097 retained cases (three data points per participant). With participant dropout rates being common in longitudinal studies, this level of attrition was anticipated. ${ }^{107,108}$ To ensure data quality and accuracy, omnibus tests under the Unrestricted Latent Class Indicator models for data missing completely at random (MCAR) were tested and shown to be non-significant (all p > .05). ${ }^{109,110}$ Preliminary tests additionally demonstrated less than 5\% missingness on dependent variables under pairwise techniques after retained cases, which has been shown to produce stable estimates. ${ }^{111}$ However, because of the inclusion of covariates, we chose a more conservative route and assumed missingness to be a function of missing at random (MAR). ${ }^{109}$ Missing data were then handled using full information maximum likelihood estimation (FIML). ${ }^{112,117}$ This strategy was chosen because FIML yields unbiased estimates under MAR hypotheses and is often equivalent to imputation techniques. ${ }^{14-118}$ In addition, imputation may produce erroneous estimates when missing patterns are relatively low and often requires substantial and unnecessary computational resources under such circumstances. ${ }^{118-120}$ 


\section{Measures}

Substance Use Initiation. Life time substance use asked participants, have you ever: “tried cigarette smoking, even just one or two puffs?"; "tried electronic cigarettes (e-cigarettes or vapors), even just one or two puffs?"; "had a drink of alcohol, other than a few sips?"; and "tried marijuana (also called weed or pot) or hashish (also called hash or hash oil)?” Response options for all substance use initiation variables were binary with "no" (coded 0) and "yes" (coded 1).

School Climate. Three sub-scales (positive student-teacher relationships, order and safety, and opportunities for student engagement) and 20-items were selected from the School Climate Measure developed by Zullig et al. ${ }^{8,124,125}$ School climate questions use a 5-point Likert type scale with response options "strongly disagree" (coded 1) to "strongly agree" (coded 5). Higher scores indicate a positive perception of school climate. For further details on SCM items, see Zullig, et al. ${ }^{124}$ and Appendix B.

\section{Covariates}

Biological Sex. Biological Sex ${ }^{51,126,127}$ was assessed by asking respondents “Are you a boy or girl?" Responses were coded 0 for males and 1 for females and the responses were represented as a dichotomous time-invariant covariate.

Family Structure. Respondents were asked to indicate their family structure ${ }^{51,126}$ using a 19-item multi-response question "Which of the following persons live in your home?" For analysis, the question was dichotomized into "lives with both biological parents" (coded 1) and "other arrangements" (coded 0) and the responses were represented as a dichotomous timeinvariant covariate. 
Maternal Education. Maternal education ${ }^{126,128}$ was captured by asking students to select one of nine response options from a singular question "What is the highest level of schooling your mother has completed?" Responses were pooled into categories to simplify analyses, “college graduate" (coded 3), "high school graduate" (coded 2), "less than high school" (coded 1), and "I don't know" (coded 0) and represented as a nominal categorical time-invariant covariate.

\section{Data Analysis}

Descriptive frequencies, means (standard deviations), scale internal consistency, and confirmatory factor analysis (CFA) estimates were analyzed using SAS 9.4®. ${ }^{129}$ Parallel latent growth curve modeling (PLGM) was selected to examine changes in school climate sub-scales and substance use initiation while controlling for sex, family structure, and maternal education over time. ${ }^{130}$ All PLGM analyses were performed in Mplus 8.0@ ${ }^{131}$ using a two-tailed distribution with p-values equal to or less than .05. Model specifications used the complex option to accommodate non-normality and non-independence of participants clustered in schools, robust standard errors, and probit transformation. ${ }^{131-133}$ Numerical integration was also used to account for latent binary and continuous dependent variable interactions between initial start-points (intercepts) and growth trajectory (slopes). Latent substance use initiation intercept and slope residuals were constrained to 1 and 0 to support model convergence. ${ }^{131}$ Intercept (óno) and slope (ó10) means represent between-person initial starting points and growth. Latent regression path estimates (B) and standard errors (SE) signify predictive relationships between school climate and substance use initiation over time. Standardized covariance $(\rho)$ and regression $(\beta)$ estimates demonstrate practical importance of predictive probabilities. Finally, model fits were determined using the deviance statistic (-2LL, FP), ${ }^{134,135}$ Akaike Information Criteria (AIC), and Bayesian 
Information Criteria (BIC). Lastly, we ran sensitivity analyses for group comparisons on a middle school sample of students who did not transition into high school $(n=818)$ and a sample of high school students $(\mathrm{n}=471)$ in $9^{\text {th }}$ and $10^{\text {th }}$ grade.

\section{RESULTS}

School climate sub-scale mean scores ranged $3.3(\mathrm{SD}=0.9)$ to $3.7(\mathrm{SD}=0.8)$ across $\mathrm{T} 1$ to T3 with all scales reporting acceptable internal consistency ( $\alpha=0.85$ to 0.94 ). Additionally, CFAs across T1 to T3 demonstrated excellent measurement fits and ranged: $\chi^{2}=929.17-950.61$ $($ all $\mathrm{df}=157, \mathrm{p}=<.01), \mathrm{CFI}=0.97-0.98, \mathrm{TLI}=0.96-0.97, \mathrm{SRMR}=0.02-0.03, \mathrm{RMSEA}=$ all $0.044( \pm 0.041,0.047)$. Alcohol was reported as the most initiated substance with $7.6 \%$ at $\mathrm{T} 1$ to $27.8 \%$ at $\mathrm{T} 3$. Electronic cigarettes $(4.5 \%$ at $\mathrm{T} 1$ to $20 \%$ at $\mathrm{T} 3$ ), combustible cigarettes ( $4.1 \%$ at $\mathrm{T} 1$ to $14.6 \%$ at $\mathrm{T} 3)$, and marijuana ( $3.2 \%$ at $\mathrm{T} 1$ to $13.7 \%$ at $\mathrm{T} 3)$ followed with less dramatic but similar trends. Additional descriptive statistics are reported in Table 5.

All results for PLGMs are described in Tables 6 through 8 with a conceptual model depicted in Figure 2. For reporting parsimony and clarity please refer to Tables 2 through 4 for between-person intercept ( $\left.\alpha_{00}\right)$ and slope ( $\left.\alpha_{10}\right)$ means. Table 6 reports the results of associations between student-teacher relationships and substance use initiation. Student-teacher relationship growth estimates between intercepts and slopes across all substance use initiation models ranged $\beta=-0.26$ to $-0.66(\mathrm{SE}=.09$ to .10 , all $\mathrm{p}<.01)$. Substance initiation $\beta \mathrm{s}$ for students' growth trajectories ranged 0.92 to 0.99 (all $\mathrm{SE}=.02, \mathrm{p}<.01$ ). Cross-lagged $\beta$ s between student-teacher relationships on substance models ranged -0.07 to -0.25 ( $\mathrm{SE}=.01$ to .04 , all $\mathrm{p}<.01)$. Crosslagged $\beta$ s for substance models on teacher relationships ranged -0.16 to -0.20 ( $\mathrm{SE}=.01$ to $.06, \mathrm{p}$ $<.01)$. Standardized covariance between intercepts ranged -0.20 to -0.32 ( $\mathrm{SE}=.05$ to .08 , all $\mathrm{p}$ $<.01)$. 
Table 7 describes the standardized association between order and safety and substance use initiation models. Growth estimates for order and safety across all substance use initiation models ranged $\beta=-0.29$ to -0.32 ( $\mathrm{SE}=.10$ to .11 , all $\mathrm{p}<.01$ ). Substance initiation $\beta$ s reported relatively consistent growth estimates and ranged 0.95 to $0.99(\mathrm{SE}=.02$ to .03 , all $\mathrm{p}<.01$ ). Cross-lagged $\beta \mathrm{s}$ for order and safety on all substance models ranged -0.07 to -0.17 ( $\mathrm{SE}=.01$ to $.06, \mathrm{p}<.01)$ and $\beta \mathrm{s}$ for substances on order and safety ranged -0.09 to $-0.20(\mathrm{SE}=.03$ to $.08, \mathrm{p}$ $<.01)$. Alcohol was the only exception $(\beta=-0.09, \mathrm{SE}=.05)$. The correlation between intercepts ranged -0.29 to -0.37 ( $\mathrm{SE}=.04$ to .06 , all $\mathrm{p}<.01)$.

Table 8 summarizes $\beta$ s between student engagement and substance use initiation. Student engagement $\beta$ s between intercepts and slopes were significant and ranged -0.09 to -0.37 ( $\mathrm{SE}=$ .02 to $.06, \mathrm{p}<.01$ ) Substance initiation growth models ranged 0.96 to 0.99 (all $\mathrm{SE}=0.2, \mathrm{p}<.01$ ). All cross-lagged $\beta$ s were significant for student engagement on substance use initiation and ranged -0.07 to -0.15 ( $\mathrm{SE}=.01$ to $.03, \mathrm{p}<.01)$. Cross-lagged $\beta$ s for substances on student engagement were all significant and ranged -0.07 to $-0.24(\mathrm{SE}=.01$ to .03$)$. The correlations between student engagement intercepts were all significant and ranged -0.20 to -0.30 ( $\mathrm{SE}=.04$ to $.07, \mathrm{p}<.01)$.

\section{DISCUSSION}

This study sought to determine the associations of initial growth trajectories between school climate and life time substance use through middle into high school. Our study presents four main findings: (1) school climate may delay substance use initiation over time, (2) perceptions of school climate decreased over time, (3) substance use initiation substantially increased over time, (4) substance use initiation reduced perceptions of school climate, and (5) group comparisons from sensitivity analysis revealed a few notable differences between a middle 
and high school groups. Although our findings may not be definitively causal, our study design and analytical techniques suggest a possible causal relationship and direction that supports the importance of a positive school climate to forestall substance use initiation. Therefore, a focus on school climate as an intervention may present an opportunity for schools to expand on their dimensions related to substance use prevention. ${ }^{47}$

First, findings suggest a positive school climate may delay initiation for all types of substances over time. Positive student-teacher relationships presented slightly stronger effects than order and safety and student engagement sub-scales across all substance models. Crosssectional studies have consistently suggested nurturing relationships between students and teachers is a salient factor that contributes to student outcomes. ${ }^{8,124,125}$ A systematic review by Fletcher, et al. ${ }^{193}$ outlined the importance of a school's ethos and how it may impact drug use. Their review generally concluded that when students mutually respect and feel connected to school they are less likely to use drugs. Our findings affirm their conclusion and suggest a positive school climate may be important for the duration of schooling. Additionally, by reviewing the correlations between intercepts, we additionally were able to better understand how school climate impacts substance use initiation between years. Our findings suggest students who maintained higher perceptions of school climate at each time-point were less likely to have initiated in substance use between years. Studies strongly support that the longer the delay in substance use initiation, the less likely students will ever use at a young age. ${ }^{185}$ Taken together, our findings may suggest a relative causal direction, as a positive school climate is likely to antecede substance use initiation. If this is the case, our findings support the ideas above and suggest a positive school climate may help prevent substance use initiation. 
Second, all school climate sub-scales also decreased over time. Our findings confirm previous longitudinal studies that found school climate appears to be fluid and dynamic. ${ }^{148}$ This finding is important because if a positive school climate may delay substance use initiation, then a focus on its preservation and sustainability throughout schooling may be necessary. Our findings may also suggest a "transition effect" may be present and interrupt students' connection with school as they reacclimate to a new environment. ${ }^{143,194}$ Therefore, perceptions of school climate may take on a new meaning as students get older. For middle school students, strengthening a positive school climate may entail promoting activities that improve bonding relationships and connectedness in school. ${ }^{195}$ For high school students, supporting academic focus and subject specialization as they prepare for adulthood may be more beneficial. ${ }^{196}$ Longitudinal studies have shown when the school environment supports a positive school life, school climate also increases in tandem. ${ }^{150}$ However, there is limited practical guidance for schools across the US as to how to bear such fruit. As discussed in the introduction, conceptualizations of school climate are diverse. This type of diversity may unintentionally and undesirably misdirect or underrepresent the broad effects of a positive school climate as a universal intervention. ${ }^{190,191}$ Our findings support the idea of transitional effects, but more studies are needed to better understand how school climate changes between middle and high school and how this may impact the broader system.

Third, as students grew older and transitioned into high school the association of initiating any substance strongly increased. This finding was anticipated as all students began in middle school, which is an age group less likely to ever have used substances. ${ }^{197-199}$ Furthermore, review of the between-person slopes suggested most students started without ever using any substance and varied as to when they would potentially initiate. A practical perspective may 
suggest that substance use initiation alludes to underlying student issues, peer influences, or sociocultural normalization of substance use. ${ }^{200,201}$ Alternatively, there may be a mathematical explanation which has been noted in the study limitations.

Fourth, students who initiated with any substance demonstrated reduced perceptions of a positive school climate. As mentioned above, student perceptions of a positive school climate may delay substance use initiation but declines over time as students grow older. Therefore, one might wonder if substance use initiation bolsters a reduction in school climate's impact? If this is the case, substance use initiation may be a potential red flag that indicates a need for additional support. ${ }^{202}$ Studies have shown that students who initiate in substance use fit a social profile and a sequential risk gradient. ${ }^{51,203}$ Students who fall into these profiles have been shown to be socially isolated and alienated, engage in delinquent behaviors with friends, and spend more unsupervised time out late at night. ${ }^{51}$ How these profiles impact school climate is relatively unknown ${ }^{149}$, but may be related to the declines found in our results. The only exception was lifetime use of alcohol on order and safety, which may indicate cultural norms and perceptions related to alcohol. ${ }^{201}$ Future research should consider comparing potential student profiles of school climate between substance initiators and non-initiators. Nevertheless, as our results suggest, a positive school climate may be more important than initially thought and be a useful strategy to help reduce the likelihood of adolescent substance use initiation.

Lastly, group comparisons from sensitivity analysis revealed a few notable differences between a middle school only sample and a high school only sample. In the middle school only group, students who initiated in either electronic or combustible cigarettes at an early age presented stronger diminishing effects on perceptions of school climate, but school climate on substance use initiation was also more substantial. These results further support our primary 
findings in that early initiation of any substance may be a warning sign, but also a positive school climate may prevent the warning. Comparatively high school students' perceptions of school climate are just as important to substance use initiation as middle schoolers' perceptions. However, without any influence from initiation of substances, high schoolers' perception of school climate demonstrated steeper declines over time. These findings support the position that there may be a difference in school climate's importance between middle and high school students as mentioned above. From a primary prevention point of view, our findings suggest that middle school may the best-last time to intervene. ${ }^{178}$ This may hold especially true when considering school climate as a universal strategy in MTSS frameworks. More research in this area is needed to better understand the relationships between school climate, substance use initiation, and potential group differences.

\section{LIMITATIONS}

First, our sample was obtained from a large group of mostly White middle school students from 16 schools in West Virginia. Findings may be limited in their representativeness to other regions of the US. Nevertheless, the samples three counties contain a spectrum of students who live in chronic rural poverty and report high rates of adolescent substance use that exceeds national estimates. ${ }^{153}$ More research on prevention programs is needed to better understand the health needs of this population. Second, the potential issue of non-matched students may exacerbate the limited representativeness. However, the mechanism that may cause nonmatching may be difficult to distinguish. Fortunately, even when participant attrition is high, parameter estimates are still likely to be accurate. ${ }^{107}$ Third, student self-reported information is subject to acquiescence and recall bias. Modeling school-level data is often fraught with statistical noise. Therefore, we were unable to entirely account for potentially important 
confounders. However, testing of similar risk factors such as substance use cross-sectionally and over time have demonstrated strong accuracy with reliability coefficients ranging .61 to $.82 .{ }^{204-}$ ${ }^{206}$ Fourth, substance use initiation measures were relatively unbalanced and may diminish precision. Modeling actual number or ordinal categories of substances used may provide additional and/or alternative information for prevention research. ${ }^{207}$ Fifth, although highly technical, the strong associations between substance use initiation intercepts and slopes are likely due to these variables not being normally distributed (i.e., 0 or 1). Furthermore, once a student initiates they are unable to initiate again, which constricts the variation of the parameter. This often occurs when latent categorical variables are influenced by latent continuous variables. ${ }^{208} \mathrm{In}$ mathematics, this interaction is often described as a latent categorical variable having a nonclosed-form solution. ${ }^{131,209}$ Therefore, numerical integration is often a requirement, as was in our analysis. ${ }^{210}$ Regardless of the complexity, longitudinal studies focused on student characteristics in the context of school climate are needed to better explain the "when" and "why" of substance use initiation. Lastly, our study only modeled three aspects of school climate. The literature around school climate is diverse and considers many aspects of the socio-organizational structures of schools. However, the three sub-scales chosen in this study are consistently found in other school climate instruments and make-up half of the SCM. Additional research is needed to better understand the full spectrum of school climate's impact on substance use initiation and student health behaviors.

\section{CONCLUSION}

A positive school climate may delay substance use initiation. The implications of these findings may support broader aspects of primary prevention to promote health of students, families and communities. Universal school-based interventions that focus on improving school 
climate may strengthen and sustain student success during the formal schooling years. Moreover, a positive school climate may help school-based frameworks like MTSS prevent substance use initiation and addresses other federal guidelines to foster desired student outcomes. Future studies that outline the relationships between school climate, student characteristics and the mechanisms of substance use are recommended.

\section{IMPLICATIONS}

Teachers, administrators, and families will continue to work tirelessly to help students be their best. ${ }^{154}$ School-based prevention frameworks like MTSS require continued research to better understand how non-academic factors like school climate influence desired student outcomes. ${ }^{155}$ Preventing substance use initiation at early ages will continue to be shaped by forces beyond the classroom, but as our findings suggest, what happens in schools may impact what happens outside of school.

In this study, students' positive perceptions of school climate naturally decreased consistently over time. Therefore, it may be important for schools to proactively keep positive perceptions of school climate as high as possible. This finding may also hint at an important transitionary effect when early adolescents move into high school. Based on what we have learned, bonding teacher relationships, school rules, and academic motivation all seem to be important to students throughout school. ${ }^{26}$ Investing in school climate as a universal intervention may bolster new opportunities for schools to prevent substance use initiation. ${ }^{87}$ In middle schools, it may be prudent to select strategies specific to improving healthy student-teacher relationships that enhance classroom connectedness and reduce alienation. ${ }^{84}$ In high school, classroom instruction or programmatic policy that encourages preparation for adulthood may be more useful. ${ }^{179}$ However, transitionary services or a programmatic safety net may be required to 
help sustain high positive perceptions of school climate. This may be a benefit to using MTSS as additional supports may already be in place in the form of Tier 2 and 3 services. ${ }^{187}$ More research and practical guidelines are necessary to apply school climate related interventions to the myriad of context specific student issues.

In many ways, schools shoulder an unbalanced portion of the social burden in their respective communities. Although schools may be limited to directly intervene on households and other macro forces, they are able to modify internal policies and procedures to support their communities' collective vision. The systemic impact education makes on communities and broader society has been understudied and debated for generations. ${ }^{20,211,212}$ What we know definitively is schools matter. ${ }^{43-45}$ Our institutions are real places that influence people's lives toward better health and quality of life. ${ }^{42}$ We feel the practical implications of this study adds value to: (1) promote and encourage a positive school climate in school as a way to reduce the likelihood of substance use, (2) advocate school climate as a central focus for collaborative school health research, (3) stimulate and encourage multidisciplinary partnerships to generate practical frameworks for school climate interventions, and (4) open avenues for public health and public education to work together to meet national academic and health goals.

\section{Human Subjects' Approval Statement}

All aspects of each annual data collection in this study, including participant involvement based on passive parental consent, were accomplished in accordance with West Virginia University’s Institutional Review Board guidelines for the protection of research participants. The following are the IRB protocols for each corresponding data collection year, 2015 (\# 1406345394), 2016 (\# 1406345394R002), and 2017 (\# 1406345394R004). 


\section{Acknowledgements}

This work was supported by the West Virginia Department of Education (WVDOE) in Charleston, WV and the Substance Abuse Mental Health Service (SAMHA) in Washington, DC; Project AWARE 2015-2020. The authors would like to extend our gratitude to the funder for their generous support. The authors would like to thank Dr. Megan L. Smith and the dedicated personnel who make the Project AWARE 2015-2020 data collection possible. 


\title{
CHAPTER 4
}

\section{Using School Climate to Impact School Attendance: Understanding the Importance of School Satisfaction between Middle and High School Students}

\begin{abstract}
BACKGROUND: Students with chronic absences tend to struggle academically and may not fully benefit from all school has to offer. A positive school climate has been shown to promote healthy behaviors and wellbeing, while reducing the likelihood of absenteeism. The purpose of this study was to determine the mediated relationships between school climate and school satisfaction on different types of absences in middle and high school students.
\end{abstract}

METHODS: Mediated path analysis was used to describe direct and indirect predictive probabilities between study variables from a sample of 6,839 middle school (response rate $=$ $82.3 \%, 48.5 \%$ female, $81.8 \%$ White) and 7,470 high school (response rate $=72.9 \%, 50.9 \%$ female, 85.0\% White) students from 26 schools and three counties in West Virginia (WV). RESULTS: Absences reduced academic performance $(\widehat{\beta}=-0.46$ to $-0.23, p<.01)$, while school climate and school satisfaction promote better grades $(\widehat{\beta}=0.08$ to $0.18, p<.01)$. School climate and school satisfaction reduced the likelihood of skipping school in both groups $(\widehat{\beta}=-011$. to $0.30, \mathrm{p}<.01)$

CONCLUSIONS: Missing a substantial amount of school days for any reason may hinder students' academic success, but truancy may require added attention. Using school climate as an intervention to reduce absences and promote school satisfaction may support large-scale school health frameworks and fulfill national educational and health milestones.

Keywords: Early adolescents, adolescents, school contentment, truancy, mediation analysis 


\section{INTRODUCTION}

\section{The Importance of School Attendance}

Students who miss a substantial number of school days tend to struggle academically and are at risk of falling behind their peers. ${ }^{53-56}$ In addition, students with a high number of absences are also more likely to leave school, which is linked to poorer health outcomes in adulthood. ${ }^{33,36-}$ ${ }^{38}$ Unfortunately, chronic absenteeism in schools has become a national concern in the United States (US). ${ }^{213}$ According to the US Department of Education, one in seven students (7 million) will miss 15 or more days of school per year. ${ }^{214}$ Evaluations of prevention strategies suggest there is no easy fix to reducing school-based absenteeism. ${ }^{215}$ This is because student absences are often influenced by a myriad of social factors such as poverty and family dysfunction. ${ }^{49}$ However, social ecological theories have helped provide a relatively broad picture of the complex pathways between student absenteeism and health related behaviors. ${ }^{26-29}$ Such theories suggest the formation of health behaviors is derived from shared experiences within a contextual environment. ${ }^{18,23-25}$ Researchers have also established that learning depends largely on school characteristics such as curriculum, internal policy, and culture. ${ }^{216-218}$ This is important because school is a uniquely influential time in most students' lives. ${ }^{219}$ For many, school is where lifelong sociocultural norms and the skills required for adulthood are established..$^{71,72,81,220}$ Strong evidence additionally indicates that high school completion is essential for social mobility and success. ${ }^{39,40}$ Although graduation rates have steadily climbed in the US, reducing the achievement gap continues to be a national priority. ${ }^{47,48}$ As long as issues like chronic academic failure $^{49}$ and absenteeism ${ }^{50}$ continue to be a determinant of student outcomes, schools will struggle to improve equity and ameliorate population disparities. ${ }^{44,60}$ 


\section{School Climate as an Intervention}

School climate is often described as the observed behavioral patterns of cultural norms, values, practices, and relationships of school life. ${ }^{13}$ Early school climate research generally focused on the organizational structure of schools, while recent studies have concentrated on understanding ecological impacts. ${ }^{64,221}$ A positive school climate has shown to promote healthy psychosocial development and wellbeing, while buffering negative effects from poverty, family dysfunction, and distress in school. ${ }^{67,180,222,223}$ School climate additionally describes the natural diversity of individual student experiences (eg, adolescent society) and how they might uniquely contribute to a school's collective social atmosphere. ${ }^{224}$ Although characteristics of the individual are important, the design of schools provides all students with the opportunity to translate and adopt knowledge, bond socially, and learn in collaborative settings ${ }^{29}{ }^{2}$ Therefore, the inherent nature of the school experience is as much a collective snap-shot of the social commons as it is a reflection of the individual personalities that contribute to it. ${ }^{225,226}$ In this way, school climate has been shown to shape the interactions between students, teachers, families, and the broader community. ${ }^{13,91}$

Negative experiences during adolescence may accumulate into phases of deviant behavior that may impact school performance and encourage truancy. ${ }^{176-178}$ Studies have revealed that school climate may reduce absenteeism and school suspensions. ${ }^{227,228}$ Research suggest that when students are engaged in a positive school climate, such as positive relationships with teachers and peers, students are less likely to externalize deviant behaviors. ${ }^{148}$ A study by Hendron and Kearney ${ }^{229}$ examined school climate's relationship with absenteeism severity and symptoms of psychopathology. Their findings demonstrated school climate reduces absenteeism and student metal health issues. In addition, school climate has been shown to be 
related to the broader psychosocial environment that impacts students' ability to do well in school and promote behaviors that may lead to sustainable long-term health. ${ }^{78}$

\section{Understanding the Role of School Satisfaction and School Climate}

Research focused on students' satisfaction with school has mostly come out of the field of positive psychology, yet has earned a cross-disciplinary spotlight in education and school health. ${ }^{137,230,231}$ Students' satisfaction with school has been described as a representation of students' social bonding with the broader institution. ${ }^{14,16,231,232}$ Alternatively, school satisfaction can be thought of as a description of someone's contentment or happiness with school life. ${ }^{233,234}$ Research also suggests school satisfaction is an important indicator of adolescent mental and emotional health due to its association with foundational constructs of adolescent society. ${ }^{66,235}$ This is important because studies suggest students who bond with their school tend to have

higher perceptions of school climate and are less likely to engage in deviant behavior. ${ }^{236,237}$ However, the research base that explains the relationship between school climate, school satisfaction, and absenteeism is still relatively scarce. ${ }^{9}$ Because students' assessment of school climate and school satisfaction happens in a psychosocial context, these two concepts are intuitively connected and may collectively impact absenteeism. ${ }^{65,238}$ This fact leaves the literature calling for more complex research designs that expand on the relationships between school climate and satisfaction with chronic school absences. ${ }^{9}$

\section{An Opportunity for School Climate and School Satisfaction to Reduce Absenteeism}

To help ameliorate hurdles in school health, the school-based policy frameworks Whole School, Whole Child, Whole Community (WSCC) and Every Student Succeeds Act (ESSA, 2015) advocate for schools to use a comprehensive assessment that includes absenteeism, risk 
behaviors, and school climate. ${ }^{80,98,189}$ However, these policies might be slightly ahead of the science meant to support them. Nevertheless, the literature remains inconclusive regarding how implemented changes in school climate might ameliorate the negative pathways that put students at risk for low attendance. ${ }^{237}$ Reasons for limited effectiveness and translational gaps are, in part, due to our fractured understanding of how changes in the ways schools operate may influence the broader social climate and subsequently student outcomes. ${ }^{80}$ Analyzing school climate could prove useful for schools to better understand how non-academic aspects of students' lives may provide a fuller picture of the educational experience. Therefore, it seems prudent to further distill the scientific understanding of school climate to help school personnel target aspects of their school toward desirable changes using policy and practice. ${ }^{91}$

The purpose of this study was to determine the mediated associations of school climate and school satisfaction on types of student absences between middle and high school students. We hypothesized that (1) students' absences would overall demonstrate negative associations with academic grades, (2) school climate and school satisfaction would be significantly associated with academic grades, (3) school climate would be associated to school satisfaction, (4) school climate and school satisfaction would demonstrate an inverse association with types of absence, and (5) results would vary between the middle and high school samples.

\section{METHODS}

\section{Participants, Procedures, and Data Management}

A prospective clustered sample of 6,839 middle school (response rate $=82.3 \%, 48.5 \%$ female, $81.8 \%$ White) and 7,470 high school students (response rate $=72.9 \%, 50.9 \%$ female, $85.0 \%$ White) students located in 26 regional schools from three counties within West Virginia 
(WV). Students from the WV counties represent southern, western, and eastern regions of the state. Students from each area signify a spectrum of diverse characteristics from families living in severe isolation/poverty to modest privilege/affluence. ${ }^{99-101}$ All aspects of the data collection were approved by West Virginia University's Institutional Review Board (IRB). Passive consent was acquired by sending a letter home to caregivers to provide an opportunity for exclusion of their children (parental opt out rate $<1 \%$ ). ${ }^{102,103}$ Surveys were administered by classroom teachers with supervision by a school contact agent to ensure confidentiality of responses. Participation was voluntary and made available to all students. Students were free to answer all or part of the survey and elect to opt-out of participation at any time. Data management and cleaning removed 236 observations due to unreliable responses. Missing data were handled using full information maximum likelihood estimation (FIML). ${ }^{12,113}$ For further details on data collection procedures, see Appendix A, Kristjansson, et al. ${ }^{51,104,105}$ and Mann, et al. ${ }^{106}$

\section{Measures}

Academic Grades. Self-reported grades were captured using a single question "What were your FINAL grades in the following subjects LAST year?" for Mathematics and English. Responses were combined to represent students' overall grades. ${ }^{121-123}$ Academic grades were then pooled into ordered categories, Mostly As/Bs (coded 2), Mostly Cs (coded1), and Mostly Ds/Fs (coded 0). Mostly As/Bs indicated higher academic performance.

School Absences. A single item, "How many days have you been absent from school during the last 30 days?", with two sub-questions: "skipped class" or "illness". Response options included "none" to "7 or more days". Based on a preliminary test of over-dispersion" ${ }^{239}$, absence variables were dichotomized to "never" absent (coded 0) and absent due to "skipped class" or "illness" (coded 1). 
School satisfaction. Five items assessed school satisfaction using a 5-point Likert type scale. ${ }^{14,16}$ Response options ranged from "applies almost always to me" (coded 1) to "applies almost never to me" (coded 5) with higher scores indicating more school satisfaction. Items were combined and used as a continuous mediator.

School Climate. Three sub-scales (positive student-teacher relationships, order and safety, and opportunities for student engagement) and 20-items were selected from the School Climate Measure developed by Zullig et al. ${ }^{8,124,125}$ School climate questions use a 5-point Likert type scale with response options "strongly disagree" (coded 1) to "strongly agree" (coded 5). Higher scores indicate a positive perception of school climate. For further details on SCM items, see Zullig, et al. ${ }^{124}$ and Appendix B.

\section{Covariates}

Biological Sex. Biological sex ${ }^{16,51,127}$ was assessed by asking respondents “Are you a boy or girl?". Male (coded 0) and female (coded 1) were represented as a dichotomous time-invariant covariate.

Family Structure. A 19-item multi-response question, "Which of the following persons live in your home?" was used to capture family structure. ${ }^{51,126}$ For analysis, the question was dichotomized into "lives with both biological parents" (coded 1) and "other arrangements" (coded 0$)$ as a dichotomous covariate.

Maternal Education. Maternal education ${ }^{126,128}$ was captured by asking students to select one of nine response options from a singular question "What is the highest level of schooling your mother has completed?" Responses were pooled into categories to simplify analyses, “college graduate" (coded 3), "high school graduate" (coded 2), "less than high school" (coded 
1), and "I don't know" (coded 0) and represented as a nominal categorical time-invariant covariate.

\section{Data Analysis}

Descriptive frequencies, means (standard deviations), scale internal consistency, and confirmatory factor analysis (CFA) estimates were analyzed using SAS 9.4®. ${ }^{129}$ Inferential analyses were performed in Mplus 8.0C ${ }^{131}$ using a two-tailed distribution and p-values equal to or less than .05. A mediated path analysis was used to describe direct and indirect predictive probabilities between school climate, school satisfaction, student attendance, and academic grades while controlling for sex, family structure, and maternal education. Model specifications used the complex option to accommodate non-normality and non-independence of participants clustered in schools, robust standard errors, and probit distribution. ${ }^{131-133}$ Monte Carlo integration was used for missingness of mediated regression paths. ${ }^{131,240,241}$ Ordinal and binary probit regression $(\widehat{\beta})$ was used to test model paths on school absences and academic grades. ${ }^{132,242}$ Multiple linear regression (B) was used to test continuous paths between school satisfaction and school climate. Model parsimony was determined using the deviance statistic (-2LL), Akaike Information Criteria (AIC), and Bayesian Information Criteria (BIC). ${ }^{134,243}$ Marginal effects for proportional odds models $\exp (\widehat{\beta})$ and standardized regression coefficients $(\beta)$ were reported to illustrate the magnitude of effect.

\section{RESULTS}

School climate sub-scales demonstrated excellent measurement fits: $\chi^{2}=1934.78(\mathrm{df}=$ $157, \mathrm{p}=<.01), \mathrm{CFI}=0.98, \mathrm{TLI}=0.97, \mathrm{SRMR}=0.02, \mathrm{RMSEA}=0.043( \pm 0.041,0.044)$ for middle school and $\chi^{2}=2097.18(\mathrm{df}=157, \mathrm{p}=<.01), \mathrm{CFI}=0.98, \mathrm{TLI}=0.98, \mathrm{SRMR}=0.02$, 
RMSEA $=0.042( \pm 0.040,0.043)$ for high school. School satisfaction also demonstrated excellent measurement fits: $\chi^{2}=13.76(\mathrm{df}=2, \mathrm{p}=<.01), \mathrm{CFI}=0.99, \mathrm{TLI}=0.99, \mathrm{SRMR}=0.01$, $\operatorname{RMSEA}=0.03( \pm 0.02,0.05)$ for middle school and $\chi^{2}=8.14(\mathrm{df}=2, \mathrm{p}=0.02), \mathrm{CFI}=0.99$, TLI $=0.99, \operatorname{SRMR}=0.02, \mathrm{RMSEA}=0.02( \pm 0.01,0.04)$ for high school. Illness was the most reported type of absence $49.8 \%$ for middle and $47.4 \%$ of high school. Lower rates $6.1 \%$ in middle and $15.1 \%$ in high school were reported for absence due to skipping. Additional descriptive figures are reported in Table 9.

All results for mediated path analysis are reported in Tables 10 and 11 with a conceptual model portrayed in Figure 3. For reporting parsimony and clarity, only direct predictive probabilities predictive $(\widehat{\beta})$ and standardized regression $(\beta)$ coefficients are outlined in this section. Table 10 describes the results for middle school analyses. All school climate models demonstrated significant predictive probabilities of skipping on academic grades and ranged $\widehat{\beta}=$ -0.41 to $-0.43($ all $\mathrm{SE}=.08, \mathrm{p}<.01)$. Illness on academic grades reported slightly smaller inverse probabilities $\widehat{\beta}=-0.23$ to $-0.25(\mathrm{SE}=$ all $.04, \mathrm{p}<.01)$. Estimates for school satisfaction were consistent across all models $\widehat{\beta}=0.18$ ( $\mathrm{SE}=.01$ to $.02, \mathrm{p}<.01$ ). School climate subscales ranged $\widehat{\beta}=0.08$ to $0.11(\mathrm{SE}=.02$ to .03 , all $\mathrm{p}<.01)$ on academic grades. School satisfaction demonstrated significant direct predictive probabilities on skipping across all models $\widehat{\beta}=-0.17$ to $-0.20($ all $\mathrm{SE}=0.03, \mathrm{p}<.01)$. School climate also illustrated direct significant probabilities on skipping and ranged $\widehat{\beta}=-0.23$ to $-0.30(\mathrm{SE}=.03$ to .04 , all $\mathrm{p}=<.01)$. Only teacher relationships $\widehat{\beta}=-0.06(\mathrm{SE}=.03, \mathrm{p}<.01)$ exhibited direct negative likelihood estimates on illness. Direct linear associations between school satisfaction and all school climate subscales reported all significant paths $\beta=0.38$ to 0.41 (all $\mathrm{SE}=.03, \mathrm{p}<.01)$. 
Table 11 describes results for high school analyses. Direct predictive probabilities of skipping demonstrated inverse estimates on academic grades ranging $\widehat{\beta}=-0.46$ to $-0.44(\mathrm{SE}=$ all $0.05, \mathrm{p}<.01)$. Illness also reported inverse estimates on academic grades and ranged $\widehat{\beta}=-0.27$ to $-0.26, \mathrm{SE}=$ all $0.04, \mathrm{p}<.01)$. School satisfaction demonstrated positive significant estimates across all paths $\widehat{\beta}=0.16$ to 0.18 ( $\mathrm{SE}=.01$ to $.02, \mathrm{p}<.01)$. Direct probabilities of school climate sub-scales ranged $\widehat{\beta}=0.06$ to 0.11 (all $\mathrm{SE}=0.02, \mathrm{p}<.01)$. School satisfaction $(\widehat{\beta}=-0.20$ to -0.19 , all $\mathrm{SE}=0.03, \mathrm{p}<.01)$ and all school climate sub-scales $(\widehat{\beta}=-0.15$ to $-0.11, \mathrm{SE}=0.03$ to $0.04, \mathrm{p}$ $<.01)$ showed significant inverse predictive probabilities on skipping. Both teacher relationships $(\widehat{\beta}=-0.10, \mathrm{SE}=0.03, \mathrm{p}<.01)$ and order and safety $(\widehat{\beta}=-0.07, \mathrm{SE}=0.02, \mathrm{p}<.01)$ demonstrated significant direct relationships to illness. Linear regression paths between school satisfaction and all school climate subscales were also observed $\beta=0.36$ to 0.41 (all $\mathrm{SE}=0.03, \mathrm{p}<.01$ ).

\section{DISCUSSION}

The purpose of this study was to examine the relationships between school climate and school satisfaction on types of student absence in middle and high school students. Academic grades were also included to provide scope and context on a school-based outcome. To help guide the reader, the following paragraphs have been ordered as follows: (1) model results of absences, school climate, and school satisfaction on academic grades, (2) the relationship between school climate and school satisfaction, (3) model results school climate and school satisfaction on absences, and (4) general variations between middle and high school students on types of student absences.

First, in middle and high school, both types of absences reduced academic grades. These results were anticipated as studies have established absenteeism as a strong predictor of 
academic risk and acheivement. ${ }^{33}$ In practical terms, when students are absent for any reason, this may hinder their ability to achieve good grades. A review by Black, et al. ${ }^{244}$ outlined an assortment of factors related to students with a high number of missed academic days. Their findings suggest students who miss a substantial amount of school also exhibited lower academic performance. However, different types of absences may matter more depending on students' circumstances. In our sample, absence due to illness demonstrated less severe effects on grades compared to students who skipped school. These results seem logical, in that, skipping school might additionally indicate underlying student issues. For example, studies that profile students with chronic absenteeism often meet similar risk classifications found in literature about school dropout. ${ }^{49,54}$ A study by Freudenberg and Ruglis ${ }^{40}$ tactfully summarize these risks into three social-ecological domains (eg, intra/interpersonal, community, and school system). Their review underscores the inherent complexity of the underlying multiple risk factors that vary in temporality, intensity, and occurrence. ${ }^{40}$ Our findings are unable to extend explanations on the complexity, but at the least, suggest different types of absence may vary in their contribution to academic achievement.

While absences reduced academic grades, school climate and school satisfaction promoted higher grades. Because school is central to the lives of most children, it is not unreasonable and moreover prudent, that liking school and forming bonding relationships may help explain behaviors related to academic achievement. ${ }^{138,236}$ School satisfaction demonstrated slightly stronger effects on academic grades than school climate. This is not to undermine school climate, which has been shown to be an essential ingredient to support better academic achievement. ${ }^{245}$ However, school satisfaction has been found to be associated to many of the processes related to academic performance like attitude and satisfaction with school, confidence 
in academic ability, and positive social engagement. ${ }^{246-248}$ Further, students with happier school experiences tend to have more positive relationships with teachers and peers, which is essential to academic functioning. ${ }^{66,249-251}$ A study by Heffner and Antaramian ${ }^{252}$ suggested that students' positive perception of their life and school were predictive of academic performance. ${ }^{252}$ Another study by State and Kern ${ }^{253}$ suggested at risk students disliked school compared to other domains of life satisfaction (i.e., family) and reported lower academic achievement. ${ }^{253}$ Needless to say, our findings support this position and school satisfaction and school climate may impact students' academic success.

Second, school climate demonstrated positive effects on school satisfaction. In a practical sense, our findings indicate that students with more positive perceptions of school climate are more likely to enjoy school. Our results reinforce similar research on the relationships between these psychosocial contructs. ${ }^{67,237}$ A study by Suldo, et al. ${ }^{67}$ showed positive relationships with teachers and a mutual respect for school rules was associated to positive perceptions of life and school. Their results also demonstrated better relationships with teachers improved students' happiness and satisfaction with school. ${ }^{67,70}$ Our findings support school climate's outward promotion of school satisfaction and relates to the general premise of the literature. Consequently, a focus on promoting a positive school climate may reinforce schoolwide satisfaction, which may collectively reduce absenteeism and create avenues for students to receive all the benefits school has to offer.

Third, across middle and high school models, school climate and school satisfaction reduced the likelihood of skipping school. These results were anticipated and are supported by the literature related to a positive school climate's impact on truancy. ${ }^{137,236}$ However, illness provided slightly separate results. Missing school due to illness was only influenced by student- 
teacher relationships and order and safety. Unexpectedly, opportunities for student engagement and school satisfaction did not reveal any significant relationships. As mention previously, we noted differences between skipping and illness on academic grades. Our findings maintain this trend and suggest different types of absences may matter. This is not to infer missing school due to illness is less important than skipping. Instead, when illness contributes to absenteeism, alternative approaches may be required to support student needs. For example, studies have shown that illness like pediatric asthma is more likely to cause chronic absenteeism and school nurses are important care providers to reduce the burden of student diseases. ${ }^{254}$ In addition, mental health issues like depression and anxiety have been shown to contribute to high rates of absenteeism as well. ${ }^{255}$ Studies suggest that positive relationships with teachers and other school personnel may buffer the effects that lead to these type of illness-based absences. A study Hendron and Kearney ${ }^{229}$ additionally described how students with less satisfaction or connection with their school were also more likely to be absent for any reason. Our results reinforce the importance of teachers and school personnel encouraging healthy relationships to reduce the likelihood school absences. More research in this area is encouraged to further outline how a positive school climate may support students toward desired academic and health outcomes.

Fourth, although school climate and school satisfaction were important to middle and high school students, there were a few notable descriptive variations. In middle school, school climate sub-scales presented more robust diminishing effects on skipping. A practical explanation of our results may suggest middle school students attribute not skipping school to emotionally supportive relationships with teachers, ${ }^{91}$ reinforcement of school rules that promote fairness $^{8}$, and engagement opportunities that may bolster social inclusivity and reduce alienation. ${ }^{17}$ In high school, school satisfaction was slightly more supportive at reducing skipping 
school. High school students may attribute school satisfaction as an alternative need for academic success as they prepare for occupational or college requirement. Further, developmental difference in older adolescents is well-established and may be reflected in students' satisfaction with their school experience. ${ }^{30}$ Additionally, school satisfaction may also be indicative of underlying aspects of adolescent society, wherein social and peer groups impact the social commons of a school's atmosphere. ${ }^{16}$

Lastly, for research purposes, these finding perhaps support a slight distinction of school climate's relationship between middle and high school. Although these explanations are mildly speculative, our findings are encouraging as the school climate literature specific to early adolescents remains relatively understudied. ${ }^{9,67}$ To date, there are limited studies that attempt to establish empirically supported correlates of school climate and satisfaction between middle and high school. ${ }^{9,62}$ Nonetheless, our findings suggest that school climate helps reduce absenteeism, which promotes a positive attitude toward school and subsequently supports academic success. Further research between these groups seems necessary as a better understanding of these differences may also help large-scale implementation of school health interventions meant to serve the needs of the whole child. ${ }^{26}$

\section{LIMITATIONS}

First, the study used a relatively homogenous sample of predominantly White middle and high school students from twenty-six schools in WV. As a result, the sample may not be representative or generalizable to students in other regions of the US. In addition, racially and ethnically diverse samples may yield alternative insights to the school climate literature. Future studies should include nationally representative samples for more generalizable inferences. Second, analyses were conducted with cross-sectional data. Modeling longitudinal information 
may provide additive support for school climates relationship to student outcomes. Third, we were unable to entirely account for potentially important confounders. In addition, our analysis did not consider counterfactuals as part of our mediation analysis. Fourth, student self-reported data may be subject to recall bias. However, our response rates for this sample were acceptable for survey research, indicating selection issues represented in the data was likely low. ${ }^{256}$ Fifth, survey length may cause response burden, survey incompletion, and large missing data patterns. However, the use of full information maximum likelihood techniques takes advantage of missing data to provide accurate parameter estimates based on available data. ${ }^{257} \mathrm{Sixth}$, a high overdispersion estimate for middle schoolers who ever skipped class required the use of alternative models. ${ }^{258}$ Modeling actual number of days absent may provide useful and alternative information for educational research. ${ }^{259}$ Lastly, caution must be emphasized interpreting the small direct and indirect predictive probabilities in this complex analysis, which likely contributes little to mediated relationships. ${ }^{241,260}$

\section{CONCLUSION}

School climate subscales and school satisfaction demonstrated diminishing effects on absenteeism. However, students' satisfaction with school and perceptions of school climate varied in the predictive strength to reduce absenteeism. Middle school students may benefit more from a positive school climate, whereas school satisfaction was more supportive in high school. School health policies like WSCC and ESSA may find an additive contribution through school climate as school administrators and practitioners strive to meet national educational and health goals. School climate assessment may provide useful information to school personnel to better understand how promoting a positive school climate may alter the school experience. Given the descriptive variations between middle and high school students, further studies that examine the 
interplay between school climate mechanisms and its relationships to academic and nonacademic variables are needed. This may hold especially true when developing recommendations for the delivery of instruction and the design of school-based interventions meant to universally serve all students using school climate.

\section{IMPLICATIONS}

In many communities, schools act as an institutional fulcrum that serves a multitude of societal functions. ${ }^{42}$ How schools support students to meet their optimum potential will continue to be a topic for researchers and educators alike. ${ }^{154}$ Policy frameworks like WSCC and ESSA still require further research to better understand how non-academic factors like school satisfaction and school climate influence desired student outcomes. ${ }^{155}$ Reducing absenteeism will continue to be shaped by curriculum and instruction, but as our findings suggest, absenteeism are related to factors beyond what happens in the classroom. Based on our findings, types of school absences are influenced by multiple, co-occurring, and context-specific aspects in a complex social-emotional setting. In addition, our results suggest that school climate is important to absenteeism and may have a strong influence to reduce factors related to academic failure.

Furthermore, our findings suggest that school climate may equally affect or be consistently important between middle and high school students. When considering the differences between middle and high school students, selecting age appropriate aspects of school climate may aid school personnel for targeted interventions. In middle schools, it may be practical to select strategies that improve healthy student-teacher relationships that enhance classroom connectedness and reduce alienation. ${ }^{84}$ In high school, classroom instruction or programmatic policy that encourages preparation for adulthood may be more useful. ${ }^{143}$ However, when considering approaches that incorporate the multidimensional nature of school climate, 
much more research is needed to best understand how school climate relates to the multitude of factors that impact student success. ${ }^{9}$

This study provides supportive evidence for the importance of assessing school climate, not only as it applies to absenteeism, but also as it applies to factors that may ameliorate or exacerbate academic failure. Reducing school absence is a current and salient topic among school districts across the US. ${ }^{50}$ Recent proposals to mitigate absenteeism outline intense interventions that require substantial resources to maintain fidelity and sustainability. Although these programs are important, our findings and the theoretical nature of school climate presents an opportunity for schools to expand their comprehension on dimensions related to student wellness and academic performance. ${ }^{62,91}$ Additionally, school-related social support (i.e., teacher-student relationships) may be a way to satisfy a healthy social-emotional environment without dedicating important resources to pilot-programs that may not yield substantial outcomes. ${ }^{261}$ Our results may also suggest a focus on fostering and promoting prosocial behaviors may be more effective at upholding educational equity and reducing achievement gaps than a focus on academic grades alone ${ }^{80}$ With many schools under financial and political constraint, ${ }^{262}$ any opportunity to enhance student outcomes with relatively little (if any) modification to their daily operations, would be a welcomed proposition.

\section{Human Subjects Approval Statement}

All aspects of data collection in this study, including participant involvement based on passive parental consent, were conducted in accordance with West Virginia University's Institutional Review Board guidelines for the protection of research participants and no identifying information of any kind was collected or reported on (protocol \# 1406345394R004). 


\section{Acknowledgements}

This work was supported by the West Virginia Department of Education (WVDOE) in Charleston, WV and the Substance Abuse Mental Health Service (SAMHA) in Washington, DC; Project AWARE 2015-2020. The authors would like to extend our gratitude to the funder for their generous support. The authors would like to thank Dr. Megan L. Smith and the dedicated personnel who make the Project AWARE 2015-2020 data collection possible. 


\section{CHAPTER 5}

\section{SUMMARY OF FINDINGS}

The summaries below are written with brevity and clarity in mind. For further expansion on the magnitude and scope of the findings, please refer to each study's implication section.

\section{Study 1 Summary}

School climate demonstrated positive associations on academic achievement. Positive perceptions of school climate appear to sustain students with As/Bs and strengthens students with $\mathrm{Cs} / \mathrm{Ds} / \mathrm{Fs}$. When considering large-scale implementation strategies, improving school climate may be useful to schools to promote improved academic achievement. Interventions that focus on school climate may help contribute to the success of school-based health promotion, while offering data-driven improvements to practice. Given the modest variation between middle and high school samples, future studies should examine the mechanisms that exist between more robust models of school climate in these groups. Results from such studies may further support generalizable recommendations for the delivery of instruction that educates the whole child.

\section{Study 2 Summary}

A positive school climate may delay substance use initiation. Practical implications of the findings suggested: (1) improving a positive school climate may be a way to reduce the likelihood of substance use initiation, (2) school climate may deserve a central focus for collaborative school health research, (3) school climate may be a way to stimulate and encourage multidisciplinary partnerships, (4) school climate may be a useful prevention framework for large-scale school health interventions, and (5) school climate may be a way for public health and public education practitioners to open avenues and meet national academic and health goals 
together. Future studies that outline the relationships between school climate, student characteristics and the mechanisms of substance use are recommended.

\section{Study 3 Summary}

School climate and school satisfaction may prevent absenteeism. However, students' satisfaction with school and perceptions of school climate varied in their magnitude of effect to reduce absenteeism. In addition, middle school students may benefit more from a positive school climate, whereas school satisfaction was more supportive in high school. School climate assessment may provide useful information to school personnel to better understand how promoting a positive school climate alters the school experience. Given the descriptive variations between middle and high school students, further studies that examine the interplay between other aspects of school climate and absenteeism in these groups are necessary. Findings from such studies may support empirical recommendations for the delivery and the design of schoolbased interventions that universally serve all students.

\section{SUMMATIVE CONCLUSION}

This dissertation intended to further clarify the relationships between school climate, academic achievement, substance use initiation, and absenteeism. Results from all studies met the goal of this dissertation and clarified some of the knowledge gaps between these relationships. Findings from all studies suggest improvements in school climate may help school systems achieve desired student outcomes. Analytic techniques used longitudinal and crosssectional designs to evaluate the usefulness of school climate to improve academic outcomes and diminish student risks. Longitudinal findings suggest school climate may improve academic achievement and reduce substance use initiation. Longitudinal findings further support the 
dynamic nature of school climate and how perceptions may change overtime. Cross-sectional findings suggest school climate strengthens school satisfaction which collectively may be used to prevent absenteeism. Using a positive school climate may ensure adolescent and child health is a part of the schools organizational structure. ${ }^{26}$ For example, strengthening positive relationships with teachers, promoting admiration for school rules, and encouraging academic motivation appear to all be useful techniques to reduce student risk and promote success in school. An improved school climate, therefore, may transcend to the classroom and fulfill much of what students need to be at their best.

The relevance of school climate's relationship to educational outcomes also has a broader importance. First, the Centers for Disease Control and Prevention (CDC) has developed the Whole School, Whole Child, Whole Community (WSCC) framework to intersect health and education by engaging the whole child. ${ }^{94,95}$ Second, Every Student Succeeds Act (ESSA) ${ }^{96}$ is meant to empower schools and promote healthy places for students to grow, develop, and learn. ${ }^{97}$ ESSA further emphasizes the use of school climate as an addition to improve on school quality. ${ }^{98}$ Third, school climate fits well as a universal strategy in a multi-tiered systems of support (MTSS) paradigm because of its inherent potential to improve outcomes by embracing positive aspects of the learning environment to impact all students. ${ }^{152}$ Findings from this dissertation support the use of school climate to shape the environments where students grow and prepare for adulthood. By better understanding the mechanisms by which school climate may influences the social environment, policies like ESSA may strengthen new improvements to instruction and school management. In this way, a clearer description of school experiences and school life may be used to maximize and prepare students for lifelong health and success. 


\section{FUTURE DIRECTIONS}

A key limitation of the school climate literature is the availability of population-level evidence. ${ }^{47,62}$ Although a few systematic and unstructured reviews exist, most empirical studies are constrained to strong contextually-based and cross-sectional designs. ${ }^{9}$ This is not a slight toward population health research. Rather, it is a call for evidence that better represents the cycles of inductive and deductive techniques in the field. ${ }^{263,264}$ For school climate, a philosophical and operational convergence on what school climate is and how it may improve students' health is desperately needed. ${ }^{265}$ In their commentary on school health programs, Mann, et al. ${ }^{26}$ poses the question, "How can we implement effective school health programs on a national scale that reliably impact students and families across entire communities and populations?". Their commentary outlines an assortment of essential steps required to make the transition from an "age of discovery" to an "age of large-scale implementation". ${ }^{26}$ Although not explicit, improving school climate may be a solution to supplement a portion of their guidance.

However, much more must be done before such steps can be consider. For starters, improving the relationship between research and school-based partnerships may help account for the difficult-to-measure characteristics found in context dependent populations. ${ }^{266}$ Second, school climate assessments still require a mechanism to translate and apply evidence (the push). ${ }^{267}$ Once evidence-based guidelines are implemented by practice, a cycle of fine-tuning may begin (the pull). ${ }^{267}$ Lastly, when these steps are refined, context becomes a translational strength toward better outcomes while keeping the discovery of new knowledge in mind. ${ }^{266}$ Using school-based partnerships to improve a positive school climate and share their stories might use logical and systematic actions to address contextual and place-based issues. 
School climate has been shown to support better school life for all students. ${ }^{61}$ However even under ESSA, assessment in core subjects (i.e., Mathematics) is often the central focus of most schools. ${ }^{96,98}$ Consequently, this creates an underlying fear that if attention is drawn away from curriculum, schools will not meet their standardized requirements and become at risk for punitive action. With an overemphasis on standardized curriculum assessment (a remnant of No Child Left Behind) schools are likely falling short to meet comprehensive child and adolescent needs. In other words, when all you have in the toolbox is a hammer, you can only pound nails. Research on a positive school climate and this dissertation suggest otherwise. Teachers and school personnel should find solace and be encouraged to attend to student needs outside of the curriculum. Schools are real places that influence people's lives. ${ }^{42}$ High school completion can be an arduous journey depending on a student's circumstance, but what we know for sure is schools and how people are treated while in school matters. ${ }^{43-45}$ Although a positive school climate may not remedy all the adversity schools and communities deal with to help their children succeed, it may be a worthy investment to ensure the health and wellbeing of all children toward the betterment of our society. 


\section{REFERENCES}

1. U.S. Department of Health and Human Services, National Institute of Health, National Cancer Institute. NCI Dictionary of Cancer Terms: Alcohol. 2018. Available at: https://www.cancer.gov/publications/dictionaries/cancerterms/search?contains=false\&q=alcohol. Accessed June 06, 2018.

2. U.S. Department of Health and Human Services, National Institute of Health, National Cancer Institute. NCI Dictionary of Cancer Terms: Cigarettes. 2018. Available at: https://www.cancer.gov/publications/dictionaries/cancer-terms/def/cigarette. Accessed June 06, 2018.

3. Steinberg L. Cognitive and affective development in adolescence. Trends Cogn Sci. 2005;9(2):69-74.

4. U.S. Department of Health and Human Services, National Institute of Health, National Cancer Institute. NCI Dictionary of Cancer Terms: Electronic cigarettes. 2018. Available at: https://www.cancer.gov/publications/dictionaries/cancer-terms/def/electroniccigarette. Accessed June 06, 2018.

5. U.S. Department of Health and Human Services, Centers for Disease Control and Prevention (CDC). Youth Risk Behavior Survey (YRBS) 2017 Standard Questionnaire Item Rationale. Atlanta, GA: U.S. Department of Health and Human Services; 2017.

6. U.S. Department of Health and Human Services, National Institute of Health, National Cancer Institute. NCI Dictionary of Cancer Terms: Marijuana. 2018. Available at: https://www.cancer.gov/publications/dictionaries/cancer-terms/def/marijuana. Accessed June 06, 2018.

7. Libbey HP. Measuring student relationships to school: Attachment, bonding, connectedness, and engagement. J Sch Health. 2004;74(7):274-283.

8. Zullig KJ, Koopman TM, Patton JM, Ubbes VA. School climate: Historical review, instrument development, and school assessment. J Psychoeduc Assess. 2010;28(2):139152.

9. Wang MT, Degol JL. School climate: A review of the construct, measurement, and impact on student outcomes. Educ Psychol Rev. 2016;28(2):315-352.

10. Devine JF, Cohen J. Making Your School Safe: Strategies to Protect Children and Promote Learning. New York, NY: Teach Coll Pr; 2007.

11. Steinberg L. Risk taking in adolescence: New perspectives from brain and behavioral science. Curr Dir Psychol Sci. 2007;16(2):55-59.

12. Valerie FR, Frank F. Risk and rationality in adolescent decision making : Implications for theory, practice, and public policy. Psychol Sci Public Interest. 2006;7(1):1-44.

13. Cohen J, McCabe L, Michelli NM, Pickeral T. School climate: Research, policy, practice, and teacher education. Teach Coll Rec. 2009;111(1):180-213.

14. Thorlindsson T, Bernburg JG. Peer groups and substance use: Examining the direct and indirect effect of leisure activity. Adolesc. 2006;41(162):321-339. 
15. Thorlindsson T, Bernburg JnG. Durkheim's theory of social order and deviance: A multilevel test. Eur Sociol Rev. 2004;20(4):271-285.

16. Kristjansson AL, Sigfusdottir ID, Allegrante JP, Helgason AR. Adolescent health behavior, contentment in school, and academic achievement. Am J Health Behav. 2009;33(1):69-79.

17. Thapa A, Cohen J, Guffey S, Higgins-D’Alessandro A. A review of school climate research. Rev Educ Res. 2013;83(3):357-385.

18. Bandura A. Social Foundations of Thought and Action: A Social Cognitive Theory. Englewood Cliffs, NJ: Prentice-Hall; 1986.

19. Ryan RM. Psychological needs and the facilitation of integrative processes. J Personal. 1995;63(3):397-427.

20. Rogers CR. Freedom to Learn: A View of What Education Might Become. Columbus, OH: C.E. Merrill Pub. Co.; 1969.

21. Piaget J. The Origins of Intelligence in Children. New York, NY: International Universities Press; 1952.

22. Harter S. Effectance motivation reconsidered: Toward a developmental model. Hum Dev. 1978;21(1):34-64.

23. Bandura A. Health promotion by social cognitive means. Health Educ Behav. 2004;31(2):143-164.

24. Bandura A, Barbaranelli C, Pastorelli C, Caprara GV, Zimbardo PG. Prosocial foundations of children's academic achievement. Psychol Sci. 2000;11(4):302-306.

25. Zimmerman BJ, Bandura A, Martinez-Pons M. Self-motivation for academic attainment: The role of self-efficacy beliefs and personal goal setting. Am Educ Res J. 1992;29(3).

26. Mann MJ, Kristjansson AL, Smith ML, Daily SM, Thomas S, Murray S. From tactics to strategy: Creating and sustaining social conditions that demand and deliver effective school health programs. $J$ Sch Health. 2018;88(5):333-336.

27. Basch CE. Healthier students are better learners: High-quality, strategically planned, and effectively coordinated school health programs must be a fundamental mission of schools to help close the achievement gap. J Sch Health. 2011;81(10):650-662.

28. Basch CE, Sliepcevich EM, Gold RS, Duncan DF, Kolbe LJ. Avoiding type III errors in health education program evaluations: A case study. Health Educ Behav. 1985;12(3):315331.

29. Allensworth DD, Institute of Medicine (IOM). Schools and Health: Our Nation's Investment. Washington, DC: National Academies Press; 1997.

30. Eccles JS, Roeser RW. Schools as Developmental Contexts during Adolescence. J Res Adolesc. 2011;21(1):225-241.

31. Eccles JS, Roeser RW. An ecological view of schools and development. In: Handbook of Research on Schools, Schooling, and Human Development. New York, NY: Routledge; 2010. 
32. Bowers AJ, Sprott R. Why tenth graders fail to finish high school: A dropout typology latent class analysis. J Educ Stud Placed Risk. 2012;17(3):129-148.

33. Bowers AJ, Sprott R, Taff SA. Do we know who will drop out?: A review of the predictors of dropping out of high school precision, sensitivity, and specificity. High Sch J. 2013;96(2):77-100.

34. Lansford JE, Dodge KA, Pettit GS, Bates JE. A public health perspective on school dropout and adult outcomes: A prospective study of risk and protective factors from age 5 to 27 years. $J$ Adolesc Health. 2016;58(6):652-658.

35. Lleras-Muney A. The relationship between education and adult mortality in the United States. Rev Econ Stud. 2005;72(1):189-221.

36. Vaughn MG, Salas-Wright CP, Maynard BR. Dropping out of school and chronic disease in the United States. J Public Health. 2014;22(3):265-270.

37. Woolf SH, Johnson RE, Phillips RL, Philipsen M. Giving everyone the health of the educated: An examination of whether social change would save more lives than medical advances. Am J Public Health. 2007;97(4):679-683.

38. Zimmerman E, Woolf SH. Understanding the relationship between education and health. Paper presented at: Roundtable on Population Health Improvement; June 5, 2014; Washington, DC.

39. American Public Health Association. The Dropout Crisis: A Public Health Problem and the Role of School-Based Healthcare. 2011. Available at:

https://www.apha.org/ /media/files/pdf/factsheets/dropout_crisis_a_public_health_proble m.ashx. Accessed June 20, 2017.

40. Freudenberg N, Ruglis J. Reframing school dropout as a public dealth issue. Prevent Chronic Dis. 2007;4(4).

41. Myers DJ. Epidemiologists, our patient is society. New Solut. 2008;18(2):107-109.

42. Myers DJ. Education and health disparities: A macro, not micro, phenomenon. New Solut. 2010;20(2):175-177.

43. Dewey J. Democracy and Education: An Introduction to the Philosophy of Education. 1st Free Press paperback ed. New York, NY: Collier-Macmillan; 1966.

44. Stack Jr SF, Waterson RA. Democracy and citizenship education: Fostering clarity of meaning through John Dewey. J Philos Hist Educ. 2013;63(1):195-207.

45. Noddings N. A richer, broader wiew of education. Society. 2015;52(3):232-236.

46. U.S. Department of Education, National Center for Education Statistics. Trends In High School Dropout And Completion Rates In The United States. 2014. Available at: https://nces.ed.gov/programs/dropout/ind 04.asp. Accessed June 07, 2018.

47. Michael SL, Merlo CL, Basch CE, Wentzel KR, Wechsler H. Critical connections: Health and academics. J Sch Health. 2015;85(11):740-758. 
48. Freeman J, Simonsen B. Examining the impact of policy and practice interventions on high school dropout and school completion rates: A systematic review of the literature. Rev Educ Res. 2015;85(2):205-248.

49. Allensworth EM, Easton JQ, Consortium on Chicago School Research IL. What Matters for Staying On-Track and Graduating in Chicago Public Highs Schools: A Close Look at Course Grades, Failures, and Attendance in the Freshman Year. Research Report. Consortium on Chicago School Research; 2007.

50. Jacob BA, Lovett K. Chronic Absenteeism: An Old Problem in Search of New Answers. 2017. Available at: https://www.brookings.edu/research/chronic-absenteeism-an-oldproblem-in-search-of-new-answers/. Accessed March 14, 2018.

51. Kristjansson AL, Mann MJ, Smith ML, Sigfusdottir ID. Social profile of middle schoolaged adolescents who use electronic cigarettes: Implications for primary prevention. Prev Sci. 2017:1-8.

52. Needham BL, Crosnoe R, Muller C. Academic failure in secondary school: The interrelated role of health problems and educational context. Soc Probl. 2004;51(4):569-586.

53. Demir K, Karabeyoğlu YA. Factors associated with absenteeism in high schools. Eurasian J Educ Res. 2016;16(62):55-74.

54. Balfanz R, Byrnes V. Chronic Absenteeism: Summarizing What We Know from Nationally Available Data. Baltimore, MD: Johns Hopkins University; 2012.

55. Bridgeland JM, Dilulio JJ, Jr., Morison KB, Civic E, Peter D, Hart Research Associates. The Silent Epidemic: Perspectives of High School Dropouts. Civic Enterprises; 2006.

56. Kearney C. An interdisciplinary model of school absenteeism in youth to inform professional practice and public policy. Educ Psychol Rev. 2008;20(3):257-282.

57. Keyes KM, Hamilton A, Kandel DB. Birth cohorts analysis of adolescent cigarette smoking and subsequent marijuana and cocaine use. Am J Public Health. 2016;106(6):1143-1149.

58. Miller ML, Hurd YL. Testing the gateway hypothesis. Neuropsychopharmacol. 2017;42(5):985-986.

59. Kandel DB, Yamaguchi K, Klein LC. Testing the gateway hypothesis. Addiction. 2006;101(4):470-472; discussion 474-476.

60. U.S. Department of Education. Chronic Absenteeism in the Nation's Schools: An Unprecedented Look at a Hidden Educational Crisis. 2017. Available at: https://ed.gov/datastory/chronicabsenteeism.html. Accessed March 10, 2018.

61. Freiberg HJ. School Climate: Measuring, Improving And Sustaining Healthy Learning Environments. London, England: Taylor \& Francis; 2005.

62. Berkowitz R, Moore H, Astor RA, Benbenishty R. A research synthesis of the associations between socioeconomic background, inequality, school climate, and academic achievement. Rev Educ Res. 2016;87(2):425-469.

63. Peguero AA, Bracy NL. School order, justice, and education: Climate, discipline practices, and dropping out. $J$ Res Adolesc. 2015;25(3):412-426. 
64. Durlak JA, Weissberg RP, Dymnicki AB, Taylor RD, Schellinger KB. The impact of enhancing students' social and emotional learning: A meta-analysis of school-based universal interventions. Child Dev. 2011;82(1):405-432.

65. Tian L, Chen H, Huebner ES. The longitudinal relationships between basic psychological needs satisfaction at school and school-related subjective well-being in adolescents. Soc Indic Res. 2014;119(1):353-372.

66. Suldo SM, Riley KN, Shaffer EJ. Academic correlates of children and adolescents' life satisfaction. Sch Psychol Int. 2006;27(5):567-582.

67. Suldo SM, Thalji-Raitano A, Hasemeyer M, Gelley CD, Hoy B. Understanding middle school students life satisfaction: Does cchool climate matter? Appl Res Qual Life. 2013;8(2):169-182.

68. Huebner ES, Diener C. Research on life satisfaction of children and youth: Implications for the delivery of school-related services. In: Eid M, Larsen RJ, Eid M, Larsen RJ, eds. The Science Of Subjective Well-Being. New York, NY: Guilford Press; 2008:376-392.

69. Mann MJ, Smith ML, Kristjansson AL. Improving academic self-efficacy, school connectedness, and identity in struggling middle school girls: a preliminary study of the REAL girls program. Health Educ Behav. 2015;42(1):117-126.

70. Natvig GK, Albrektsen G, Qvarnstrøm U. Associations between psychosocial factors and happiness among school adolescents. Int J Nurs Pract. 2003;9(3):166-175.

71. Burnett S, Thompson S, Bird G, Blakemore SJ. Pubertal development of the understanding of social emotions: Implications for education. Learn Individ Differ. 2011;21(6):681-689.

72. Spengler M, Roberts BW, Lüdtke O, Martin R, Brunner M. Student characteristics and behaviours in childhood predict self-reported health in middle adulthood. Eur J Pers. 2016;30(5):456-466.

73. U.S. Department of Education NCES. Enrollment Trends. Digest of Education Statistics, 2015 (NCES 2016-014) 2016. Available at: https://nces.ed.gov/fastfacts/display.asp?id=65. Accessed December 03, 2017.

74. U.S. Department of Education NCES. Fast Facts: Elementary and Secondary Education Enrollment. 2017. Available at: https://nces.ed.gov/fastfacts/display.asp?id=372. Accessed December 03, 2017.

75. U.S. Department of Education, National Center for Education Statistics, Common Core of Data (CCD). Public Elementary/Secondary School Universe Survey 2000-01 through 2015-16. 2017. Available at: https://nces.ed.gov/programs/digest/d17/tables/dt17_216.30.asp. Accessed May 02, 2018.

76. Svirydzenka N, Aitken J, Dogra N. Research and partnerships with schools. Soc Psychiatry Psychiatr Epidemiol. 2016;51(8):1203-1209.

77. Allensworth D, Lewallen TC, Stevenson B, Katz S. Addressing the Needs of the Whole Child: What Public Health Can Do to Answer the Education Sector's Call for a Stronger Partnership. Prev Chronic Dis. 2011;8(2):A44. 
78. Bradshaw CP, Koth CW, Thornton LA, Leaf PJ. Altering school climate through schoolwide positive behavioral interventions and supports: Findings from a group-randomized effectiveness trial. Prev Sci. 2009;10(2):100-115.

79. Bradshaw CP, Reinke WM, Brown LD, Bevans KB, Leaf PJ. Implementation of schoolwide positive behavioral interventions and supports (PBIS) in elementary schools: Observations from a randomized trial. Educ Treat Children. 2008;31(1):1-26.

80. Birch D, Videto D. Promoting health and academic success: The whole school, whole community, whole child approach. Hum Kinet. 2015.

81. Curran T, Wexler L. School-based positive youth development: A systematic review of the literature. J Sch Health. 2017;87(1):71-80.

82. Berg G. From structural dilemmas to institutional imperatives: a descriptive theory of the school as an institution and of school organizations. J Curric Stud. 2007;39(5):577-596.

83. Riesch SK, Tosi CB, Thurston CA. Accessing Young Adolescents and Their Families for Research. Image J Nurs Sch. 1999;31(4):323-326.

84. Blum RW. A case for school connectedness. Educ Leadersh. 2005;62(7):16-19.

85. Basch CE. Healthier students are better learners: A missing link in school reforms to close the achievement gap. J Sch Health. 2011;81(10):593-598.

86. Blum RW, Bastos FI, Kabiru CW, Le LC. Adolescent health in the 21st century. Lancet. 2012;379(9826):1567-1568.

87. Resnick MD, Catalano RF, Sawyer SM, Viner R, Patton GC. Seizing the opportunities of adolescent health. Lancet. 2012;379(9826):1564-1567.

88. National Center for Education Statistics. Average Number of Hours in the School Day and Average Number of Days in the School Year for Public Schools, by State: 2007-08. 2009. Available at: https://nces.ed.gov/surveys/sass/tables/sass0708 035 s1s.asp. Accessed July 23, 2017.

89. Silvers JA, McRae K, Gabrieli JDE, Gross JJ, Remy KA, Ochsner KN. Age-related differences in emotional reactivity, regulation, and rejection sensitivity in adolescence. Emotion. 2012;12(6):1235-1247.

90. Murray NG, Low BJ, Hollis C, Cross AW, Davis SM. Coordinated school health programs and academic achievement: A systematic review of the literature. $J$ Sch Health. 2007;77(9):589-600.

91. Cohen J, Brown P, Corrigan M, Higgins-D’Alessandro A. School climate and culture improvement: A prosocial strategy that recognizes, educates, and supports the whole child and the whole school community. Handb Prosocial Educ. 2012:227-270.

92. Piscatelli J, Lee C. State Policies on School Climate and Bully Prevention Efforts: Challenges and Opportunities for Deepening State Policy Support for Safe and Civil Schools. 2011. Available at: https://files.eric.ed.gov/fulltext/ED566375.pdf. Accessed March 26, 2018. 
93. Voight A, Hanson T, Regional Educational Laboratory W, National Center for Education E, Regional A, WestEd. How Are Middle School Climate And Academic Performance Related Across Schools And Over Time? . Regional Educational Laboratory West; 2017.

94. Division of Adolescent and School Health. Whole School, Whole Community, Whole Child. 2016. Available at: https://www.cdc.gov/healthyyouth/wscc/. Accessed October, 14, 2017.

95. Rasberry CN, Slade S, Lohrmann DK, Valois RF. Lessons learned from the whole child and coordinated school health approaches. J Sch Health. 2015;85(11):759-765.

96. Senate Committee on Health Education Labor and Pensions. The every child achieves act of 2015. June 29, 2016. Available at:

https://www.help.senate.gov/imo/media/The_Every_Child_Achieves_Act_of_2015-summary.pdf. Accessed July, 23, 2017.

97. Healthy School Campaign. Leveraging New Education Law to Support Health and Learning. 2017. Available at: https://healthyschoolscampaign.org/policy/essa/. Accessed December 03, 2017.

98. Every Student Succeeds Act (ESSA). December 10, 2015. Available at: https:/www.ed.gov/essa?src=rn. Accessed July 23, 2017.

99. Appalachian Regional Commission (ARC). Person Below Poverty Level, 2011-2015. 2011-2015. Available at:

https://www.arc.gov/reports/custom report.asp?REPORT ID=70. Accessed May 15, 2018.

100. University of Wisconsin Population Health Institute. County Health Rankings: 2018 West Virginia State Report. 2018. Available at:

http://www.countyhealthrankings.org/explore-health-rankings/reports/statereports/2018/west-virginia. Accessed May 13, 2018.

101. United Health Foundation. America's Health Rankings: 2017 West Virginia Annual Report Summary. 2017. Available at: https://www.americashealthrankings.org/learn/reports/2017-annual-report/statesummaries-west-virginia. Accessed May 13, 2018.

102. Chartier M, Stoep AV, McCauley E, Herting JR, Tracy M, Lymp J. Passive versus active parental permission: Implications for the ability of school-based depression screening to reach youth at risk. $J$ Sch Health. 2008;78(3):157-164; quiz 184-156.

103. Levine RJ. Research involving children: An interpretation of the new regulations. Ethics Hum Res. 1983;5(4):1-5.

104. Kristjansson AL, Sigfusson J, Sigfusdottir ID, Allegrante JP. Data collection procedures for school-based surveys among adolescents: the Youth in Europe Study. J Sch Health. 2013;83(9):662-667.

105. Kristjansson AL, Kogan SM, Mann MJ, et al. Does early exposure to caffeine promote smoking and alcohol use behavior? A prospective analysis of middle school students. Addiction. 2018. 
106. Mann MJ, Smith ML, Kristjansson AL. Energy drink consumption and substance use risk in middle school students. Prev Med Rep. 2016;3:279-282.

107. Gustavson K, von Soest T, Karevold E, Roysamb E. Attrition and generalizability in longitudinal studies: Findings from a 15-year population-based study and a Monte Carlo simulation study. BMC Public Health. 2012;12:918.

108. Tambs K, Ronning T, Prescott CA, et al. The Norwegian Institute of Public Health twin study of mental health: Examining recruitment and attrition bias. Twin Res Hum Genet. 2009;12(2):158-168.

109. Little RJA, Rubin DB. Statistical Analysis with Missing Data. 2nd ed. ed. Hoboken, NJ: Wiley; 2002.

110. Little RJA. A test of missing completely at random for multivariate data with missing values. J Am Stat Assoc. 1988;83(404):1198-1202.

111. Marshall A, Altman DG, Holder RL. Comparison of imputation methods for handling missing covariate data when fitting a Cox proportional hazards model: A resampling study. BMC Med Res Methodol. 2010;10:112.

112. Mazza GL, Enders CK, Ruehlman LS. Addressing item-level missing data: A comparison of proration and full information maximum likelihood estimation. Multivariate Behav Res. 2015;50(5):504-519.

113. Schafer JL, Graham JW. Missing data: Our view of the state of the art. Psychol Methods. 2002;7(2):147-177.

114. Cham H, Reshetnyak E, Rosenfeld B, Breitbart W. Full information maximum likelihood estimation for latent variable interactions with incomplete indicators. Multivariate Behav Res. 2017;52(1):12-30.

115. Graham JW. Missing data analysis: Making it work in the real world. Annu Rev Psychol. 2009;60(1):549-576.

116. Graham JW. Adding missing-data-relevant variables to FIML-based structural equation models. Struct Equ Modeling. 2003;10(1):80-100.

117. Collins LM, Schafer JL, Kam CM. A comparison of inclusive and restrictive strategies in modern missing data procedures. Psychol Methods. 2001;6(4):330-351.

118. Graham JW, Olchowski AE, Gilreath TD. How many imputations are really needed? Some practical clarifications of multiple imputation theory. Prev Sci. 2007;8(3):206-213.

119. Lewin A, Brondeel R, Benmarhnia T, Thomas F, Chaix B. Attrition bias related to missing outcome data: A longitudinal simulation study. Epidemiol. 2018;29(1):87-95.

120. White IR, Carlin JB. Bias and efficiency of multiple imputation compared with completecase analysis for missing covariate values. Stat Med. 2010;29(28):2920-2931.

121. Harwell MR, Gatti GG. Rescaling ordinal data to interval data in educational research. Rev Educ Res. 2001;71(1):105-131. 
122. Kuncel NR, Credé M, Thomas LL. The validity of self-reported grade point averages, class ranks, and test scores: A meta-analysis and review of the literature. Rev of Educ Res. 2016;75(1):63-82.

123. Sticca F, Goetz T, Bieg M, Hall NC, Eberle F, Haag L. Examining the accuracy of students' self-reported academic grades from a correlational and a discrepancy perspective: Evidence from a longitudinal study. PLoS One. 2017;12(11):e0187367.

124. Zullig KJ, Collins R, Ghani N, et al. Preliminary development of a revised version of the school climate measure. Psychol Assess. 2015;27(3):1072-1081.

125. Zullig KJ, Collins R, Ghani N, Patton JM, Huebner ES, Ajamie J. Psychometric support of the school climate measure in a large, diverse sample of adolescents: a replication and extension. J Sch Health. 2014;84(2):82-90.

126. Kristjánsson ÁL, Sigfúsdóttir ID. The role of parental support, parental monitoring, and time spent with parents in adolescent academic achievement in Iceland: A structural model of gender differences. Scand J Educ Res. 2009;53(5):481-496.

127. Marcenaro-Gutierrez O, Lopez-Agudo LA, Ropero-García MA. Gender differences in adolescents' academic achievement. Young. 2017;26(3):250-270.

128. Holmes EK, Holladay HM, Hill EJ, Yorgason JB. Are mothers' work-to-family conflict, school involvement, and work status related to academic achievement? J Child Fam Stud. 2018;27(6):1881-1898.

129. SAS Institute. Base SAS 9.4 Procedures Guide: Statistical Procedures. 2nd ed. Cary, NC: SAS Institute; 2013.

130. Cheong J, MacKinnon D, Khoo ST. Investigation of mediational processes using parallel process latent growth curve modeling. Struct Equ Modeling. 2003;10(2):238-262.

131. Muthen L, Muthen, BO. Mplus User's Guide. 8th ed. Los Angeles, CA: Muthen and Muthen; 2017.

132. Liao TF. Interpreting Probability Models: Logit, Probit, and Other Generalized Linear Models. Thousand Oaks, CA: Sage; 1994.

133. Masyn KE, Petras H, Liu W. Growth curve models with categorical outcomes. In: Encycl Criminol Crim Justice. Springer; 2014:2013-2025.

134. Lee TK, Wickrama K, O’Neal CW. Application of latent growth curve analysis with categorical responses in social behavioral research. Struct Equ Modeling. 2018;25(2):294-306.

135. Geiser C. Data Analysis with Mplus. English edition. ed. New York, NY: The Guilford Press; 2013.

136. Maxwell LE. School building condition, social climate, student attendance and academic achievement: A mediation model. J Environ Psychol. 2016;46:206-216.

137. Huebner ES, Funk BA, Gilman R. Cross-sectional and longitudinal psychosocial correlates of adolescent life satisfaction reports. Can J Sch Psychol. 2000;16(Part 1):5364. 
138. Huebner ES, McCullough G. Correlates of school satisfaction among adolescents. $J$ Educ Res. 2000;93(5):331-335.

139. Morse LL, Allensworth DD. Placing students at the center: The whole school, whole community, whole child model. J Sch Health. 2015;85(11):785-794.

140. Bronfenbrenner U, Morris PA. The ecology of developmental processes. In: Handbook of Child Psychology. 5th ed. New York, NY1998:992-1082.

141. Bronfenbrenner U. The ecology of human development: Experiments by nature and design. Cambridge, MA: Harvard University Press; 1979.

142. Centers for Disease Control and Prevention (CDC). Whole School, Whole Community, Whole Child: A Collaborative Approach to Learning and Health. Washington, DC, Alexandria, VA: US Department of Health and Human Service, Centers for Disease Control and Prevention, ASCD; 2014.

143. Goldstein SE, Boxer P, Rudolph E. Middle school transition stress: Links with academic performance, motivation, and school experiences. Contemp Sch Psychol. 2015;19(1):2129.

144. West MR, Schwerdt G. The middle school plunge: Achievement tumbles when young students change schools. Educ Next. 2012;12(2):63-68.

145. Bellmore A. Peer rejection and unpopularity: Associations with GPAs across the transition to middle school. J Educ Psychol. 2011;103(2):282-295.

146. Lee J. Tripartite growth trajectories of reading and math achievement. Am Educ Res J. 2010;47(4):800-832.

147. Akos P, Rose RA, Orthner D. Sociodemographic moderators of middle school transition effects on academic achievement. J Early Adolesc. 2014;35(2):170-198.

148. Wang MT, Dishion TJ. The trajectories of adolescents' perceptions of school climate, deviant peer affiliation, and behavioral problems during the middle school years. $J$ Res Adolesc. 2012;22(1):40-53.

149. Way SM. School discipline and disruptive classroom behavior: The moderating effects of student perceptions. Sociol Q. 2011;52(3):346-375.

150. Wang MT, Eccles JS. School context, achievement motivation, and academic engagement: A longitudinal study of school engagement using a multidimensional perspective. Learn Instruc. 2013;28:12-23.

151. Hopson LM, Lee E. Mitigating the effect of family poverty on academic and behavioral outcomes: The role of school climate in middle and high school. Child Youth Serv Rev. 2011;33(11):2221-2229.

152. Payton J, Weissberg RP, Durlak JA, et al. The positive impact of social and emotional learning for kindergarten to eighth-grade students: Findings from three scientific reviews. Collab Acad Soc Emot Learn. 2008.

153. U.S. Department of Health and Human Services, Office of Adolescent Health. West Virginia Adolescent Substance Use Facts. 2017. Available at: 
https://www.hhs.gov/ash/oah/facts-and-stats/national-and-state-data-sheets/adolescentsand-substance-abuse/west-virginia/index.html. Accessed May 20, 2018.

154. Birch DA, Priest HM, Mitchell QP. Advocacy for quality school health education: The role of public health educators as professionals and community members. Health Educator. 2015;47(1):38-44.

155. Rooney LE, Videto DM, Birch DA. Using the whole school, shole community, whole child model: Implications for practice. J Sch Health. 2015;85(11):817-823.

156. Macklem GL. Evidence-based Tier 1, Tier 2, and Tier 3 mental health interventions in schools. In: Macklem GL, ed. Evidence-Based School Mental Health Services. New York, NY: Springer New York; 2011:19-37.

157. Domitrovich CE, Bradshaw CP, Greenberg MT, Embry D, Poduska JM, Ialongo NS. Integrated models of school-based prevention: Logic and theory. Psychol Sch. 2010;47(1):71-88.

158. Johnston LD, Miech RA, O'Malley PM, Bachman JG, Schulenberg JE, Patrick ME. Monitoring the Future National Survey Results on Drug Use, 1975-2017: Overview, Key Fidings on Adolescent Drug Use. Ann Arbor, MI: The University of Michigan; 2018.

159. U.S. Department of Health and Human Services. E-Cigarette Use among Youth and Young Adults. A Report of the Surgeon General. Atlanta, GA 2016.

160. Kristjansson AL, Sigfusdottir ID. E-cigarette use and relations to tobacco and alcohol use among adolescents. BMC Medicine. 2015;13(1).

161. Wisk LE, Weitzman ER. Substance use patterns through early adulthood : Results for youth with and without chronic conditions. Am J Prev Med. 2016;51(1):33-45.

162. Schulte MT, Hser YI. Substance use and associated health conditions throughout the lifespan. Public Health Rev. 2014;35(2).

163. Derefinko KJ, Charnigo RJ, Peters JR, Adams ZW, Milich R, Lynam DR. Substance use trajectories from early adolescence through the transition to college. J Stud Alcohol Drugs. 2016;77(6):924-935.

164. Coomber K, Toumbourou JW, Miller P, Staiger PK, Hemphill SA, Catalano RF. Rural adolescent alcohol, tobacco, and illicit drug use: A comparison of students in Victoria, Australia, and Washington State, United States. J Rural Health. 2011;27(4):409-415.

165. National Institute on Drug Abuse. Opioid-Related Overdose Deaths. 2018. Available at: https://www.drugabuse.gov/drugs-abuse/opioids/opioid-summaries-by-state/westvirginia-opioid-summary. Accessed June 10, 2018.

166. Volkow N. Addressing the Opioid Crisis Means Confronting Socioeconomic Disparities. 2017. Available at: https:/www.drugabuse.gov/about-nida/norasblog/2017/10/addressing-opioid-crisis-means-confronting-socioeconomic-disparities. Accessed June 10, 2018.

167. Kroutil L, Colliver J, Gfroerer J. OAS Data Review: Age and Cohort Patterns of Substance Use among Adolescents. Rockville, MD: Substance Abuse and Mental Health Services Administration. Office of Applied Studies; 2010. 
168. Chen C, Storr C, Anthony J. Early-onset drug use and risk for drug dependence problems. Addict Behav. 2009;34(3):319-322.

169. Allegrante JP, Sigfusdottir ID, Kristjansson AL, Helgason AR. Social correlates of cigarette smoking among Icelandic adolescents: A population-based cross-sectional study. BMP Public Health. 2008;8(1):86.

170. Substance Abuse and Mental Health Services Administration, Center for Behavioral Health Statistics and Quality. The TEDS report: Age of substance use initiation among treatment admission 18 to 30. 2014. Available at: https://archive.samhsa.gov/data/2k14/TEDS142/sr142-initiation-age-2014.htm. Accessed May 07, 2018.

171. King KM, Chassin L. A prospective study of the effects of age of initiation of alcohol and drug use on young adult substance dependence. J Stud Alcohol Drugs. 2007;68(2):256265.

172. Caetano R, Mills BA, Vaeth PAC, Reingle J. Age at first drink, drinking, binge drinking, and DSM-5 alcohol use disorder among hispanic national groups in the United States. Alcoholism: Clinical Exp Res. 2014;38(5):1381-1389.

173. Sigfusdottir ID, Kristjansson AL, Gudmundsdottir ML, Allegrante JP. Substance use prevention through school and community-based health promotion: A transdisciplinary approach from Iceland. Glob Health Promot. 2011;18(3):23-26.

174. Sigfusdottir ID, Thorlindsson T, Kristjansson AL, Roe KM, Allegrante JP. Substance use prevention for adolescents: The icelandic model. Health Promot Int. 2009;24(1):16-25.

175. Kleinjan M, Engels RC. Substance use: Determinants and opportunities for prevention in the family and school context. New Dir Youth Dev. 2014;2014(141):15-32, 19.

176. Salinas-Miranda AA, Salemi JL, King LM, et al. Adverse childhood experiences and health-related quality of life in adulthood: revelations from a community needs assessment. Health Qual Life Outcomes. 2015;13:123.

177. Mann MJ, Kristjansson AL, Sigfusdottir ID, Smith ML. The role of community, family, peer, and school factors in group bullying: Implications for school-based intervention. $J$ Sch Health. 2015;85(7):477-486.

178. Mann MJ, Kristjansson AL, Smith ML, Sigfusdottir ID. The Influence of negative life events and problem behavior on grades in early adolescence: Pathways to academic risk in the middle grades. RMLE Online. 2016;39(10):1-13.

179. Larusso MD, Romer D, Selman RL. Teachers as builders of respectful school climates: Implications for adolescent drug use norms and depressive symptoms in high school. $J$ Youth Adolesc. 2008;37(4):386-398.

180. Ruus V-R, Veisson M, Leino M, et al. Students' well-being, coping, academic success, and school climate. Appl Res Qual Life. 2007;35(7):919-936.

181. Positive Behavioral Interventions and Supports (PBIS). Multi-tiered System of Support (MTSS) and PBIS. 2018. Available at: https://www.pbis.org/school/mtss. Accessed June $11,2018$. 
182. Substance Abuse Mental Health Services. Prevention of Substance Abuse and Mental Illness. 2017. Available at: https://www.samhsa.gov/prevention. Accessed November 16, 2017.

183. Institute of Medicine (IOM), Committee on Prevention of Mental Disorders, Substance Abuse Among Children and Youth, et al. Preventing Mental, Emotional, and Behavioral Disorders Among Young People: Progress and Possibilities. Washington, DC: National Academies Press; 2009.

184. Mrazek PJ, Haggerty RJ, Eaton WW. Reducing risks for mental disorders: Frontiers for preventive intervention research. J Nerv Ment Dis. 1996;184(12):758.

185. Stanis JJ, Andersen SL. Reducing substance use during adolescence: A translational framework for prevention. Psychopharmacol. 2014;231(8):1437-1453.

186. Wilson SJ, Lipsey MW. School-based interventions for aggressive and disruptive behavior: Update of a meta-analysis. Am J Prev Med. 2007;33(2 Suppl):S130-143.

187. Bosworth K, Judkins M. Tapping into the power of school climate to prevent bullying: One application of schoolwide positive behavior interventions and supports. Theory Pract. 2014;53(4):300-307.

188. Sugai G, Horner RR. A promising approach for expanding and sustaining school-wide positive behavior support. Sch Psychol Rev. 2006;35(2):245-259.

189. Lewallen TC, Hunt H, Potts-Datema W, Zaza S, Giles W. The whole school, whole community, whole child model: A new approach for improving educational attainment and healthy development for students. J Sch Health. 2015;85(11):729-739.

190. Sugai G, O'Keeffe BV, Fallon LM. A contextual consideration of culture and schoolwide positive behavior support. J Posit Behav Interv. 2011;14(4):197-208.

191. Bradshaw CP, Waasdorp TE, Debnam KJ, Johnson SL. Measuring school climate in high schools: A focus on safety, engagement, and the environment. J Sch Health. 2014;84(9):593-604.

192. Martin AJ. Prescriptive statements and educational practice: What can structural equation modeling (SEM) offer? Educ Psychol Rev. 2011;23(2):235-244.

193. Fletcher AMS, Bonell CPD, Hargreaves JPD. School effects on young people's drug use: A systematic review of intervention and observational studies. $J$ Adolesc Health. 2008;42(3):209-220.

194. Madjar N, Cohen-Malayev M. Perceived school climate across the transition from elementary to middle school. Sch Psychol Q. 2016;31(2):270-288.

195. Goodenow C. Classroom belonging among early adolescent students: Relationships to motivation and achievement. J Early Adoles. 1993;13(1):21-43.

196. Scott TM, Hirn RG, Alter PJ. Teacher instruction as a predictor for student engagement and disruptive behaviors. Prev Sch Fail. 2014;58(4):193-200.

197. Lee C-K, Corte C, Stein KF. Drinker identity: Key risk factor for adolescent alcohol use. $J$ Sch Health. 2018;88(3):253-260. 
198. Mason WA, Patwardhan I, Smith GL, et al. Cumulative contextual risk at birth and adolescent substance initiation: Peer mediation tests. Drug Alcohol Depend. 2017;177:291-298.

199. Burdzovic Andreas J, Jackson KM. Adolescent Alcohol Use Before and After the High School Transition. Alcohol Clin Exp Res. 2015;39(6):1034-1041.

200. Chakroun N, Johnson EI, Swendsen J. Mood and personality-based models of substance use. Psychol Addict Behav. 2010;24(1):129-136.

201. Sznitman SR, Kolobov T, Bogt Tt, et al. Exploring substance use normalization among adolescents: A multilevel study in 35 countries. Soc Sci Med. 2013;97:143-151.

202. Briesch AM, Chafouleas SM, Chaffee RK. Analysis of state-level guidance regarding school-based, universal screening for social, emotional, and behavioral risk. Sch Mental Health. 2017;10(2):147-162.

203. Kristjansson AL, Mann MJ, Sigfusdottir ID. Licit and illicit substance use by adolescent e-cigarette users compared with conventional cigarette smokers, dual users, and nonusers. $J$ Adolesc Health. 2015;57(5):562-564.

204. Brener ND, Collins JL, Kann L, Warren CW, Williams BI. Reliability of the youth risk behavior survey questionnaire. Am J Epidemiol. 1995;141(6):575-580.

205. Brener ND, Kann L, McManus T, Kinchen SA, Sundberg EC, Ross JG. Reliability of the 1999 youth risk behavior survey questionnaire. $J$ Adolesc Health. 2002;31(4):336-342.

206. Zullig KJ, Pun S, Patton JM, Ubbes VA. Reliability of the 2005 middle school youth risk behavior survey. $J$ Adolesc Health. 2006;39(6):856-860.

207. Buu A, Li R, Tan X, Zucker RA. Statistical models for longitudinal zero-inflated count data with applications to the substance abuse field. Stat Med. 2012;31(29):4074-4086.

208. Muthén BO. Second-generation structural equation modeling with a combination of categorical and continuous latent variables: New opportunities for latent class/latent growth modeling. In: Collins LM, Sayer A, eds. New Methods for the Analysis of Change. Washington, DC 2001:291-322.

209. Muthén B, Asparouhov T. Latent Variable Analysis with Categorical Outcomes: Multiple-group and Growth Modeling in Mplus. Mplus Web Notes: No. 42002. Available at: http://www.statmodel.com/download/webnotes/CatMGLong.pdf. Accessed March 18, 2018.

210. Rabe-Hesketh S, Skrondal A, Pickles A. Maximum likelihood estimation of limited and discrete dependent variable models with nested random effects. $J$ Econom. 2005;128(2):301-323.

211. Perry AC. The management of a city school. Sch Rev. 1909;17(7):513.

212. Dewey J, Archambault RD. John Dewey on Education: Selected Writings. Chicago, IL: University of Chicago Press; 1974.

213. Hedy NC, Charlene MR-T, Kari S. Chronic early absence: What states can do. Phi Delta Kappan. 2016;98(2):22-27. 
214. U.S. Department of Education, Office of Civil Rights. Key Data Highlights on Equity and Opportunity Gaps in Our Nation's Public Schools. 2016. Available at: https://ed.gov/about/offices/list/ocr/docs/2013-14-first-look.pdf. Accessed April 6, 2018.

215. Simons E, Hwang S-A, Fitzgerald EF, Kielb C, Lin S. The impact of school building conditions on student absenteeism in Upstate New York. Am J Public Health. 2010;100(9):1679-1686.

216. Illeris K. How We Learn: Learning and Non-Learning in School and Beyond. 2nd ed. New York, NY Routledge; 2006.

217. Ormrod JE. How We Think and Learn: Theoretical Perspectives and Practical Implications. New York, NY: Cambridge University Press; 2017.

218. Glanz K, Rimer BK, Viswanath K. Health Behavior and Health Education: Theory, Research, and Practice. 4th ed. San Francisco, CA: Jossey-Bass; 2008.

219. Forrest CB, Bevans KB, Riley AW, Crespo R, Louis TA. Health and school outcomes during children's transition into adolescence. J Adolesc Health. 2013;52(2):186-194.

220. Wyn JG, White R. Rethinking Youth. London, England: SAGE Publications; 1996.

221. Anderson CS. The search for school climate: A review of the research. Rev Educ Res. 1982;52(3):368-420.

222. Wang MT, Selman RL, Dishion TJ, Stormshak EA. A tobit regression analysis of the covariation between middle school students' perceived school climate and behavioral problems. J Res Adolesc. 2010;20(2):274-286.

223. Lester L, Cross D. The relationship between school climate and mental and emotional wellbeing over the transition from primary to secondary school. Psychol Wellbeing Theory Res Pract. 2015;5(1):1-15.

224. Padilla AM, Perez W. Acculturation, social identity, and social cognition: A new perspective. Hisp J Behav Sci. 2003;25(1):35-55.

225. Bandura A. Social cognitive theory: An agentic perspective. Annu Rev Psychol. 2001;52(1):1-26.

226. Bandura A, Barbaranelli C, Caprara GV, Pastorelli C. Multifaceted impact of selfefficacy beliefs on academic functioning. Child Dev. 1996;67(3):1206-1222.

227. Astor R, Guerra N, Van Acker R. How can we improve school safety research? Educ Res. 2010;39(1):69-78.

228. Lee T, Cornell D, Gregory A, Fan X. High suspension schools and dropout rates for black and white students. Educ Treat Children. 2011;34(2):167-192.

229. Hendron M, Kearney CA. School climate and student absenteeism and internalizing and externalizing behavioral problems. Child Sch. 2016;38(2):109-116.

230. Zullig KJ, Koopman TM, Huebner ES. Beyond GPA: Toward more comprehensive assessments of students' school experiences. Child Indic Res. 2009;2(1):95-108.

231. Seligman ME, Csikszentmihalyi M. Positive psychology: An introduction. Am Psychol. 2000;55(1):5-14. 
232. Huebner ES. Initial development of the student's life satisfaction scale. Sch Psychol Int. 1991;12(3):231-240.

233. Diener E, Oishi S, Lucas RE. Subjective well-being: The science of happiness and life satisfaction. In: Lopez SJ, Snyder CR, Lopez SJ, Snyder CR, eds. Oxford Handbook of Positive Psychology. 2nd ed. New York, NY, US: Oxford University Press; 2009:187194.

234. Biswas-Diener R, Diener E. The subjective well-being of the homeless, and lessons for happiness. Soc Indic Res. 2006;76(2):185-205.

235. Huebner ES. Correlates of life satisfaction in children. Sch Psychol Q. 1991;6(2):103111.

236. Huebner ES, Gilman R, Reschly A, Hall R. Positive schools. In: Lopez SJ, Snyder CR, eds. Oxford Handbook of Positive Psychology. 2nd ed. Oxford, NY: Oxford University Press; 2009:561-569.

237. Zullig KJ, Huebner ES, Patton JM. Relationships among school climate domains and school satisfaction. Psychol Sch. 2011;48(2):133-145.

238. Weissberg RP. Enhancing Children's Wellness: Healthy Children 2010. Thousand Oaks, CA: Sage Publications; 1997.

239. Hilbe JM. Negative Binomial Regression. Cambridge, MA: Cambridge University Press; 2007.

240. Muthén L. The Appropriate Use of Integration. 2013. Available at: http://www.statmodel.com/discussion/messages/22/14949.html?1381170693. Accessed February, 26, 2017.

241. Muthén BO. Application of causally defined direct and indirect effects in mediation analysis using SEM in Mplus. 2011. https://pdfs.semanticscholar.org/776d/2df784e67ab691bbffc280d3f4a480740300.pdf.

242. Agresti A. Categorical Data Analysis. Somerset, MA: John Wiley \& Sons; 2013.

243. Raudenbush SW, Bryk AS. Hierarchical Linear Models: Applications and Data Analysis Methods. 2nd ed. Thousand Oaks, CA: Sage Publications; 2002.

244. Black AT, Seder RC, Kekahio W. Review of Research on Student Nonenrollment and Chronic Absenteeism: A Report for the Pacific Region. Washington, DC: U.S. Department Of Education; 2014.

245. Daily SM, Mann MJ, Kristjansson AL, Smith ML, Zullig KJ. School climate and academic achievement in middle and high school students'. J Sch Health. 2018.

246. Lewis AD, Huebner ES, Malone PS, Valois RF. Life satisfaction and student engagement in adolescents. $J$ Youth Adolesc. 2011;40(3):249-262.

247. Gilman R, Huebner ES. Characteristics of adolescents who report very high life satisfaction. J Youth Adolesc. 2006;35(3):293-301.

248. Suldo SM, Huebner ES. Is extremely high life satisfaction during adolescence advantageous? Soc Indic Res. 2006;78(2):179-203. 
249. Danielsen AG, Samdal O, Hetland J, Wold B. School-related social support and students' perceived life satisfaction. J Educ Res. 2009;102(4):303-318,320.

250. Suldo SM, Shaffer EJ, Riley KN. A social-cognitive-behavioral model of academic predictors of adolescents' life satisfaction. Sch Psychol Q. 2008;23(1):56-69.

251. Suldo SM, Shaunessy E, Hardesty R. Relationships among stress, coping, and mental health in high-achieving high school students. Psychol Sch. 2008;45(4):273-290.

252. Heffner AL, Antaramian SP. The role of life satisfaction in predicting student engagement and achievement. J Happiness Stud. 2015;17(4):1681-1701.

253. State TM, Kern L. Life satisfaction among high school students with social, emotional, and behavioral problems. J Posit Behav Interv. 2017;19(4):205-215.

254. Rodriguez E, Rivera DA, Perlroth D, Becker E, Wang NE, Landau M. School nurses' role in asthma management, school absenteeism, and cost savings: A demonstration project. $J$ Sch Health. 2013;83(12):842-850.

255. Burton CM, Marshal MP, Chisolm DJ. School absenteeism and mental health among sexual minority youth and heterosexual youth. J Sch Psychol. 2014;52(1):37-47.

256. Fowler FJ. Survey Research Methods. 5th ed. Los Angeles, CA: SAGE; 2014.

257. Savalei V, Falk CF. Robust two-stage approach outperforms robust full information maximum likelihood with incomplete nonnormal data. Struct Equ Modeling. 2014;21(2):280-302.

258. Min Y, Agresti A. Random effect models for repeated measures of zero-inflated count data. Stat Modelling. 2005;5(1):1-19.

259. Desjardins CD. Modeling zero-inflated and overdispersed count data: An empirical study of school suspensions. J Exp Educ. 2016;84(3):449-472.

260. Imai K, Keele L, Tingley D. A general approach to causal mediation analysis. Psychol Methods. 2010;15(4):309-334.

261. Tian L, Tian Q, Huebner ES. School-related social support and adolescents' schoolrelated subjective well-being: The mediating role of basic psychological needs satisfaction at school. Soc Indic Res. 2016;128(1):105-129.

262. Baker BD, Sciarra DG, Farrie D. Is school funding fair? A national report card. Educ Law Center. 2014.

263. Northridge ME, Greenberg MR. Strengthening the Evidence Base for Public Health. Am J Public Health. 2005;95(11):1882.

264. Rimer BK, Glanz K, Rasband G. Searching for evidence about health education and health behavior interventions. Health Educ Behav. 2001;28(2):231-248.

265. Chirkina TA, Khavenson TE. School Climate. Sov Educ. 2018;60(2):133-160.

266. Brownson RC, Diez Roux AV, Swartz K. Commentary: Generating rigorous evidence for public health: the need for new thinking to improve research and practice. Annu Rev Public Health. 2014;35(1):1-7. 
267. Green LW. Public health asks of systems science: To advance our evidence-based practice, can you help us get more practice-based evidence? Am J Public Health. 2006;96(3):406-409.

268. Cronbach LJ, Meehl PE. Construct validity in psychological tests. Psychol Bulletin. 1955;52(4):281-302.

269. Wyrick DL, Bond L. Reducing sensitive survey response bias in research on adolescents: a comparison of web-based and paper-and-pencil administration. Am J Health Promot. 2011;25(5):349-352. 


\section{TABLES AND FIGURES}

Table 1. Descriptive Results for School Climate and Academic Grades

Sample Frequencies, Scale Means, Standard Deviation, and Reliability Coefficients, $n=2604$

\begin{tabular}{|c|c|c|c|c|c|c|}
\hline \multirow[b]{2}{*}{ Variable } & \multicolumn{2}{|c|}{2015} & \multicolumn{2}{|c|}{2016} & \multicolumn{2}{|c|}{2017} \\
\hline & $\mathrm{n}$ & $\%$ & $\mathrm{n}$ & $\%$ & $\mathrm{n}$ & $\%$ \\
\hline \multicolumn{7}{|l|}{ Academic Grades } \\
\hline Mostly As/Bs & 1797 & 80.5 & 1689 & 77.5 & 1702 & 74.9 \\
\hline Mostly Cs & 327 & 14.7 & 362 & 16.6 & 399 & 17.6 \\
\hline Mostly Ds/Fs & 106 & 4.8 & 129 & 5.9 & 171 & 7.5 \\
\hline \multicolumn{7}{|l|}{ Biological Sex } \\
\hline Female/Male & $1138 / 950$ & $54.5 / 45.5$ & & & & \\
\hline \multicolumn{7}{|l|}{ Race } \\
\hline White/All other races & $1817 / 280$ & $86.7 / 13.3$ & & & & \\
\hline \multicolumn{7}{|l|}{ Maternal Education } \\
\hline Coll grad/HS grad & $696 / 615$ & $34.2 / 30.2$ & & & & \\
\hline Less HS/Not sure & $146 / 581$ & $7.2 / 28.4$ & & & & \\
\hline \multicolumn{7}{|l|}{ Family Structure (lives with) } \\
\hline Biological parents/Other arrangement & $1195 / 902$ & $57.0 / 43.0$ & & & & \\
\hline Scale Variable & $\mathrm{M}(\mathrm{SD})$ & $\alpha$ & $\mathrm{M}(\mathrm{SD})$ & $\alpha$ & $\mathrm{M}(\mathrm{SD})$ & $\alpha$ \\
\hline Student-teacher relationships & $3.6(0.8)$ & 0.91 & $3.4(0.9)$ & 0.93 & $3.3(0.9)$ & 0.94 \\
\hline Order, safety, and discipline & $3.7(0.8)$ & 0.85 & $3.6(0.9)$ & 0.88 & $3.5(0.9)$ & 0.90 \\
\hline Student engagement & $3.8(0.8)$ & 0.86 & $3.7(0.9)$ & 0.88 & $3.6(0.9)$ & 0.89 \\
\hline
\end{tabular}

Missingness of observations due to pairwise techniques not reported. Coll $=$ College, $\mathrm{HS}=$ High School, Grad $=$ Graduate. $\alpha=$ Cronbach's alpha coefficient. ${ }^{268}$ 
Table 2. Model Results for Teacher Relationships and Academic Grades

Parallel Latent Growth Model Intercepts, Slopes, and Unstandardized/Standardized Regression Estimates for Student Teacher Relationships, $\mathrm{n}=2511$

\begin{tabular}{|c|c|c|c|c|c|c|c|c|}
\hline \multirow[b]{2}{*}{ Parameter } & \multirow{2}{*}{$\begin{array}{l}\text { Acad. Grades } \\
\text { B (SE) }\end{array}$} & \multirow{2}{*}{$\begin{array}{l}\text { SC1 } \\
\mathrm{B}(\mathrm{SE})\end{array}$} & \multirow{2}{*}{$\begin{array}{l}\text { As/Bs } \\
\mathrm{B}(\mathrm{SE})\end{array}$} & \multirow{2}{*}{$\begin{array}{l}\text { SC1 } \\
\mathrm{B}(\mathrm{SE})\end{array}$} & \multirow{2}{*}{$\begin{array}{l}\text { Cs } \\
\mathrm{B}(\mathrm{SE})\end{array}$} & \multirow{2}{*}{$\begin{array}{l}\text { SC1 } \\
\mathrm{B}(\mathrm{SE})\end{array}$} & \multirow{2}{*}{$\begin{array}{l}\text { Ds/Fs } \\
\mathrm{B}(\mathrm{SE})\end{array}$} & \multirow{2}{*}{$\begin{array}{l}\text { SC1 } \\
\text { B (SE) }\end{array}$} \\
\hline & & & & & & & & \\
\hline Intercept & $0.47(.13) * *$ & $3.42(.06) * *$ & $0.47(.13) * *$ & $3.42(.06) * *$ & $-0.73(.09) * *$ & $3.42(.05) * *$ & $-1.86(.21) * *$ & $3.42(.06) * *$ \\
\hline Slope & $-0.92(.21) * *$ & $0.18(.15)$ & $-0.93(.18) * *$ & $0.19(.11)$ & $0.33(.11) * *$ & $0.21(.14)$ & $0.90(.26) * *$ & $0.19(.04)$ \\
\hline Int. $\rightarrow$ Slope & $-0.10(.05) *$ & $-0.09(.04) *$ & $-0.11(.06)$ & $-0.09(.04) *$ & $-0.11(.12)$ & $-0.10(.04) * *$ & $-0.13(.07) *$ & $-0.09(.04) *$ \\
\hline SC1 X Grade & $-0.01(.01)$ & $0.23(.06) * *$ & $-0.01(.01)$ & $0.23(.05) * *$ & $0.03(.06)$ & $-0.11(.02) *$ & $0.01(.02)$ & $-0.27(.08) * *$ \\
\hline Slope $\leftrightarrow$ Slope & $0.03(.01) * *$ & & $0.04(.01) * *$ & & $-0.02(.01) *$ & & $-0.01(.02)$ & \\
\hline Std Est & $\beta(\mathrm{SE})$ & $\beta(\mathrm{SE})$ & $\beta(\mathrm{SE})$ & $\beta(\mathrm{SE})$ & $\beta(\mathrm{SE})$ & $\beta(\mathrm{SE})$ & $\beta(\mathrm{SE})$ & $\beta(\mathrm{SE})$ \\
\hline Int. $\rightarrow$ Slope & $-0.33(.16) *$ & $-0.25(.09) * *$ & $-0.35(.20)$ & $-0.25(.09) * *$ & $-0.33(.31)$ & $-0.26(.09) * *$ & $-0.48(.24) *$ & $-0.24(.10) *$ \\
\hline SC1 X Grade & $-0.08(.07)$ & $0.30(.08) * *$ & $-0.09(.06)$ & $0.27(.08) * *$ & $0.10(.06)$ & $-0.20(.01) *$ & $0.04(.12)$ & $-0.45(.11) * *$ \\
\hline Slope $\leftrightarrow$ Slope & $0.28(.13) *$ & & $0.30(.10) * *$ & & $-0.29(.15) *$ & & $-0.09(.23)$ & \\
\hline$-2 \mathrm{LL}(\mathrm{FP})$ & $24558.14(29)$ & & $22978.26(28)$ & & $22978.26(28)$ & & $19786.04(28)$ & \\
\hline $\mathrm{AIC} / \mathrm{BIC}$ & $24616.14 / 2478$ & & $23034.26 / 2319$ & & $22584.06 / 2274$ & & $19842.04 / 200$ & \\
\hline
\end{tabular}

$\mathrm{p}<.01^{* *}, \mathrm{p}<.05^{*} .-2 \mathrm{LL}=$ Deviance, FP = Free Parameters, Std. Est. = Standardized Estimate, SC1 = Student-Teacher Relationships, Int. $=$ Intercept, Acad.

Grades $=$ Academic Grades. Estimates include covariates and pairwise adjustment. School Clusters $=16$. 
Table 3. Model Results for Order and Safety and Academic Grades

Parallel Latent Growth Model Intercepts, Slopes, and Unstandardized/Standardized Regression Estimates for Order and Safety, $\mathrm{n}=2512$

\begin{tabular}{|c|c|c|c|c|c|c|c|c|}
\hline & Acad. Grades & $\mathrm{SC} 2$ & $\mathrm{As} / \mathrm{Bs}$ & $\mathrm{SC} 2$ & Cs & $\mathrm{SC} 2$ & $\mathrm{Ds} / \mathrm{Fs}$ & $\mathrm{SC} 2$ \\
\hline Parameter & $\mathrm{B}(\mathrm{SE})$ & $\mathrm{B}(\mathrm{SE})$ & $\mathrm{B}(\mathrm{SE})$ & B (SE) & $\mathrm{B}(\mathrm{SE})$ & $\mathrm{B}(\mathrm{SE})$ & $\mathrm{B}(\mathrm{SE})$ & B (SE) \\
\hline Intercept & $0.47(.12) * *$ & $3.64(.06) * *$ & $0.47(.18) * *$ & $3.64(.06) * *$ & $-0.74(.18) * *$ & $3.64(.05) * *$ & $-1.89(.22) * *$ & $3.64(.06) * *$ \\
\hline Slope & $-0.96(.25) * *$ & $0.28(.18)$ & $-0.90(.25) * *$ & $0.28(.19)$ & $0.27(.14) *$ & $0.30(.19)$ & $0.98(.26) * *$ & $0.27(.19)$ \\
\hline Int. $\rightarrow$ Slope & $-0.09(.04) *$ & $-0.11(.05) *$ & $-0.11(.06)$ & $-0.12(.05) *$ & $-0.12(.05)$ & $-0.12(.04) * *$ & $-0.14(.06) *$ & $-0.11(.05) *$ \\
\hline SC2 X Grade & $-0.02(.01)$ & $0.23(.07) * *$ & $-0.02(.01) *$ & $0.21(.07) * *$ & $0.04(.02) *$ & $-0.09(.04) *$ & $0.01(.02)$ & $-0.27(.07) * *$ \\
\hline Slope $\leftrightarrow$ Slope & $0.03(.01) *$ & & $0.03(.01) *$ & & $-0.02(.01)$ & & $-0.01(.02)$ & \\
\hline Std Est & $\beta(\mathrm{SE})$ & $\beta(\mathrm{SE})$ & $\beta(\mathrm{SE})$ & $\beta(\mathrm{SE})$ & $\beta(\mathrm{SE})$ & $\beta(\mathrm{SE})$ & $\beta(\mathrm{SE})$ & $\beta(\mathrm{SE})$ \\
\hline Int. $\rightarrow$ Slope & $-0.31(.16) *$ & $-0.25(.09) * *$ & $-0.36(.20)$ & $-0.25(.09) * *$ & $-0.32(.31)$ & $-0.25(.09) * *$ & $-0.55(.26) *$ & $-0.25(.04) * *$ \\
\hline SC2 X Grade & $-0.10(.05)$ & $0.29(.09) * *$ & $-0.11(.05) *$ & $0.24(.01) * *$ & $-0.15(.07) *$ & $-0.16(.08) *$ & $-0.01(.04)$ & $-0.46(.11) * *$ \\
\hline Slope $\leftrightarrow$ Slope & $0.25(.11) *$ & & $0.25(.11) *$ & & $-0.23(.17)$ & & $-0.15(.22)$ & \\
\hline$-2 \mathrm{LL}(\mathrm{FP})$ & \multicolumn{2}{|l|}{$24681.74(29)$} & \multicolumn{2}{|l|}{$23104.74(28)$} & \multicolumn{2}{|l|}{$22650.31(28)$} & \multicolumn{2}{|l|}{$19902.18(28)$} \\
\hline $\mathrm{AIC} / \mathrm{BIC}$ & \multicolumn{2}{|c|}{$24739.74 / 24908.77$} & \multicolumn{2}{|c|}{$23160.74 / 23323.94$} & \multicolumn{2}{|c|}{$22706.31 / 22869.51$} & \multicolumn{2}{|c|}{$19958.18 / 20121.38$} \\
\hline
\end{tabular}

$\mathrm{p}<.01^{* *}, \mathrm{p}<.05^{*} .-2 \mathrm{LL}=$ Deviance, FP $=$ Free Parameters, Std. Est. = Standardized Estimate, SC2 $=$ Order and Safety, Int. $=$ Intercept, Acad. Grades $=$

Academic Grades. Estimates include covariates and pairwise adjustment. School Clusters $=16$. 
Table 4. Model Results for Student Engagement and Academic Grades

Parallel Latent Growth Model Intercepts, Slopes, and Unstandardized/Standardized Regression Estimates for Student Engagement, $\mathrm{n}=2512$

\begin{tabular}{|c|c|c|c|c|c|c|c|c|}
\hline \multirow[b]{2}{*}{ Parameter } & \multirow{2}{*}{$\begin{array}{l}\text { Acad. Grades } \\
\text { B (SE) }\end{array}$} & \multirow{2}{*}{$\begin{array}{l}\text { SC3 } \\
\mathrm{B}(\mathrm{SE})\end{array}$} & \multirow{2}{*}{$\begin{array}{l}\text { As/Bs } \\
\text { B (SE) }\end{array}$} & \multirow{2}{*}{$\begin{array}{l}\text { SC3 } \\
\mathrm{B}(\mathrm{SE})\end{array}$} & \multirow{2}{*}{$\begin{array}{l}\text { Cs } \\
\text { B (SE) }\end{array}$} & \multirow{2}{*}{$\begin{array}{l}\text { SC3 } \\
\text { B (SE) }\end{array}$} & \multirow{2}{*}{$\begin{array}{c}\text { Ds/Fs } \\
\text { B (SE) }\end{array}$} & \multirow{2}{*}{$\begin{array}{l}\text { SC3 } \\
\text { B (SE) }\end{array}$} \\
\hline & & & & & & & & \\
\hline Intercept & $0.48(.12) * *$ & $3.72(.05) * *$ & $0.47(.13) * *$ & $3.72(.05) * *$ & $-0.73(.09) * *$ & $3.72(.05) * *$ & $-1.90(.22) * *$ & $3.72(.06) * *$ \\
\hline Slope & $-0.75(.25) * *$ & $0.35(.13) * *$ & $-0.77(.24) * *$ & $0.35(.13) * *$ & $0.35(.30) * *$ & $0.36(.14) * *$ & $0.63(.30) *$ & $0.33(.09) *$ \\
\hline Int. $\rightarrow$ Slope & $-0.09(.05) *$ & $-0.14(.03) * *$ & $-0.11(.06)$ & $-0.14(.03) * *$ & $-0.11(.12)$ & $-0.14(.03) * *$ & $-0.14(.07) *$ & $-0.14(.03) * *$ \\
\hline SC2 X Grade & $-0.01(.01)$ & $0.16(.07) *$ & $-0.01(.01)$ & $0.17(.06) * *$ & $0.02(.02)$ & $-0.11(.04) * *$ & $-0.01(.02)$ & $-0.17(.08) *$ \\
\hline Slope $\leftrightarrow$ Slope & $0.03(.01) * *$ & & $0.03(.01) * *$ & & $-0.01(.01)$ & & $-0.02(.02)$ & \\
\hline Std Est & $\beta(\mathrm{SE})$ & $\beta(\mathrm{SE})$ & $\beta(\mathrm{SE})$ & $\beta(\mathrm{SE})$ & $\beta(\mathrm{SE})$ & $\beta(\mathrm{SE})$ & $\beta(\mathrm{SE})$ & $\beta(\mathrm{SE})$ \\
\hline Int. $\rightarrow$ Slope & $-0.32(.16) *$ & $-0.29(.06) * *$ & $-0.35(.20)$ & $-0.30(.06) * *$ & $-0.33(.30)$ & $-0.30(.06) * *$ & $-0.54(.02) *$ & $-0.29(.06) * *$ \\
\hline SC1 X Drug & $-0.03(.06)$ & $0.22(.09) * *$ & $-0.04(.06)$ & $0.20(.08) * *$ & $0.06(.07)$ & $-0.19(.07) * *$ & $-0.03(.10)$ & $-0.30(.13) *$ \\
\hline Slope $\leftrightarrow$ Slope & $0.26(.10) * *$ & & $0.24(.10) *$ & & $-0.15(.15)$ & & $-0.29(.18)$ & \\
\hline$-2 \mathrm{LL}(\mathrm{FP})$ & \multicolumn{2}{|l|}{$24587.87(28)$} & \multicolumn{2}{|l|}{$23008.97(28)$} & \multicolumn{2}{|l|}{$22550.21(28)$} & \multicolumn{2}{|l|}{$19808.34(28)$} \\
\hline $\mathrm{AIC} / \mathrm{BIC}$ & \multicolumn{2}{|c|}{$24645.87 / 24814.90$} & \multicolumn{2}{|c|}{$23064.97 / 23228.17$} & \multicolumn{2}{|c|}{$22606.21 / 22769.42$} & \multicolumn{2}{|c|}{$19864.34 / 20027.55$} \\
\hline
\end{tabular}

$\mathrm{p}<.01 * *, \mathrm{p}<.05^{*} .-2 \mathrm{LL}=$ Deviance, $\mathrm{FP}=$ Free Parameters, Std. Est. = Standardized Estimate, SC3 = Student Engagement, Int. $=$ Intercept, Acad. Grades $=$

Academic Grades. Estimates include covariates and pairwise adjustment. School Clusters $=16$. 
Table 5. Descriptive Results for School Climate and Substance Initiation

Sample Frequencies, Scale Means, Standard Deviation, and Reliability Coefficients, $n=2097$

\begin{tabular}{|c|c|c|c|c|c|c|}
\hline \multirow[b]{2}{*}{ Variable } & \multicolumn{2}{|c|}{2015} & \multicolumn{2}{|c|}{2016} & \multicolumn{2}{|c|}{2017} \\
\hline & $\mathrm{n}$ & $\%$ & $\mathrm{n}$ & $\%$ & $\mathrm{n}$ & $\%$ \\
\hline \multicolumn{7}{|l|}{ Biological sex } \\
\hline Female/Male & $1138 / 950$ & $54.5 / 45.5$ & & & & \\
\hline \multicolumn{7}{|l|}{ Race } \\
\hline White/All other races & $1817 / 280$ & $86.7 / 13.3$ & & & & \\
\hline \multicolumn{7}{|l|}{ Maternal education } \\
\hline Coll Grad/HS Grad & $696 / 615$ & $34.2 / 30.2$ & & & & \\
\hline Less HS/Not Sure & $146 / 581$ & $7.2 / 28.4$ & & & & \\
\hline \multicolumn{7}{|l|}{ Family structure (lives with) } \\
\hline Biological parents/Other arrangement & $1195 / 902$ & $57.0 / 43.0$ & & & & \\
\hline \multicolumn{7}{|l|}{ Ever tried e-cigarettes } \\
\hline No/Yes & $1784 / 67$ & $96.38 / 3.6$ & $1626 / 145$ & $91.8 / 8.2$ & $1530 / 313$ & $83.0 / 17.0$ \\
\hline \multicolumn{7}{|l|}{ Ever tried cigarettes } \\
\hline No/Yes & $1796 / 56$ & $96.9 / 3.1$ & $1670 / 107$ & 93.9/6.1 & $1619 / 228$ & $87.6 / 12.4$ \\
\hline \multicolumn{7}{|l|}{ Ever drank alcohol } \\
\hline No/Yes & $1740 / 194$ & $88.8 / 11.2$ & $1397 / 433$ & $76.3 / 23.7$ & $1397 / 433$ & $76.3 / 23.7$ \\
\hline \multicolumn{7}{|l|}{ Ever tried marijuana } \\
\hline No/Yes & $1789 / 31$ & $98.3 / 1.7$ & $1668 / 67$ & $96.1 / 3.9$ & $1625 / 200$ & $89.0 / 11.0$ \\
\hline Scale Variable & $\mathrm{M}(\mathrm{SD})$ & $\alpha$ & $\mathrm{M}(\mathrm{SD})$ & $\alpha$ & $\mathrm{M}(\mathrm{SD})$ & $\alpha$ \\
\hline Student-teacher relationships & $3.6(0.8)$ & 0.91 & $3.5(0.9)$ & 0.93 & $3.3(0.9)$ & 0.94 \\
\hline Order, safety, and discipline & $3.8(0.8)$ & 0.85 & $3.6(0.9)$ & 0.88 & $3.5(0.9)$ & 0.90 \\
\hline Student engagement & $3.8(0.8)$ & 0.86 & $3.7(0.9)$ & 0.88 & $3.6(0.9)$ & 0.89 \\
\hline
\end{tabular}

Missingness of observations due to pairwise techniques not reported. Coll $=$ College, HS $=$ High School, Grad $=$

Graduate. $\alpha=$ Cronbach's alpha coefficient. ${ }^{268}$ 
Table 6. Model Results for Teacher Relationships and Substance Initiation

Parallel Latent Growth Model Intercepts, Slopes, and Unstandardized/Standardized Regression Estimates for Teacher Relationships, $\mathrm{n}=2,022$

\begin{tabular}{|c|c|c|c|c|c|c|c|c|}
\hline \multirow[b]{2}{*}{ Parameter } & \multirow{2}{*}{$\begin{array}{l}\text { E-cigarettes } \\
\mathrm{B}(\mathrm{SE})\end{array}$} & \multirow{2}{*}{$\begin{array}{l}\mathrm{SC} 1 \\
\mathrm{~B}(\mathrm{SE})\end{array}$} & \multirow{2}{*}{$\begin{array}{l}\text { Cigarettes } \\
\text { B (SE) }\end{array}$} & \multirow{2}{*}{$\begin{array}{l}\text { SC1 } \\
\text { B (SE) }\end{array}$} & \multirow{2}{*}{$\begin{array}{l}\text { Alcohol } \\
\text { B (SE) }\end{array}$} & \multirow{2}{*}{$\begin{array}{l}\mathrm{SC} 1 \\
\mathrm{~B}(\mathrm{SE})\end{array}$} & \multirow{2}{*}{$\begin{array}{l}\text { Marijuana } \\
\mathrm{B}(\mathrm{SE})\end{array}$} & \multirow{2}{*}{$\begin{array}{l}\text { SC1 } \\
\text { B (SE) }\end{array}$} \\
\hline & & & & & & & & \\
\hline Intercept & $-2.45(.23) * *$ & $3.51(.06) * *$ & $-2.51(.18) * *$ & $3.51(.06) * *$ & $-2.50(.18) * *$ & $3.51(.05) * *$ & $-3.08(.17) * *$ & $3.50(.06) * *$ \\
\hline Slope & $3.80(.42) * *$ & $0.12(.10)$ & $3.68(.33) * *$ & $0.11(.11)$ & $3.56(.30) * *$ & $0.10(.14)$ & $3.83(.23) * *$ & $0.58(.09) * *$ \\
\hline Int. $\rightarrow$ Slope & $1.42(.20) * *$ & $-0.12(.04) * *$ & $1.55(.06) * *$ & $-0.11(.04) * *$ & $1.13(.08) * *$ & $-0.11(.04) *$ & $0.96(.16) * *$ & $-0.29(.02) * *$ \\
\hline SC1 X Drug & $-0.05(.01)^{* *}$ & $-0.22(.04) * *$ & $-0.05(.02) * *$ & $-0.19(.03) * *$ & $-0.04(.02) *$ & $-0.18(.03) * *$ & $-0.09(.02) * *$ & $-0.28(.06) * *$ \\
\hline Int. $\leftrightarrow$ Int. & \multicolumn{2}{|l|}{$-0.15(.03) * *$} & \multicolumn{2}{|l|}{$-0.17(.04) * *$} & \multicolumn{2}{|l|}{$-0.19(.03) * *$} & \multicolumn{2}{|l|}{$-0.20(.06) * *$} \\
\hline Std. Est. & $\beta(\mathrm{SE})$ & $\beta(\mathrm{SE})$ & $\beta(\mathrm{SE})$ & $\beta(\mathrm{SE})$ & $\beta(\mathrm{SE})$ & $\beta(\mathrm{SE})$ & $\beta(\mathrm{SE})$ & $\beta(\mathrm{SE})$ \\
\hline Int. $\rightarrow$ Slope & $0.99(.02) * *$ & $-0.28(.09) * *$ & $0.99(.02) * *$ & $-0.29(.09) * *$ & $0.96(.02) * *$ & $-0.26(.10) * *$ & $0.93(.02) * *$ & $-0.66(.04) * *$ \\
\hline SC1 X Drug & $-0.18(.04) * *$ & $-0.10(.02) * *$ & $-0.20(.07) * *$ & $-0.07(.01) * *$ & $-0.16(.06) *$ & $-0.10(.01) * *$ & $-0.20(.04) * *$ & $-0.25(.05) * *$ \\
\hline Int. $\leftrightarrow$ Int. & $-0.25(.05) * *$ & & $-0.28(0.7) * *$ & & $-0.31(.06) * *$ & & $-0.20(.07) * *$ & \\
\hline$-2 \mathrm{LL}(\mathrm{FP})$ & \multicolumn{2}{|l|}{$15904.81(26)$} & \multicolumn{2}{|l|}{$15399.22(26)$} & \multicolumn{2}{|l|}{$16461.02(26)$} & \multicolumn{2}{|l|}{$15388.62(25)$} \\
\hline $\mathrm{AIC} / \mathrm{BIC}$ & \multicolumn{2}{|c|}{$15956.81 / 16102.72$} & \multicolumn{2}{|c|}{$15451.22 / 15597.13$} & \multicolumn{2}{|c|}{$16513.02 / 16658.93$} & \multicolumn{2}{|c|}{$15438.62 / 15438.92$} \\
\hline
\end{tabular}

$\mathrm{p}=<.01 * *, \mathrm{p}=<.05^{*} .-2 \mathrm{LL}=$ Deviance, $\mathrm{FP}=$ Free Parameters, Std. Est. $=$ Standardized Estimate, SC1 = Teacher Relationships, Int. $=$ Intercept. Estimates include covariate adjustment. School Clusters $=16$. 
Table 7. Model Results for Order and Safety and Substance Initiation

Parallel Latent Growth Model Intercepts, Slopes, and Unstandardized/Standardized Regression Estimates for Order and Safety, $\mathrm{n}=2,023$

\begin{tabular}{|c|c|c|c|c|c|c|c|c|}
\hline & E-cigarettes & $\mathrm{SC} 2$ & Cigarettes & $\mathrm{SC} 2$ & Alcohol & $\mathrm{SC} 2$ & Marijuana & $\mathrm{SC} 2$ \\
\hline Parameter & B (SE) & $\mathrm{B}(\mathrm{SE})$ & B (SE) & B (SE) & $\mathrm{B}(\mathrm{SE})$ & B (SE) & B (SE) & $\mathrm{B}(\mathrm{SE})$ \\
\hline Intercept & $-2.27(.26) * *$ & $3.72(.07) * *$ & $-2.48(.18) * *$ & $3.72(.07) * *$ & $-2.49(.19) * *$ & $3.72(.06) * *$ & $-3.08(.18) * *$ & $3.72(.07) * *$ \\
\hline Slope & $3.62(.38) * *$ & $0.28(.18)$ & $3.80(.35) * *$ & $0.28(.18)$ & $3.38(.29) * *$ & $0.23(.18)$ & $3.86(.24) * *$ & $0.38(.17) * *$ \\
\hline Int. $\rightarrow$ Slope & $1.38(.09) * *$ & $-0.15(.05) * *$ & $1.56(.07) * *$ & $-0.15(.05) * *$ & $0.97(.08) * *$ & $-0.13(.06) * *$ & $1.06(.06) * *$ & $-0.15(.05) * *$ \\
\hline SC2 X Drug & $-0.05(.02) * *$ & $-0.22(.04) * *$ & $-0.05(.02) * *$ & $-0.22(.06) * *$ & $-0.02(.02)$ & $-0.21(.04) * *$ & $-0.04(.02) *$ & $-0.28(.06) * *$ \\
\hline Int. $\leftrightarrow$ Int. & $-0.16(.04) * *$ & & $-0.17(.04) * *$ & & $-0.20(0.3) * *$ & & $-0.18(.04) * *$ & \\
\hline Std. Est. & $\beta(\mathrm{SE})$ & $\beta(\mathrm{SE})$ & $\beta(\mathrm{SE})$ & $\beta(\mathrm{SE})$ & $\beta(\mathrm{SE})$ & $\beta(\mathrm{SE})$ & $\beta(\mathrm{SE})$ & $\beta(\mathrm{SE})$ \\
\hline Int. $\rightarrow$ Slope & $0.99(.02) * *$ & $-0.32(.10) * *$ & $0.99(.02) * *$ & $-0.32(.10) * *$ & $0.98(.11) * *$ & $-0.29(.09) * *$ & $0.95(.03) * *$ & $-0.32(.10) * *$ \\
\hline SC2 X Drug & $-0.17(.06) * *$ & $-0.09(.02) * *$ & $-0.20(.08) * *$ & $-0.08(.02) * *$ & $-0.09(.05)$ & $-0.07(.01) * *$ & $-0.15(.07) *$ & $-0.15(.03) * *$ \\
\hline Int. $\leftrightarrow$ Int. & $-0.28(.07) * *$ & & $-0.28(.07) * *$ & & $-0.37(.04) * *$ & & $-0.30(.06) * *$ & \\
\hline$-2 \mathrm{LL}(\mathrm{FP})$ & \multicolumn{2}{|l|}{$16069.51(26)$} & \multicolumn{2}{|l|}{$15573.36(26)$} & \multicolumn{2}{|l|}{$16632.91(26)$} & \multicolumn{2}{|l|}{$15286.61(26)$} \\
\hline $\mathrm{AIC} / \mathrm{BIC}$ & \multicolumn{2}{|c|}{$16121.51 / 16267.43$} & \multicolumn{2}{|c|}{$15625.36 / 15771.28$} & \multicolumn{2}{|c|}{$16684.91 / 16830.83$} & \multicolumn{2}{|c|}{$15338.61 / 15484.53$} \\
\hline
\end{tabular}

$\mathrm{p}=<.01^{* *}, \mathrm{p}=<.05^{*} .-2 \mathrm{LL}=$ Deviance, FP = Free Parameters, Std. Est. = Standardized Estimate, SC2 = Order and Safety, Int. $=$ Intercept. Estimates include covariate adjustment. School Clusters $=16$. 
Table 8. Model Results for Student Engagement and Substance Initiation

Parallel Latent Growth Model Intercepts, Slopes, and Unstandardized/Standardized Regression Estimates for Student Engagement, $\mathrm{n}=2,023$

\begin{tabular}{|c|c|c|c|c|c|c|c|c|}
\hline \multirow[b]{2}{*}{ Parameter } & \multirow{2}{*}{$\begin{array}{l}\text { E-cigarettes } \\
\text { B (SE) }\end{array}$} & \multirow{2}{*}{$\begin{array}{l}\text { SC3 } \\
\mathrm{B}(\mathrm{SE})\end{array}$} & \multirow{2}{*}{$\begin{array}{l}\text { Cigarettes } \\
\mathrm{B}(\mathrm{SE})\end{array}$} & \multirow{2}{*}{$\begin{array}{l}\text { SC3 } \\
\mathrm{B}(\mathrm{SE})\end{array}$} & \multirow{2}{*}{$\begin{array}{l}\text { Alcohol } \\
\text { B (SE) }\end{array}$} & \multirow{2}{*}{$\begin{array}{l}\text { SC3 } \\
\mathrm{B}(\mathrm{SE})\end{array}$} & \multirow{2}{*}{$\begin{array}{l}\text { Marijuana } \\
\mathrm{B}(\mathrm{SE})\end{array}$} & \multirow{2}{*}{$\begin{array}{l}\text { SC3 } \\
\mathrm{B}(\mathrm{SE})\end{array}$} \\
\hline & & & & & & & & \\
\hline Intercept & $-2.45(.23) * *$ & $3.79(.05) * *$ & $-2.49(.17) * *$ & $3.79(.06) * *$ & $-2.48(.16) * *$ & $3.79(.05) * *$ & $-3.12(.18) * *$ & $3.79(.05) * *$ \\
\hline Slope & $3.91(.41) * *$ & $0.34(.12) * *$ & $3.82(.25) * *$ & $0.33(.11) *$ & $3.36(.23) * *$ & $0.37(.12) * *$ & $3.85(.29) * *$ & $0.33(.13) * *$ \\
\hline Int. $\rightarrow$ Slope & $1.40(.07) * *$ & $-0.18(.03) * *$ & $1.56(.07) * *$ & $-0.18(.03) * *$ & $1.05(.07) * *$ & $-0.17(.03) * *$ & $1.29(.09) * *$ & $-0.16(.03) * *$ \\
\hline SC3 X Drug & $-0.06(.01) * *$ & $-0.23(.02) * *$ & $-0.07(.02) * *$ & $-0.19(.03) * *$ & $-0.04(.02) * *$ & $-0.17(.03) * *$ & $-0.03(.02) * *$ & $-0.18(.03) * *$ \\
\hline Int. $\leftrightarrow$ Int. & $-0.13(.03) * *$ & & $-0.13(.04) * *$ & & $-0.17(.02) * *$ & & $-0.19(.03) * *$ & \\
\hline Std. Est. & $\beta(\mathrm{SE})$ & $\beta(\mathrm{SE})$ & $\beta(\mathrm{SE})$ & $\beta(\mathrm{SE})$ & $\beta(\mathrm{SE})$ & $\beta(\mathrm{SE})$ & $\beta(\mathrm{SE})$ & $\beta(\mathrm{SE})$ \\
\hline Int. $\rightarrow$ Slope & $0.99(.02) * *$ & $-0.36(.06) * *$ & $0.99(.02) * *$ & $-0.37(.05) * *$ & $0.96(.02) * *$ & $-0.35(.06) * *$ & $0.97(.02) * *$ & $-0.36(.06) * *$ \\
\hline SC3 X Drug & $-0.20(.03) * *$ & $-0.10(.01) * *$ & $-0.24(.05) * *$ & $-0.07(.01) * *$ & $-0.12(.05) * *$ & $-0.10(.01) * *$ & $-0.17(.06) * *$ & $-0.15(.03) * *$ \\
\hline Int. $\leftrightarrow$ Int. & $-0.20(.05) * *$ & & $-0.21(.07) * *$ & & $-0.30(.04) * *$ & & $-0.21(.06) * *$ & \\
\hline$-2 \mathrm{LL}(\mathrm{FP})$ & \multicolumn{2}{|l|}{$16023.09(26)$} & \multicolumn{2}{|l|}{$15519.03(26)$} & \multicolumn{2}{|l|}{$16588.87(26)$} & \multicolumn{2}{|l|}{$15243.63(26)$} \\
\hline $\mathrm{AIC} / \mathrm{BIC}$ & \multicolumn{2}{|c|}{$16075.09 / 16221.02$} & \multicolumn{2}{|c|}{$15571.03 / 15716.95$} & \multicolumn{2}{|c|}{$16640.87 / 16786.79$} & \multicolumn{2}{|c|}{$15358.63 / 15358.95$} \\
\hline
\end{tabular}

$\mathrm{p}=<.01^{* *}, \mathrm{p}=<.05^{*} .-2 \mathrm{LL}=$ Deviance, FP = Free Parameters, Std. Est. = Standardized Estimate, SC3 = Student Engagement, Int. $=$ Intercept. Estimates include covariate adjustment. School Clusters $=16$. 
Table 9. Descriptive Results for School Climate and Absences

Sample Frequencies, scale means, standard deviations, and reliability coefficients

\begin{tabular}{|c|c|c|c|c|}
\hline \multirow[b]{2}{*}{ Demographic Variable } & \multicolumn{2}{|c|}{ Middle school $n=6283$} & \multicolumn{2}{|c|}{ High school $\mathrm{n}=7217$} \\
\hline & $\mathrm{n}$ & "\% & $\mathrm{n}$ & $\%$ \\
\hline \multicolumn{5}{|l|}{ Academic grades } \\
\hline Mostly As/Bs & 4318 & 88.2 & 5028 & 82.7 \\
\hline Mostly Cs & 414 & 8.5 & 730 & 11.9 \\
\hline Mostly Ds/Fs & 163 & 3.3 & 325 & 5.4 \\
\hline \multicolumn{5}{|l|}{ Skipped or cut class } \\
\hline No/Yes & $4305 / 280$ & $93.9 / 6.1$ & $4858 / 865$ & $85.0 / 15.1$ \\
\hline \multicolumn{5}{|l|}{ Illness } \\
\hline No/Yes & $2489 / 2469$ & $50.2 / 49.8$ & $3166 / 2860$ & $52.5 / 47.4$ \\
\hline \multicolumn{5}{|l|}{ Sex } \\
\hline Female/Male & $3022 / 3224$ & $48.4 / 51.6$ & $3636 / 3534$ & $50.7 / 49.3$ \\
\hline \multicolumn{5}{|l|}{ Race } \\
\hline White/All other races & $5133 / 1150$ & $81.7 / 18.3$ & $6115 / 1102$ & $84.7 / 15.3$ \\
\hline \multicolumn{5}{|l|}{ Family structure (live with) } \\
\hline Biological parents/Other arrangements & $3553 / 2730$ & $56.5 / 43.5$ & $3706 / 3511$ & $51.3 / 48.7$ \\
\hline \multicolumn{5}{|l|}{ Maternal education } \\
\hline Coll Grad/HS Grad & $1598 / 1535$ & $26.6 / 25.6$ & $2242 / 2299$ & $32.8 / 32.0$ \\
\hline Less HS/Not Sure & $371 / 2513$ & $6.1 / 41.7$ & $698 / 1768$ & $1.0 / 25.2$ \\
\hline Scale Variable & $\mathrm{M}(\mathrm{SD})$ & $\alpha$ & $\mathrm{M}(\mathrm{SD})$ & $\alpha$ \\
\hline School satisfaction & $3.7(1.2)$ & 0.88 & $3.4(1.2)$ & 0.87 \\
\hline Teacher relationships & $3.5(0.9)$ & 0.92 & $3.1(0.9)$ & 0.94 \\
\hline Order and safety & $3.7(0.9)$ & 0.88 & $3.2(0.9)$ & 0.91 \\
\hline Student engagement & $3.7(0.9)$ & 0.88 & $3.4(0.9)$ & 0.91 \\
\hline
\end{tabular}

Missingness of observations due to pairwise techniques not reported. Coll $=$ College, $\mathrm{HS}=$ High School Grad $=$ Graduate. $\alpha=$ Cronbach's alpha coefficient. ${ }^{268}$ 
Table 10. Model Results for School Climate and Types of Absences - Middle School Mediated Path Analysis Direct and Indirect Effects

\begin{tabular}{|c|c|c|c|c|c|c|c|c|c|}
\hline \multirow[b]{2}{*}{ DV (Model Type) } & \multicolumn{3}{|c|}{$\begin{array}{l}\text { Teacher Relationships } \\
\qquad \mathrm{n}=4822\end{array}$} & \multicolumn{3}{|c|}{$\begin{array}{l}\text { Order and Safety } \\
\qquad \mathrm{n}=4799\end{array}$} & \multicolumn{3}{|c|}{$\begin{array}{l}\text { Student Engagement } \\
\qquad \mathrm{n}=4790\end{array}$} \\
\hline & $\widehat{\beta}$ & SE & $\exp (\widehat{\beta})$ & $\widehat{\beta}$ & SE & $\exp (\widehat{\beta})$ & $\widehat{\beta}$ & $\mathrm{SE}$ & $\exp (\widehat{\beta})$ \\
\hline \multicolumn{10}{|l|}{ Grades (OPR) } \\
\hline Skipped $\rightarrow$ & $-0.41 * *$ & 0.08 & 0.67 & $-0.43 * *$ & 0.08 & 0.65 & $-0.42 * *$ & 0.08 & 0.66 \\
\hline $\mathrm{SC} \rightarrow \mathrm{SS} \rightarrow \mathrm{Skip} \rightarrow$ & $0.04 * *$ & 0.01 & 1.04 & $0.04 * *$ & 0.01 & 1.04 & $0.04 * *$ & 0.01 & 1.04 \\
\hline $\mathrm{SS} \rightarrow$ Skip $\rightarrow$ & $0.07 * *$ & 0.01 & 1.07 & $0.08 * *$ & 0.01 & 1.08 & $0.08 * *$ & 0.01 & 1.09 \\
\hline $\mathrm{SC} \rightarrow$ Skip $\rightarrow$ & $0.12 * *$ & 0.03 & 1.13 & $0.11 * *$ & 0.03 & 1.12 & 0.10 & 0.02 & 1.10 \\
\hline Illness $\rightarrow$ & $-0.23 * *$ & 0.04 & 0.79 & $-0.23 * *$ & 0.04 & 0.79 & $-0.25 * *$ & 0.04 & 0.79 \\
\hline $\mathrm{SC} \rightarrow \mathrm{SS} \rightarrow \mathrm{Ill} \rightarrow$ & 0.01 & 0.01 & - & 0.01 & 0.01 & - & 0.01 & 0.01 & - \\
\hline $\mathrm{SS} \rightarrow \mathrm{Ill} \rightarrow$ & 0.01 & 0.01 & - & 0.01 & 0.01 & - & 0.01 & 0.01 & - \\
\hline $\mathrm{SC} \rightarrow \mathrm{Ill} \rightarrow$ & $0.02 *$ & 0.01 & 1.02 & 0.01 & 0.01 & - & 0.01 & 0.01 & - \\
\hline School Sat $\rightarrow$ & $0.18^{* *}$ & 0.02 & 1.19 & $0.18^{* *}$ & 0.02 & 1.20 & $0.18 * *$ & 0.01 & 1.19 \\
\hline $\mathrm{SC} \rightarrow \mathrm{SS} \rightarrow$ & $0.10 * *$ & 0.01 & 1.10 & $0.09 * *$ & 0.01 & 1.10 & $0.09 * *$ & 0.01 & 1.09 \\
\hline SC Subscale $\rightarrow$ & $0.11 * *$ & 0.03 & 1.12 & $0.08 * *$ & 0.02 & 1.09 & $0.10 * *$ & 0.03 & 1.10 \\
\hline \multicolumn{10}{|l|}{ Skipped (PR) } \\
\hline School Sat $\rightarrow$ & $-0.17 * *$ & 0.03 & 0.85 & $-0.18 * *$ & 0.03 & 0.84 & $-0.20 * *$ & 0.03 & 0.82 \\
\hline $\mathrm{SC} \rightarrow \mathrm{SS} \rightarrow$ & $-0.09 * *$ & 0.02 & 0.91 & $-0.09 * *$ & 0.02 & 0.91 & $-0.10 * *$ & 0.02 & 0.90 \\
\hline SC Subscale $\rightarrow$ & $-0.30 * *$ & 0.04 & 0.74 & $-0.26^{* *}$ & 0.04 & 0.77 & $-0.23 * *$ & 0.03 & 0.80 \\
\hline \multicolumn{10}{|l|}{ Illness (PR) } \\
\hline School Sat $\rightarrow$ & -0.02 & 0.03 & - & -0.02 & 0.03 & - & -0.02 & 0.03 & - \\
\hline $\mathrm{SC} \rightarrow \mathrm{SS} \rightarrow$ & -0.01 & 0.01 & - & -0.01 & 0.01 & - & -0.01 & 0.01 & - \\
\hline SC Subscale $\rightarrow$ & $-0.06^{* *}$ & 0.03 & 0.94 & $-0.05^{* *}$ & 0.03 & 0.96 & -0.04 & 0.03 & - \\
\hline School Sat. (MLR) & B & SE & $\beta$ & B & SE & $\beta$ & B & $\mathrm{SE}$ & $\beta$ \\
\hline SC Subscale $\rightarrow$ & $0.54 * *$ & 0.03 & 0.41 & $0.52 * *$ & 0.03 & 0.39 & $0.51 * *$ & 0.03 & 0.38 \\
\hline$-2 \mathrm{LL}(\mathrm{FP})$ & \multicolumn{3}{|c|}{$25994.75(27)$} & \multicolumn{3}{|c|}{$26008.69(27)$} & \multicolumn{3}{|c|}{$25958.22(27)$} \\
\hline $\mathrm{AIC} / \mathrm{BIC}$ & \multicolumn{3}{|c|}{$26048.75 / 26223.46$} & \multicolumn{3}{|c|}{$26062.69 / 26012.22$} & \multicolumn{3}{|c|}{$26012.22 / 26186.76$} \\
\hline
\end{tabular}

${ }^{* *} \mathrm{p} \leq .01,{ }^{*} \mathrm{p} \leq .05 . \mathrm{OPR}=$ ordinal probit regression, $\mathrm{PR}=$ probit regression, MLR $=$ multiple linear regression, $\mathrm{SC}=$ School Climate, school sat and SS $=$ School Satisfaction. Analyses includes covariate adjustment and pairwise techniques. 
Table 11. Model Results for School Climate and Types of Absences - High School

Mediated Path Analysis Direct and Indirect Effects

\begin{tabular}{|c|c|c|c|c|c|c|c|c|c|}
\hline \multirow[b]{2}{*}{ DV (Model Type) } & \multicolumn{3}{|c|}{$\begin{array}{l}\text { Teacher Relationships } \\
\qquad \mathrm{n}=5917\end{array}$} & \multicolumn{3}{|c|}{$\begin{array}{l}\text { Order and Safety } \\
\qquad \mathrm{n}=5917\end{array}$} & \multicolumn{3}{|c|}{$\begin{array}{l}\text { Student Engagement } \\
\qquad \mathrm{n}=5920\end{array}$} \\
\hline & $\widehat{\beta}$ & $\mathrm{SE}$ & $\exp (\widehat{\beta})$ & $\widehat{\beta}$ & SE & $\exp (\widehat{\beta})$ & $\widehat{\beta}$ & SE & $\exp (\widehat{\beta})$ \\
\hline \multicolumn{10}{|l|}{ Grades (PR) } \\
\hline Skipped $\rightarrow$ & $-0.44 * *$ & 0.05 & 0.64 & $-0.46^{* *}$ & 0.05 & 0.63 & $-0.45^{* *}$ & 0.05 & 0.64 \\
\hline $\mathrm{SC} \rightarrow \mathrm{SS} \rightarrow$ Skip $\rightarrow$ & $0.05 * *$ & 0.01 & 1.05 & $0.04 * *$ & 0.01 & 1.04 & $0.05^{* *}$ & 0.01 & 1.05 \\
\hline $\mathrm{SS} \rightarrow$ Skip $\rightarrow$ & $0.09 * *$ & 0.01 & 1.09 & $0.09 * *$ & 0.01 & 1.10 & $0.09 * *$ & 0.01 & 1.09 \\
\hline $\mathrm{SC} \rightarrow$ Skip $\rightarrow$ & $0.06^{* *}$ & 0.03 & 1.06 & $0.07 * *$ & 0.02 & 1.07 & $0.05^{* *}$ & 0.01 & 1.05 \\
\hline Illness $\rightarrow$ & $-0.26^{* *}$ & 0.04 & 0.77 & $-0.27 * *$ & 0.04 & 0.76 & $-0.27 * *$ & 0.04 & 0.77 \\
\hline $\mathrm{SC} \rightarrow \mathrm{SS} \rightarrow \mathrm{Ill} \rightarrow$ & 0.01 & 0.01 & - & 0.01 & 0.01 & - & 0.01 & 0.01 & - \\
\hline $\mathrm{SS} \rightarrow \mathrm{Ill} \rightarrow$ & 0.01 & 0.01 & - & 0.01 & 0.01 & - & 0.01 & 0.01 & - \\
\hline $\mathrm{SC} \rightarrow \mathrm{Ill} \rightarrow$ & $0.03 * *$ & 0.02 & 1.03 & $0.02 *$ & 0.02 & 0.88 & 0.02 & 0.01 & - \\
\hline School Sat. $\rightarrow$ & $0.16 * *$ & 0.02 & 1.18 & $0.18 * *$ & 0.02 & 1.20 & $0.16^{* *}$ & 0.02 & 1.18 \\
\hline $\mathrm{SC} \rightarrow \mathrm{SS} \rightarrow$ & $0.09 * *$ & 0.01 & 1.09 & $0.09 * *$ & 0.01 & 1.09 & $0.09 * *$ & 0.01 & 1.09 \\
\hline SC Subscale $\rightarrow$ & $0.11 * *$ & 0.02 & 1.12 & $0.06^{*}$ & 0.02 & 1.06 & $0.11 * *$ & 0.02 & 1.12 \\
\hline \multicolumn{10}{|l|}{ Skipped (PR) } \\
\hline School Sat. $\rightarrow$ & $-0.20 * *$ & 0.03 & 0.82 & $-0.19 * *$ & 0.03 & 0.83 & $-0.20 * *$ & 0.03 & 0.82 \\
\hline $\mathrm{SC} \rightarrow \mathrm{SS} \rightarrow$ & $-0.11 * *$ & 0.02 & 0.90 & $-0.09 * *$ & 0.01 & 0.91 & $-0.11 * *$ & 0.01 & 0.90 \\
\hline SC Subscale $\rightarrow$ & $-0.13 * *$ & 0.03 & 0.88 & $-0.15^{* *}$ & 0.02 & 0.86 & $-0.11 * *$ & 0.02 & 0.89 \\
\hline \multicolumn{10}{|l|}{ Illness (PR) } \\
\hline School Sat. $\rightarrow$ & -0.03 & 0.03 & - & -0.04 & 0.03 & - & -0.04 & 0.03 & - \\
\hline $\mathrm{SC} \rightarrow \mathrm{SS} \rightarrow$ & -0.02 & 0.01 & - & -0.02 & 0.01 & - & -0.02 & 0.01 & - \\
\hline SC Subscale $\rightarrow$ & $-0.10 * *$ & 0.03 & 0.93 & $-0.07 * *$ & 0.02 & 0.94 & -0.06 & 0.04 & - \\
\hline School Sat. (MLR) & B & SE & $\beta$ & $\mathrm{B}$ & SE & $\beta$ & $\mathrm{B}$ & $\mathrm{SE}$ & $\beta$ \\
\hline SC Subscale $\rightarrow$ & $0.54 * *$ & 0.02 & 0.41 & $0.48 * *$ & 0.01 & 0.36 & $0.51 * *$ & 0.01 & 0.38 \\
\hline$-2 \mathrm{LL}(\mathrm{FP})$ & \multicolumn{3}{|c|}{$34590.02(27)$} & \multicolumn{3}{|c|}{$34655.79(27)$} & \multicolumn{3}{|c|}{$34619.18(27)$} \\
\hline $\mathrm{AIC} / \mathrm{BIC}$ & \multicolumn{3}{|c|}{$34644.02 / 34823.86$} & \multicolumn{3}{|c|}{$34709.79 / 34889.53$} & \multicolumn{3}{|c|}{$34673.18 / 34852.93$} \\
\hline
\end{tabular}

${ }^{* *} \mathrm{p} \leq .01,{ }^{*} \mathrm{p} \leq .05 . \mathrm{OPR}=$ ordinal probit regression, $\mathrm{PR}=$ probit regression, MLR $=$ multiple linear regression, $\mathrm{SC}=$ School Climate, school sat and SS $=$ School Satisfaction. Analyses includes covariate adjustment and pairwise techniques. 


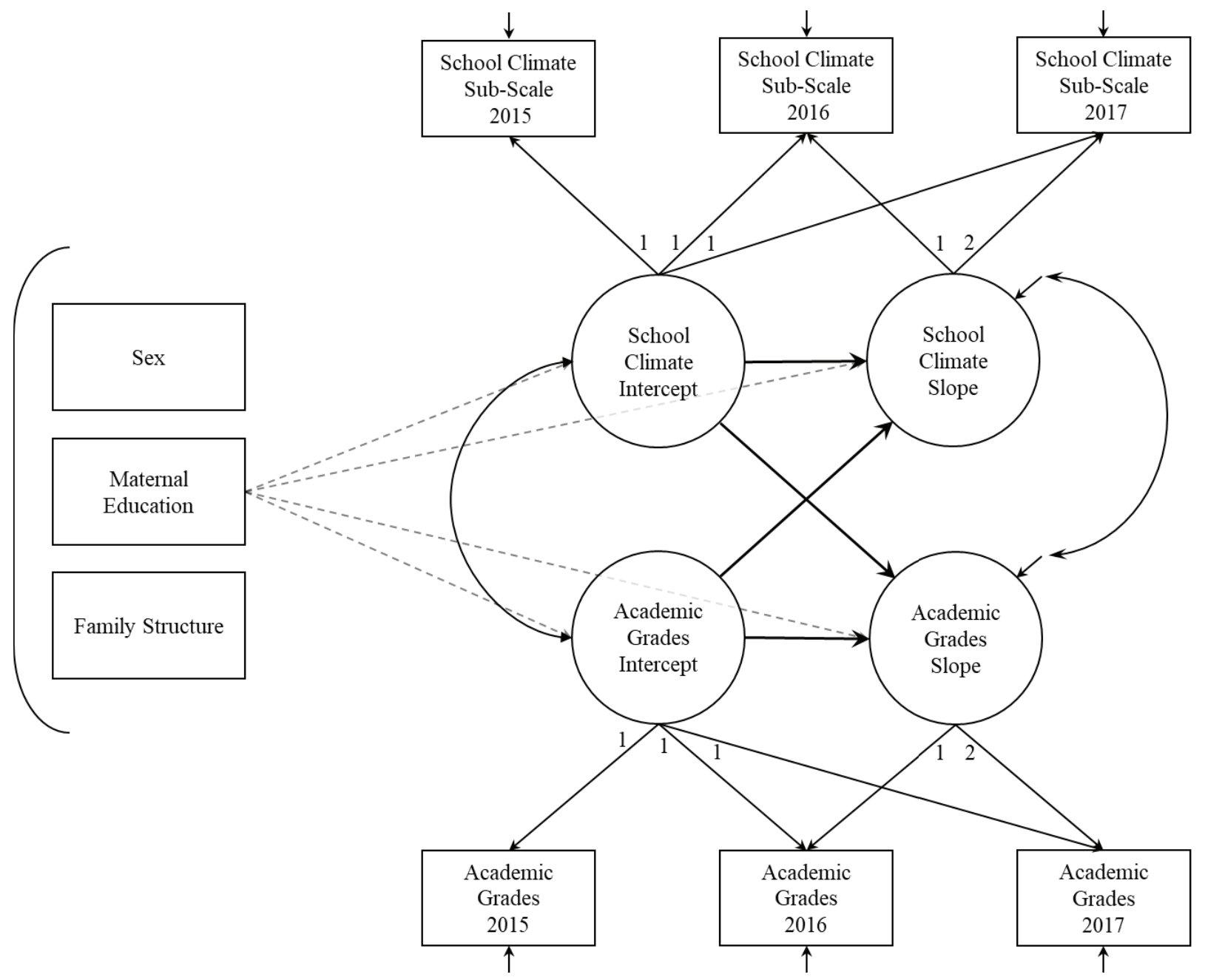

Figure 1. Parallel Latent Growth Model for School Climate and Academic Grades 


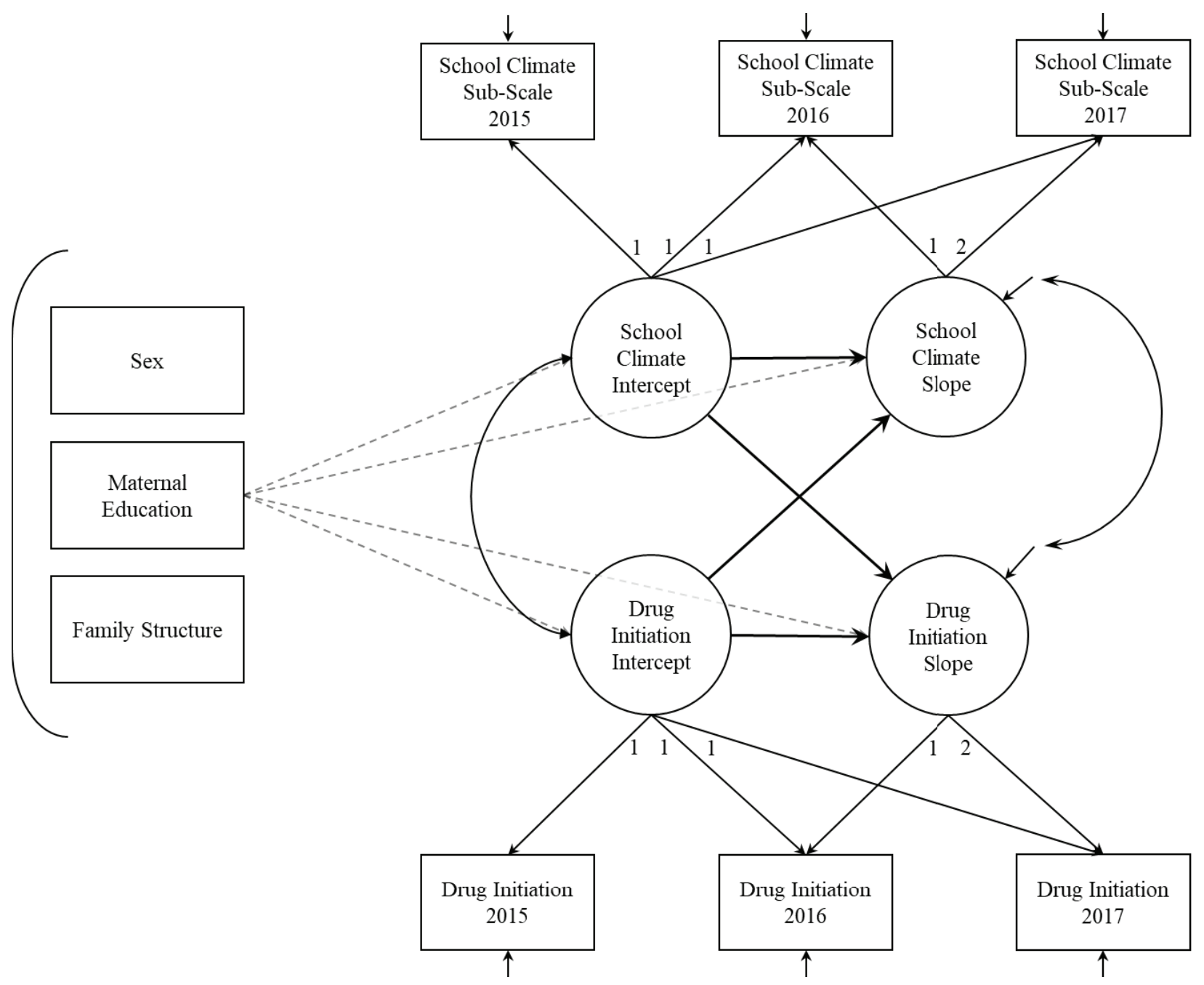

Figure 2. Parallel Latent Growth Model for School Climate and Substance Use Initiation 


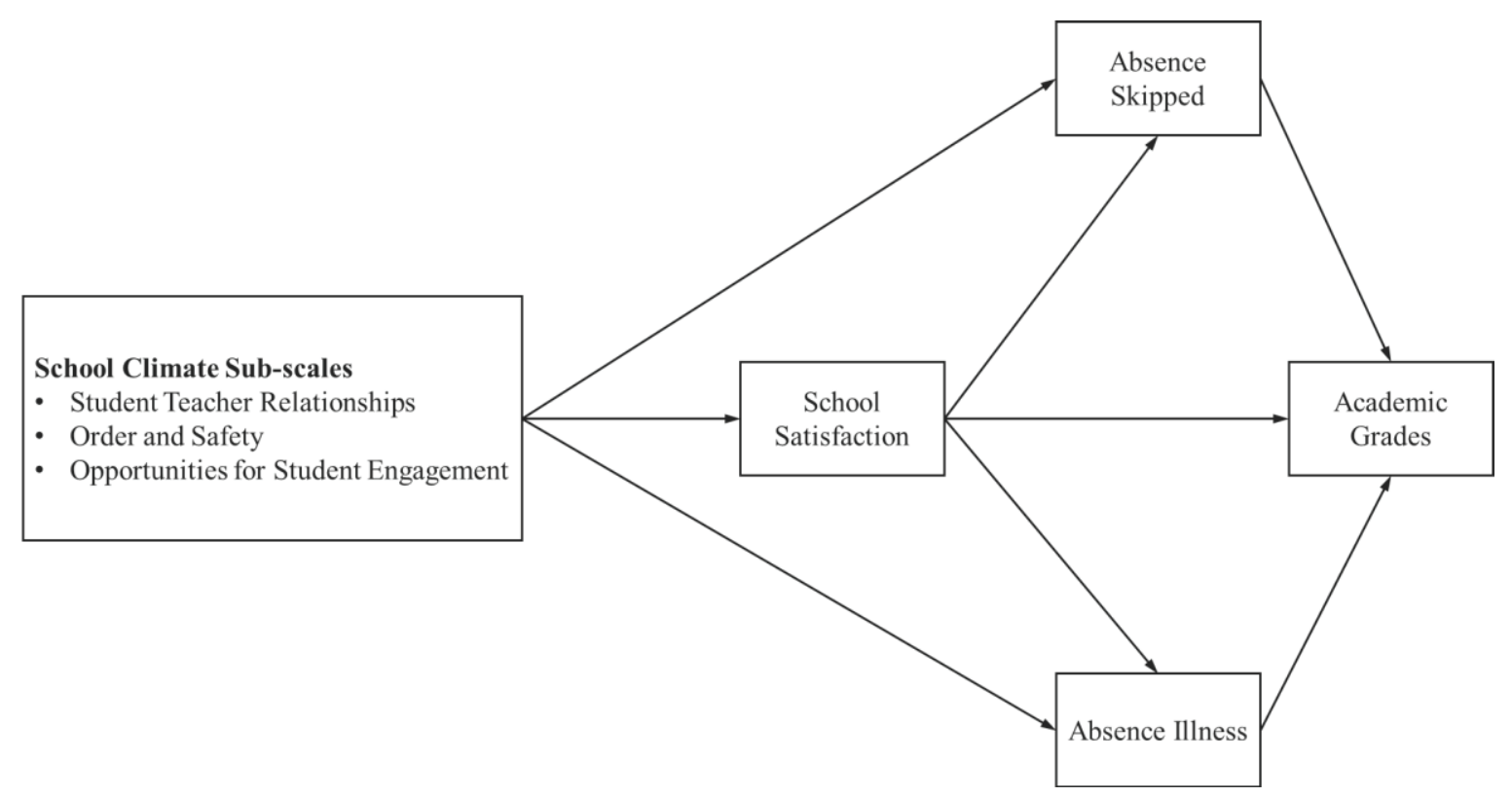

Figure 3. Mediated Path Analysis Model for School Climate and Types of Absences 


\section{APPENDIX A}

\section{DATA SOURCES}

The data sources (three annual waves) for this dissertation were drawn from the 2015, 2016, and 2017 Project AWARE (AWARE) collections. AWARE is a statewide child and adolescent mental/emotional health intervention that serves 26 southern, eastern, and western regional schools in West Virginia. Researchers at West Virginia University's (WVU) School of Public Health were recruited to evaluate AWARE, which focuses on strengthening protective and reducing risk factors related to substance use, teen parenting, and school dropout. A population sampling methodology was used to collect student-based information related to empirically established child and adolescent health domains: (1) parents and family, (2) the school, (3) friends and peers, and (4) leisure time. Funding support for AWARE was provided by The Substance Abuse and Mental Health Services Administration (SAMHSA) in Washington, DC, The West Virginia Department of Education (WVDOE) in Charleston, WV, and The Sisters of Saint Joseph's Charitable Fund in Parkersburg, WV.

\section{Theoretical Framework}

The theoretical framework for AWARE uses a five-phase community planning model based on the Icelandic Model proposed by Sigfusdottir, et al. ${ }^{174}$ The five-phase planning model allows for iterative cycles of data collection, descriptive and inferential analyses, and recommended guidance to promote local action.

Phase 1 begins with the formation of coalitions of primary stakeholders within each targeted community/school district. Coalitions comprise of representatives from targeted schools, 
local municipalities, and WVU School of Public Health faculty/staff (research team). Meetings are scheduled, convened, and coordinated to outline an approach for each targeted school district.

Phase 2 requires a shift in action to stimulate the local community. The research team uses West Virginia's fact sheets from the Youth Risk Behavioral Surveillance System (YRBSS) to generate discussion about the scope and severity of risk factors among adolescents within the state. Discussions are used to educate citizens and clarify an understanding of student risk at the local level. The information (i.e., meeting minutes) obtained from stakeholders was used to inform survey instrument development and refinement, which was made available to an average of 17,500 students in middle and high school.

Phase 3 involves fostering action among the 26 targeted middle and high schools. Research team staff coordinate and prepare each school for data collection using a series of systematic steps outlined in the data collection section below.

Phase 4 requires the research team to analyze, translate, and disseminate the data in a useable form for continued local action and professional publication.

Phase 5 initiates a reflective iteration of steps 1 to 4 . The results of the first data collection (baseline) will inform and potentially modify following data collections.

\section{Data Collection}

Data collection procedures for school-based surveys follow closely to procedures recommended by Kristjansson, et al. ${ }^{104}$ The data collection process was carried out in several stages which match phases within the community-based planning model.

Stage 1: Five to six months prior to data collection, coalitions were formed for each targeted school. Correspondence was sent to all school principals inviting them to participate as 
members of the coalition. Invitation letters outlined the intention of AWARE, why their participation is essential to AWAREs success, and how their participation benefits the community. Specific to each school, invitation letters were appended with a brief infographic containing descriptive information related to student risk factors. If confirmation or participation was not indicated by a school principal, a follow-up letter was mailed, and a telephone call was placed two-weeks after the initial invitation. Research team and select coalition members then schedule an in-person discussion to encourage selected schools to participate.

Stage 2: Four to five months prior to data collection, a brief literacy appropriate letter was sent to parents of students informing them of the study and planned data collection. Similar to the principals' letter, an infographic with information about regional student risk factor was provided to parents. During this time, coalition members attended local school board and parentteacher meetings to discuss the AWARE. Parents with a history of proactive school involvement were invited to join the coalition to facilitate the AWAREs success.

Stage 3: Two to three months prior to data collection, a second letter was sent to parents. Letters reminded parents of AWARE with an attached passive consent form for their review. During this time, five town-hall style meetings (one per school) were held presenting the details of AWARE to attendees to facilitate community "buy-in" and the survey method process.

Stage 4: One to two months prior to data collection, meetings with principals and faculty were held to discuss logistics and survey protocols for each school. Each school was assigned a trained data collector to support teachers and oversight of the data collection protocol.

Stage 5: Two weeks prior to data collection, all trained data collectors were sent instrumentation packets with necessary materials. 
One week prior to data collection, a literacy appropriate passive consent letter with a short memo was sent with students intended for their parents or caregivers. Participation was voluntary and made available to all students without capturing direct identifiers (i.e., names). Data was collected using an anonymous paper-and-pencil or web-based questionnaire, which has been shown to have little difference in quality response rates among adolescents. ${ }^{269}$ Students were instructed not to write their names or any other identifying information on the questionnaire or accompanying envelope. Students were free to answer all or part of the survey and opt out of participation at any time.

To reduce respondent bias, self-reported unique school ID numbers were recorded for each survey. If a web-based format was used, each student had to enter their ID number twice as an exact match before the system will allow the survey to be completed. If a student was unable to remember their ID number, the data collector was notified for technical assistance. The AWARE survey contains 230 items and takes an average of 30 to 45 minutes to complete.

All aspects of each annual AWARE data collection, including participant involvement based on passive parental consent, were accomplished in accordance with West Virginia University's Institutional Review Board (IRB) guidelines for the protection of research participants. The following are the IRB protocols for each corresponding data collection year, 2015 (\# 1406345394), 2016 (\# 1406345394R002), and 2017 (\# 1406345394R004).

Stage 6: At the end of each data collection cycle, a letter of gratitude and small monetary incentive in the form of a check was provided to both the schools, data collectors, and SCAs for their assistance and participation. Once data cleaning and preparation are finalized, the analysis and iterative reflection process begin. 


\section{APPENDIX B}

\section{SCHOOL CLIMATE MEASURE ITEMS AT A GLANCE}

\section{Positive Student - Teacher Relationships}

1. Teachers understand my problems

2. Teacher and staff seem to take a real interest in my future

3. Teachers are available when I need to talk to them

4. It is easy to talk with teachers

5. Students get along well with teachers

6. Teachers at my school help us children with our problems

7. My teachers care about me

8. My teacher makes me feel good about myself

\section{Order, Safety, and Discipline}

1. Classroom rules are applied equally

2. Problems in this school are solved by students and staff

3. The rules of the school are fair

4. School rules are enforced consistently and fairly

5. My teachers make it clear to me when I have misbehaved in class

6. Discipline in fair

\section{Opportunities for Student Engagement}

1. Student have the same opportunity in class to speak, and be listened to

2. Students can express feelings and thoughts about school, work, and life

3. Students "different" in any way are treated with respect

4. Nobody in my school is excluded from being successful

5. Females and male are treated as equals at school

6. I can participate in a lot of interesting activities in school 